\title{
Evaluating heavy-duty diesel engine aftertreatment devices with a split exhaust configuration
}

\author{
Eric Roy Corrigan \\ West Virginia University
}

Follow this and additional works at: https://researchrepository.wvu.edu/etd

\section{Recommended Citation}

Corrigan, Eric Roy, "Evaluating heavy-duty diesel engine aftertreatment devices with a split exhaust configuration" (2001). Graduate Theses, Dissertations, and Problem Reports. 1109.

https://researchrepository.wvu.edu/etd/1109

This Thesis is protected by copyright and/or related rights. It has been brought to you by the The Research Repository @ WVU with permission from the rights-holder(s). You are free to use this Thesis in any way that is permitted by the copyright and related rights legislation that applies to your use. For other uses you must obtain permission from the rights-holder(s) directly, unless additional rights are indicated by a Creative Commons license in the record and/ or on the work itself. This Thesis has been accepted for inclusion in WVU Graduate Theses, Dissertations, and Problem Reports collection by an authorized administrator of The Research Repository @ WVU. For more information, please contact researchrepository@mail.wvu.edu. 


\title{
Evaluating Heavy-Duty Diesel Engine Aftertreatment
}

\section{Devices with a Split Exhaust Configuration}

By

Eric R. Corrigan

\author{
A THESIS \\ Submitted to \\ The College of Engineering and Mineral Resources \\ at \\ West Virginia University \\ in partial fulfillment of the requirements \\ for the degree of \\ Master of Science \\ in \\ Mechanical Engineering \\ Nigel N. Clark, Ph.D., Chair \\ W. Scott Wayne, Ph.D. \\ Gregory J. Thompson, Ph.D. \\ Department of Mechanical and Aerospace Engineering \\ Morgantown, West Virginia \\ 2001
}

Keywords: Diesel Engines, Emissions Measurements, Aftertreatment, Split Exhaust 


\section{ABSTRACT \\ EVALUATING HEAVY-DUTY DIESEL ENGINE AFTERTREATMENT DEVICES WITH A SPLIT EXHAUST CONFIGURATION}

By Eric R. Corrigan

West Virginia University evaluated diesel oxidation catalysts (DOC) and lean- $\mathrm{NO}_{\mathrm{X}}$ catalysts as part of the Diesel Emissions Control-Sulfur Effects (DECSE) program. In order to perform thermal aging of the $\mathrm{DOC}$ and lean- $\mathrm{NO}_{\mathrm{X}}$ catalysts simultaneously and economically, each catalyst was sized to accommodate half of the engine exhaust flow. Simultaneous catalyst aging was then achieved by splitting the engine exhaust into two streams such that approximately half of the total exhaust flowed through the DOC and half through the lean- $\mathrm{NO}_{\mathrm{X}}$ catalyst. This necessitated splitting the engine exhaust into two streams during emissions measurements. The fraction of exhaust entering the measurement system was calculated based on a comparison of measured $\mathrm{CO}_{2}$ concentrations taken during a full flow exhaust run and a partial flow exhaust run. Emissions sampled from the partial exhaust stream were then corrected based on these measured $\mathrm{CO}_{2}$ concentrations to reflect the original full flow levels. Integrated engine-out emissions measured in the split exhaust streams during transient operation generally agreed well with emissions measured using the full exhaust stream. Measured emissions in the partial exhaust configuration remained within 5\% of a 50/50 split except at idle or low power operation. When these results from a split flow test were corrected back to full flow levels, all measured emissions were within $11 \%$ of the full exhaust case for transient tests and $13 \%$ for steady state tests. Split exhaust emissions levels were hard to quantify at low exhaust flow rates. 


\section{Acknowledgements}

My time in Morgantown has been an excellent experience that I will never forget. Looking back on almost 2 years of graduate school, I realize that several people have influenced this adventure. I will do my best in acknowledging everyone.

I must first thank Dr. Nigel Clark for twisting my arm into participating in the graduate program at WVU. There was not much arm twisting involved, just him saying I will pay you to go to school. Seriously, I want to thank him for giving me latitude in course selection and in research activities that I was involved in at the ERC. I have enjoyed listening to his different philosophies on just about everything that we discussed.

I also wish to recognize Dr. W. Scott Wayne for his guidance and patience during the entire DECSE program. His attitude was always positive about anything that we were ever involved with together. For that, I am grateful. Dr. Greg Thompson needs acknowledged for teaching me that great things happen when people work together. So much more is accomplished if everyone is on the same page and involved in the activity. I want to thank both Scott and Greg for agreeing to be on my committee.

My parents deserve more recognition than I could ever acknowledge. I thank them for their endless love and support. I also want to thank them for setting high goals for me to achieve and not excepting anything but my best effort. Thanks, Brian and Jason, for being brothers that would do anything and everything for me.

Next, I need to thank all the staff at the ERC namely Richard Atkinson, Tom Spencer, Wayne Hildebrand, Andy Pertl, and Mike Traver for taking countless hours explaining various procedures and concepts to me. Dan Carder deserves recognition for his guidance on certain issues. I also want to recognize Talus Park, Matt Hawkins, and Marcus Gilbert for their initial 
guidance during my graduate career. Nigel, that is why it has taken me so long to finish. Just kidding! I also thank Emily Cirillo, Jason Snyder, Brad Bane, Ben Shade, Eric Meyer, Andy Fuller, and Jason Evans for their assistance along the way.

I want to wish all the recognized people the very best and I will do my best to stay in contact with each and everyone of you. Well, I need to get back to work and polish up this monstrosity that I am calling my thesis. 


\section{Table of Contents}

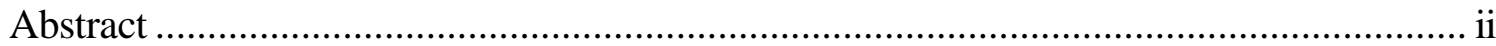

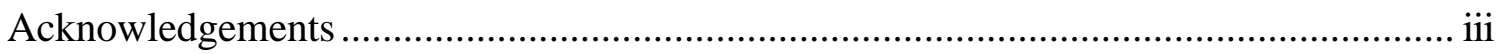

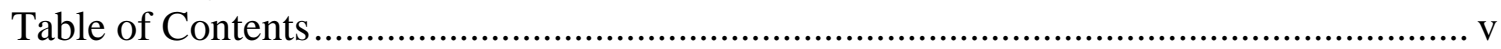

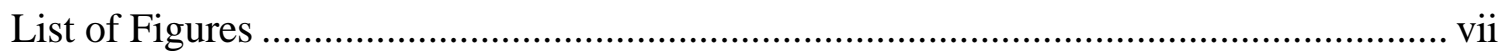

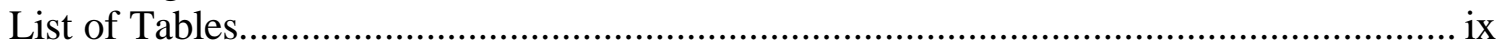

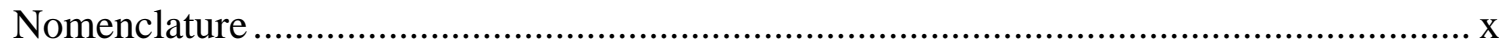

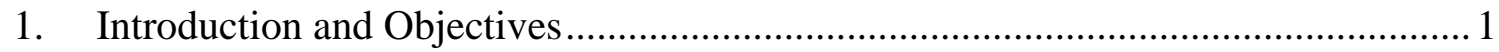

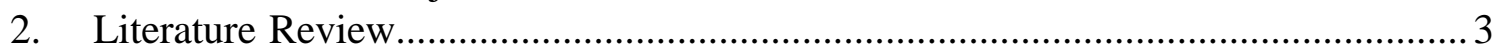

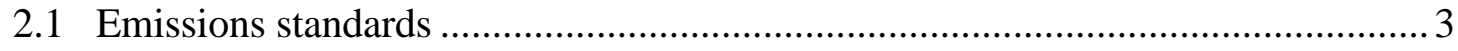

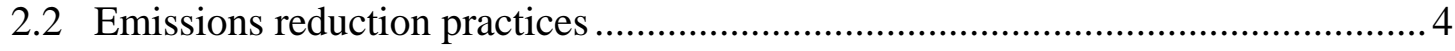

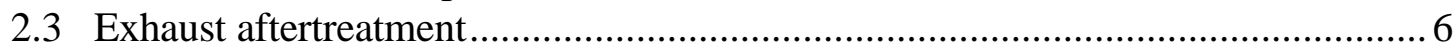

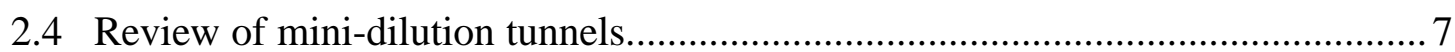

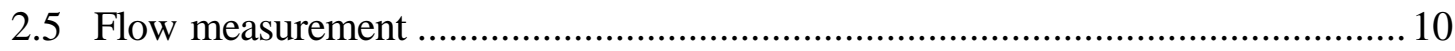

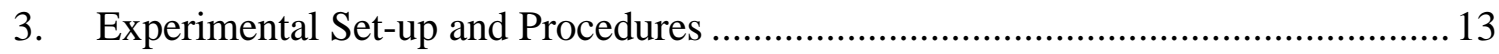

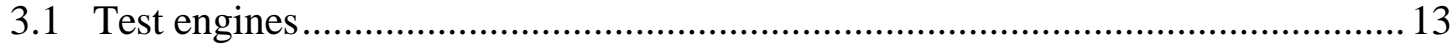

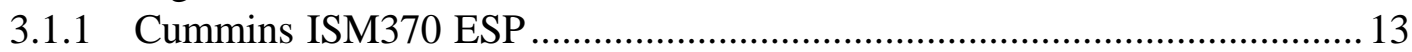

3.1.2 Navistar T444E............................................................................... 15

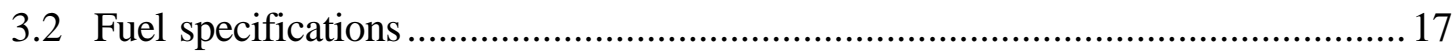

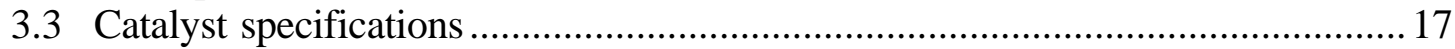

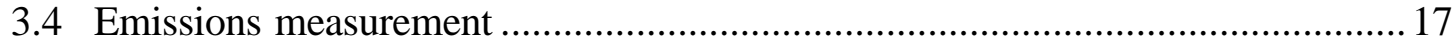

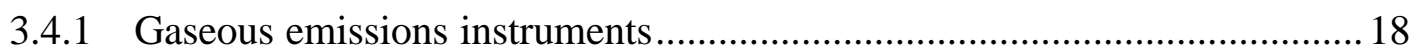

3.4.2 Particulate matter measurement ........................................................... 20

3.5 Discussion of Engine and Emission Research Center at WVU .........................2 21

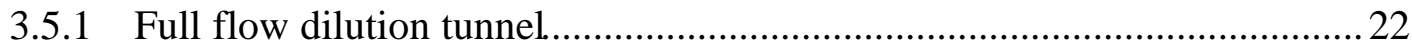

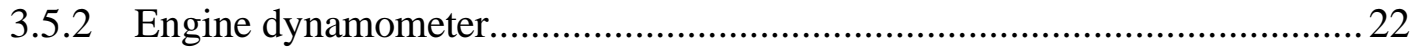

3.5.3 Critical flow venturies...................................................................... 23

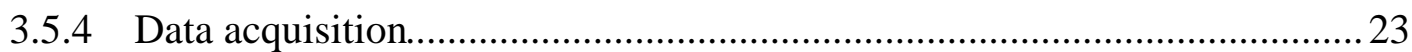

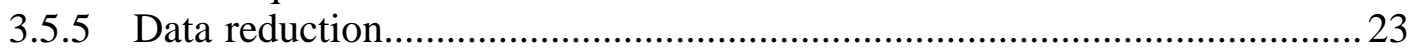

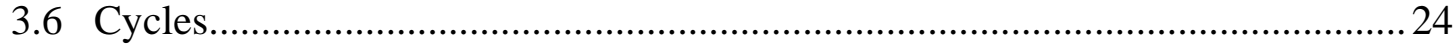

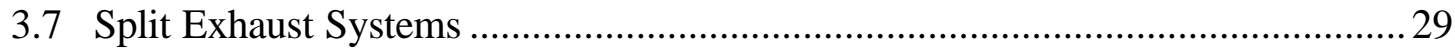

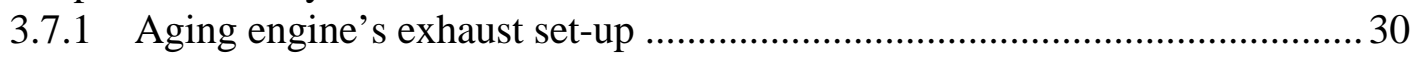

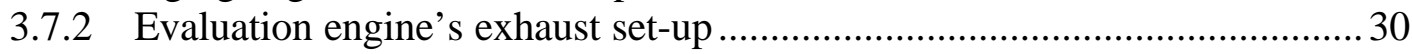

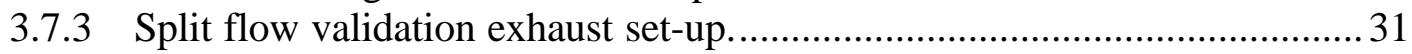

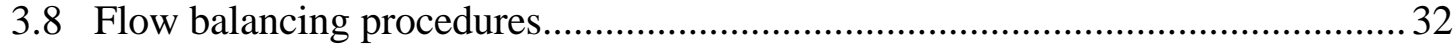

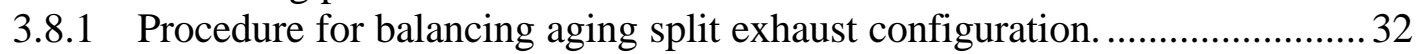

3.8.2 Procedure for balancing evaluation split exhaust configuration. ...................33

3.8.3 Procedure for balancing split exhaust validation set-up............................ 36

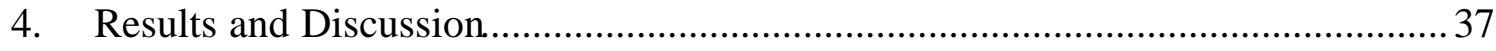

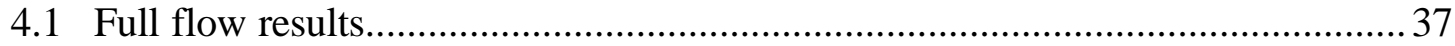

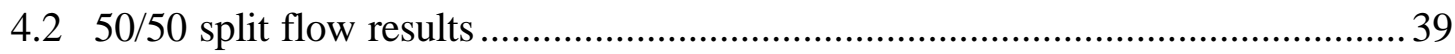

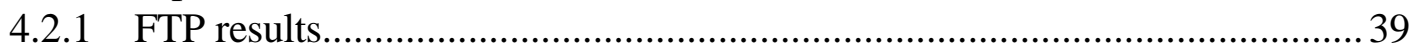

4.2.2 Steady-state results .............................................................................. 42

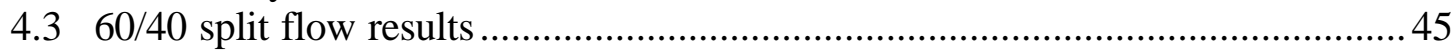




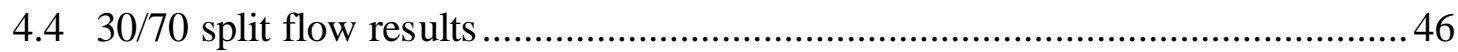

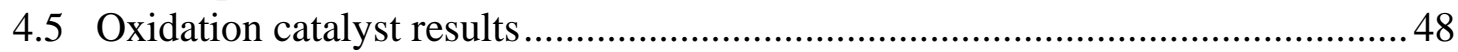

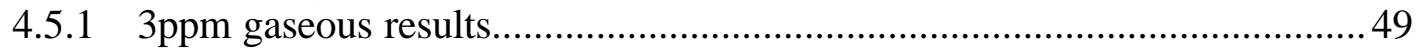

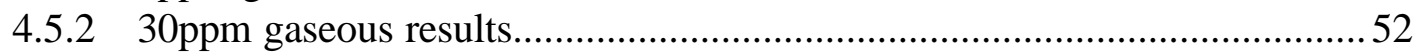

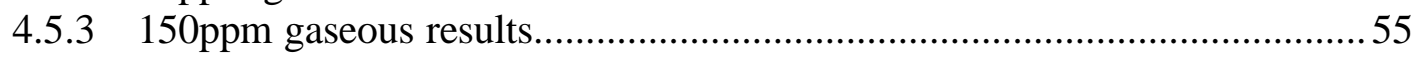

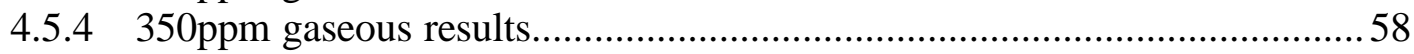

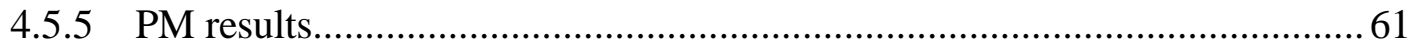

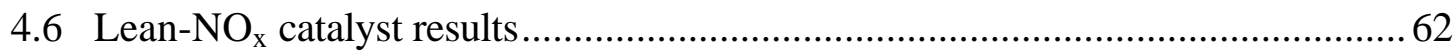

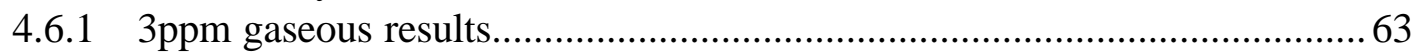

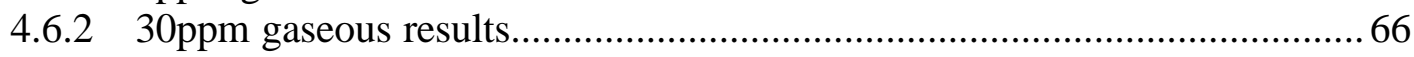

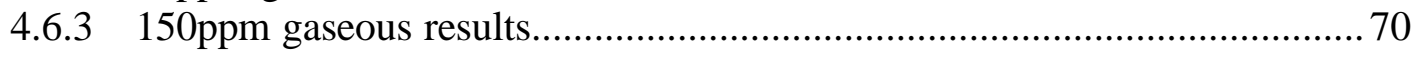

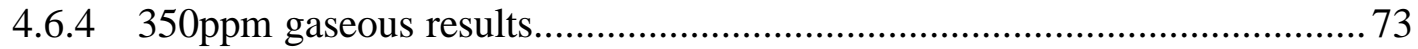

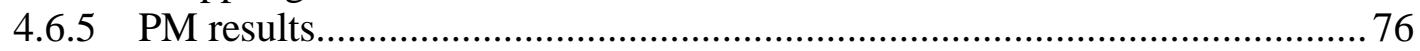

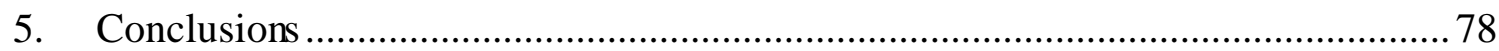

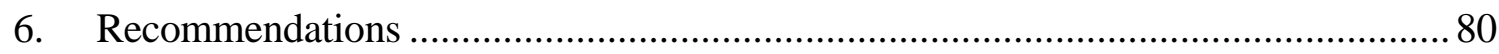

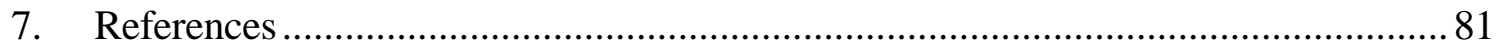

Appendix A: Certificates of Analysis of the Diesel Fuel Formulations with Four Different Sulfur

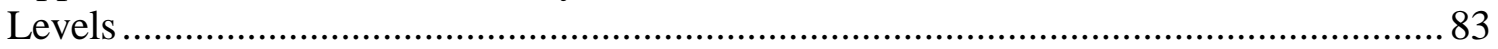




\section{List of Figures}

Figure 3.1: Cummins ISM370 ESP power torque map.

Figure 3.2: Cummins ISM370 connected to GE dynamometer.

Figure 3.3: Navistar T444E power torque map.

Figure 3.4: Navistar T444E connected to GE dynamometer.

Figure 3.5: Gaseous emissions instruments.

Figure 3.6: FTP engine speed.

Figure 3.7: FTP engine torque.

Figure 3.8: Mimicked FTP75 engine speed.

Figure 3.9: Mimicked FTP75 engine torque.

Figure 3.10: Picture of set-up for catalyst aging.

Figure 3.11: Exhaust configuration for aging the catalyst.

Figure 3.12: Exhaust configuration for evaluation of catalysts.

Figure 3.13: Calibrations of orifices for the Navistar aging set-up.

Figure 3.14: Typical split ratios for Cummins ISM370.

Figure 4.1: Continuous FTP $\mathrm{CO}_{2}$ for full flow and 50/50 split flow exhaust configurations.

Figure 4.2: Continuous FTP $\mathrm{NO}_{\mathrm{x}}$ for full flow and 50/50 split flow exhaust configurations.

Figure 4.3: Continuous FTP CO for full flow and 50/50 split flow exhaust configurations.

Figure 4.4: Continuous FTP HC for full flow and 50/50 split flow exhaust configurations.

Figure 4.5: Accumulated $\mathrm{HC}$ during the FTP full flow and $\mathrm{CO}_{2}$ corrected 50/50 split flow.

Figure 4.6: Accumulated $\mathrm{CO}$ during the FTP for full flow and $\mathrm{CO}_{2}$ corrected 50/50 split flow.

Figure 4.7: Accumulated $\mathrm{NO}_{\mathrm{x}}$ during the FTP for full flow and $\mathrm{CO}_{2}$ corrected 50/50 split flow.

Figure 4.8: Comparison between full flow $\mathrm{CO}_{2}$ and 50/50 split flow $\mathrm{CO}_{2}$.

Figure 4.9: Measured exhaust flow during 50/50 SSC cycle.

Figure 4.10: Comparison between full flow $\mathrm{CO}_{2}$ and $60 / 40$ split flow $\mathrm{CO}_{2}$.

Figure 4.11: Measured exhaust flow during 60/40 SSC cycle.

Figure 4.12: Comparison between full flow $\mathrm{CO}_{2}$ and 30/70 split flow $\mathrm{CO}_{2}$.

Figure 4.13: Measured exhaust flow during 30/70 SSC cycle.

Figure 4.14: Modal split ratios for validation study.

Figure 4.15: FTP accumulated $\mathrm{HC}$ for $3 \mathrm{ppm}$ oxidation catalyst through the aging period.

Figure 4.16: Percent reduction of $\mathrm{HC}$ for $3 \mathrm{ppm}$ oxidation catalyst.

Figure 4.17: FTP accumulated CO for 3ppm oxidation catalyst through the aging period.

Figure 4.18: Percent reduction of $\mathrm{CO}$ for $3 \mathrm{ppm}$ oxidation catalyst.

Figure 4.19: FTP accumulated $\mathrm{CO}_{2}$ for $3 \mathrm{ppm}$ oxidation catalyst through the aging period.

Figure 4.20: FTP accumulated $\mathrm{NO}_{\mathrm{x}}$ for $3 \mathrm{ppm}$ oxidation catalyst through the aging period.

Figure 4.21: FTP accumulated $\mathrm{HC}$ for 30ppm oxidation catalyst through the aging period.

Figure 4.22: Percent reduction of $\mathrm{HC}$ for 30ppm oxidation catalyst.

Figure 4.23: FTP accumulated CO for 30ppm oxidation catalyst through the aging period.

Figure 4.24: Percent reduction of $\mathrm{CO}$ for 30ppm oxidation catalyst.

Figure 4.25: FTP accumulated $\mathrm{CO}_{2}$ for 30ppm oxidation catalyst through the aging period.

Figure 4.26: FTP accumulated $\mathrm{NO}_{\mathrm{x}}$ for $30 \mathrm{ppm}$ oxidation catalyst through the aging period. Figure 4.27: FTP accumulated HC for 150ppm oxidation catalyst through the aging period. Figure 4.28: Percent reduction of $\mathrm{HC}$ for 150ppm oxidation catalyst.

Figure 4.29: FTP accumulated $\mathrm{CO}$ for $150 \mathrm{ppm}$ oxidation catalyst through the aging period. Figure 4.30: Percent reduction of CO for 150ppm oxidation catalyst. 
Figure 4.31: FTP accumulated $\mathrm{CO}_{2}$ for $150 \mathrm{ppm}$ oxidation catalyst through the aging period. Figure 4.32: FTP accumulated $\mathrm{NO}_{\mathrm{x}}$ for $150 \mathrm{ppm}$ oxidation catalyst through the aging period. Figure 4.33: FTP accumulated HC for 350ppm oxidation catalyst through the aging period. Figure 4.34: Percent reduction of $\mathrm{HC}$ for $350 \mathrm{ppm}$ oxidation catalyst.

Figure 4.35: FTP accumulated CO for 350ppm oxidation catalyst through the aging period. Figure 4.36: Percent reduction of $\mathrm{CO}$ for $350 \mathrm{ppm}$ oxidation catalyst.

Figure 4.37: FTP accumulated $\mathrm{CO}_{2}$ for $350 \mathrm{ppm}$ oxidation catalyst through the aging period. Figure 4.38: FTP accumulated $\mathrm{NO}_{\mathrm{x}}$ for $350 \mathrm{ppm}$ oxidation catalyst through the aging period. Figure 4.39: Total PM collected during oxidation catalyst evaluations.

Figure 4.40: Continuous accumulated PM from TEOM for the oxidation catalysts.

Figure 4.41: ESC4 accumulated $\mathrm{HC}$ for $3 \mathrm{ppm}$ lean- $\mathrm{NO}_{\mathrm{x}}$ catalyst through the aging period.

Figure 4.42: Percent increase of $\mathrm{HC}$ for $3 \mathrm{ppm}$ lean- $\mathrm{NO}_{\mathrm{x}}$ catalyst.

Figure 4.43: ESC4 accumulated $\mathrm{CO}$ for $3 \mathrm{ppm}$ lean- $\mathrm{NO}_{\mathrm{x}}$ catalyst through the aging period.

Figure 4.44: Percent increase of $\mathrm{CO}$ for $3 \mathrm{ppm}$ lean- $\mathrm{NO}_{\mathrm{x}}$ catalyst.

Figure 4.45: ESC4 accumulated $\mathrm{CO}_{2}$ for $3 \mathrm{ppm}$ lean- $\mathrm{NO}_{\mathrm{x}}$ catalyst through the aging period.

Figure 4.46: ESC4 accumulated $\mathrm{NO}_{\mathrm{x}}$ for $3 \mathrm{ppm}$ lean- $\mathrm{NO}_{\mathrm{x}}$ catalyst through the aging period.

Figure 4.47: Percent reduction of $\mathrm{NO}_{\mathrm{x}}$ for $3 \mathrm{ppm}$ lean- $\mathrm{NO}_{\mathrm{x}}$ catalyst.

Figure 4.48: ESC4 accumulated $\mathrm{HC}$ for $30 \mathrm{ppm}$ lean- $\mathrm{NO}_{\mathrm{x}}$ catalyst through the aging period.

Figure 4.49: Percent increase of $\mathrm{HC}$ for 30ppm lean- $\mathrm{NO}_{\mathrm{x}}$ catalyst.

Figure 4.50: ESC4 accumulated $\mathrm{CO}$ for 30ppm lean- $\mathrm{NO}_{\mathrm{x}}$ catalyst through the aging period.

Figure 4.51: Percent increase of $\mathrm{CO}$ for 30ppm lean- $\mathrm{NO}_{\mathrm{x}}$ catalyst.

Figure 4.52: ESC4 accumulated $\mathrm{CO}_{2}$ for 30ppm lean- $\mathrm{NO}_{\mathrm{x}}$ catalyst through the aging period. Figure 4.53: ESC4 accumulated $\mathrm{NO}_{\mathrm{x}}$ for $30 \mathrm{ppm}$ lean- $\mathrm{NO}_{\mathrm{x}}$ catalyst through the aging period. Figure 4.54: Percent reduction of $\mathrm{NO}_{\mathrm{x}}$ for $30 \mathrm{ppm}$ lean- $\mathrm{NO}_{\mathrm{x}}$ catalyst.

Figure 4.55: ESC4 accumulated $\mathrm{HC}$ for $150 \mathrm{ppm}$ lean- $\mathrm{NO}_{\mathrm{x}}$ catalyst through the aging period. Figure 4.56: Percent increase of $\mathrm{HC}$ for $150 \mathrm{ppm}$ lean- $\mathrm{NO}_{\mathrm{x}}$ catalyst.

Figure 4.57: ESC4 accumulated $\mathrm{CO}$ for $150 \mathrm{ppm}$ lean- $\mathrm{NO}_{\mathrm{x}}$ catalyst through the aging period. Figure 4.58: Percent increase of $\mathrm{CO}$ for $150 \mathrm{ppm}$ lean- $\mathrm{NO}_{\mathrm{x}}$ catalyst.

Figure 4.59: ESC4 accumulated $\mathrm{CO}_{2}$ for $150 \mathrm{ppm}$ lean- $\mathrm{NO}_{\mathrm{x}}$ catalyst through the aging period. Figure 4.60: ESC4 accumulated $\mathrm{NO}_{\mathrm{x}}$ for $150 \mathrm{ppm}$ lean- $\mathrm{NO}_{\mathrm{x}}$ catalyst through the aging period. Figure 4.61: Percent reduction of $\mathrm{NO}_{\mathrm{x}}$ for $150 \mathrm{ppm}$ lean- $\mathrm{NO}_{\mathrm{x}}$ catalyst.

Figure 4.62: ESC4 accumulated $\mathrm{HC}$ for $350 \mathrm{ppm}$ lean- $\mathrm{NO}_{\mathrm{x}}$ catalyst through the aging period. Figure 4.63: Percent increase of $\mathrm{HC}$ for $350 \mathrm{ppm}$ lean- $\mathrm{NO}_{\mathrm{x}}$ catalyst.

Figure 4.64: ESC4 accumulated $\mathrm{CO}$ for 350ppm lean- $\mathrm{NO}_{\mathrm{x}}$ catalyst through the aging period.

Figure 4.65: Percent increase of $\mathrm{CO}$ for $350 \mathrm{ppm}$ lean- $\mathrm{NO}_{\mathrm{x}}$ catalyst.

Figure 4.66: ESC4 accumulated $\mathrm{CO}_{2}$ for $350 \mathrm{ppm}$ lean- $\mathrm{NO}_{\mathrm{x}}$ catalyst through the aging period. Figure 4.67: ESC4 accumulated $\mathrm{NO}_{\mathrm{x}}$ for $350 \mathrm{ppm}$ lean- $\mathrm{NO}_{\mathrm{x}}$ catalyst through the aging period. Figure 4.68: Percent reduction of $\mathrm{NO}_{\mathrm{x}}$ for $350 \mathrm{ppm}$ lean- $\mathrm{NO}_{\mathrm{x}}$ catalyst.

Figure 4.69: Total PM collected during lean- $\mathrm{NO}_{\mathrm{x}}$ catalyst evaluations.

Figure 4.70: Continuous accumulated PM from TEOM for the lean- $\mathrm{NO}_{\mathrm{x}}$ catalysts. 


\section{List of Tables}

Table 2.1: FTP heavy-duty diesel emissions standards comprised by the EPA.

Table 2.2: Description of aftertreatment technologies.

Table 3.1: Engine specifications.

Table 3.2: Set-points of the ESC4 steady-state cycle performed.

Table 3.3: Set-points of the NAV4 steady-state cycle performed.

Table 3.4: Parameters used in the development of the FTP75.

Table 3.5: Steady-state cycles for catalyst aging.

Table 3.6: Steady-state cycle for split exhaust validation.

Table 4.1: Split exhaust validation transient results.

Table 4.2: Split exhaust validation steady-state results. 


\section{Nomenclature}

\begin{tabular}{|c|c|}
\hline $\mathrm{CFV}$ & Critical Flow Venturi \\
\hline $\mathrm{CO}$ & Carbon Monoxide \\
\hline $\mathrm{CO}_{2}$ & Carbon Dioxide \\
\hline CVS & Constant Volume Sampling \\
\hline DECSE & Diesel Emissions Control-Sulfur Effects \\
\hline DOC & Diesel Oxidation Catalyst \\
\hline EERC & Engine and Emission Research Center \\
\hline EGR & Exhaust Gas Recirculation \\
\hline EPA & Environmental Protection Agency \\
\hline ESC4 & Steady-state cycle conducted on the Cummins \\
\hline FTP & Federal Test Procedure, Transient heavy-duty cycle \\
\hline $\begin{array}{l}\text { FTP75 } \\
\text { g/bhp-hr }\end{array}$ & $\begin{array}{l}\text { Transient cycle conducted on the Navistar } \\
\text { grams per brake horsepower hour }\end{array}$ \\
\hline $\mathrm{H}_{2} \mathrm{O}$ & Water \\
\hline $\mathrm{HC}$ & Hydrocarbon \\
\hline Hp & horsepower \\
\hline in $\mathrm{H}_{2} \mathrm{O}$ & inches of water \\
\hline ISO & International Organization for Standardization \\
\hline NAV4 & Steady-state cycle conducted on the Navistar \\
\hline $\mathrm{N}_{2}$ & Nitrogen \\
\hline NO & Nitrogen Monoxide \\
\hline $\mathrm{NO}_{2}$ & Nitrogen Dioxide \\
\hline $\mathrm{NO}_{\mathrm{x}}$ & Oxides of Nitrogen \\
\hline $\mathrm{O}_{2}$ & Oxygen \\
\hline PM & Particulate Matter \\
\hline ppm & parts per million \\
\hline scfm & standard cubic feet per minute \\
\hline SCR & Selective catalytic reduction \\
\hline $\mathrm{SO}_{2}$ & Sulfur Dioxide \\
\hline $\mathrm{SO}_{3}$ & Sulfate \\
\hline SSC & Steady-state cycle used for the split exhaust validation \\
\hline TEOM & Tapered Element Oscillating Microbalance \\
\hline UDDS & Urban Driving Dynamometer Schedule \\
\hline WVU & West Virginia University \\
\hline
\end{tabular}




\section{Introduction and Objectives}

Heavy-duty diesel emissions are being scrutinized for their effect on the environment. The United States Environmental Protection Agency (EPA) regulates various components of the exhaust produced from the diesel engine. Hydrocarbons (HC), carbon monoxide $(\mathrm{CO})$, oxides of nitrogen $\left(\mathrm{NO}_{\mathrm{x}}\right)$, and particulate matter $(\mathrm{PM})$ are the chemical species currently regulated by the EPA. Mainly, $\mathrm{NO}_{\mathrm{x}}$ and $\mathrm{PM}$ are the components of concern to the public because PM has been classified as "highly likely" to be a carcinogen while $\mathrm{NO}_{\mathrm{x}}$ promotes the formation of smog [22]. The EPA has proposed and is finalizing heavy-duty diesel emissions standards for the 2007 model year. These standards are coupled with a proposal that will reduce sulfur content in diesel fuel in June of 2006 from 500 parts per million (ppm) cap to $15 \mathrm{ppm}$ cap. In 2007, when the proposed standards take effect, heavy-duty trucks and buses will contribute more than half of the $\mathrm{NO}_{\mathrm{x}}$ and PM from all highway vehicles [5]. The proposal requiring the conversion to low-sulfur diesel fuel enables technologies with aftertreatment of the diesel exhaust that will aid in meeting the 2007 emissions standards.

West Virginia University evaluated two catalyst technologies as part of the Diesel Emissions Control-Sulfur Effects (DECSE) program. The DECSE program is a joint government/industry program to determine the impact of diesel fuel sulfur levels on emission control systems whose use could lower emissions of $\mathrm{NO}_{\mathrm{x}}$ and $\mathrm{PM}$ from on-highway trucks in the 2002 and 2004 model years [3]. Two types of diesel oxidation catalysts (DOC) and two types of lean- $\mathrm{NO}_{\mathrm{x}}$ catalysts were evaluated with four different sulfur levels of diesel fuel namely 3ppm, 30ppm, 150ppm, and 350ppm. High temperature diesel oxidation and lean$\mathrm{NO}_{\mathrm{x}}$ catalysts were tested on a Cummins ISM370 ESP (10.8 liter, 370 horsepower) engine typical of heavy-duty line haul truck applications. Low temperature diesel oxidation and 
lean- $\mathrm{NO}_{\mathrm{x}}$ catalysts were tested on a Navistar T444E (7.3 liter, 210 horsepower) engine typical of medium-duty applications. Each catalyst was aged for 250 hours with evaluations occurring at the beginning, 50 hours, 150 hours, and at the end of the aging period. In order to age the DOC and the lean- $\mathrm{NO}_{\mathrm{x}}$ catalysts simultaneously and economically, catalysts were designed for half of the diesel exhaust flow. Catalyst aging was achieved by splitting the diesel exhaust into two different streams so that approximately half of the exhaust flowed through the DOC and half through the lean- $\mathrm{NO}_{\mathrm{x}}$ catalyst. Since each catalyst could only accommodate half of the exhaust, it was necessary to split the exhaust during catalyst-out emissions evaluations. For testing catalyst performance, half of the exhaust passed through the catalyst and into a full-scale dilution tunnel for emissions measurement while the other half of the exhaust was directed into a bypass catalyst and vented into the atmosphere.

The objective for this thesis was to determine the validity of exhaust splitting for evaluation of aftertreatment devices. This was accomplished by examining full flow exhaust $\mathrm{CO}_{2}$ concentrations with no catalyst and comparing them to "half-flow" engine-out $\mathrm{CO}_{2}$ concentrations. Results from a split flow validation study, which include measured exhaust flow through each catalyst branch, are presented. Catalyst performance on an accumulated basis is also discussed. 


\section{Literature Review}

This chapter provides background information about emissions standards and emissions reduction practices. Different types of aftertreatment methods, both catalysts and adsorbers, are described as well as a review on Mini-dilution tunnels. Several flow measurement devices are discussed regarding flow principles and device governing equations.

\subsection{Emissions standards}

Emissions standards play a major role in the design of the modern diesel engine. These regulations require that all diesel engines produced by the manufacturer must meet or exceed the standard for the model year of the engine. The regulated limits are specified in brake-specific units of grams per brake horsepower hour (g/bhp-hr). Table 2.1 lists past and present standards as well as proposed future standards for on-highway heavy-duty compression-ignition engines performing the Federal Test Procedure (FTP) cycle [4]. Required levels for $\mathrm{CO}$ and $\mathrm{HC}$ are moot because modern diesel engines produce $\mathrm{CO}$ and $\mathrm{HC}$ well below the standards

Table 2.1: FTP heavy-duty diesel emissions standards comprised by the EPA.

\begin{tabular}{|c|c|c|c|c|}
\hline Year & CO & HC & NO $_{\mathbf{x}}$ & PM \\
\hline \multicolumn{5}{|c|}{ The units for the values are g/bhp-hr. } \\
\hline 1990 & 15.5 & 1.3 & 6.0 & 0.60 \\
\hline 1991 & 15.5 & 1.3 & 5.0 & 0.25 \\
\hline 1994 & 15.5 & 1.3 & 5.0 & 0.10 \\
\hline 1998 & 15.5 & 1.3 & 4.0 & 0.10 \\
\hline $2004^{*}$ & 15.5 & 1.3 & 2.4 & 0.10 \\
\hline $2007^{*}$ & 15.5 & 1.3 & 0.2 & 0.01 \\
\hline
\end{tabular}
combined with $\mathrm{HC}$ 
The creation of the FTP heavy-duty transient cycle provided a universal schedule used in evaluating exhaust produced by the engine. The FTP was developed to mimic actual heavy-duty truck and bus operation in and around urban areas of the United States. A DC or AC dynamometer capable of supplying and absorbing power is required to perform the cycle because of the transient nature of and certain motoring segments of the FTP. The transient cycle is 20 minutes in length and usually is performed three times for emissions certification. The first cycle is labeled as a cold start FTP that is conducted after the engine's coolant and oil temperatures have stabilized between $68^{\circ} \mathrm{F}$ and $86^{\circ} \mathrm{F}$ for 15 minutes. The second cycle is called a warm start FTP and begins 20 minutes after completion of the first cycle. The third cycle is the same as the second cycle. These two cycles' emissions values are then combined by using one seventh of the cold start test and six sevenths of the warm start test to yield emissions results that must satisfy or exceed the emissions standards from the EPA for that given engine's year of production $[1,12]$. In practice, several warm start tests are conducted.

\subsection{Emissions reduction practices}

The compression-ignition engine has experienced substantial improvement over the years from an emissions point of view. Various techniques have been implemented in the design and control strategies of the diesel engine to increase the power while reducing emissions. One method used in $\mathrm{NO}_{\mathrm{x}}$ reduction is retarding the timing of the fuel injection into the cylinder. This decreases the maximum temperature of the combustion process and also reduces the time that the gases spend at high temperatures and since $\mathrm{NO}_{\mathrm{x}}$ formation is

highly dependent upon temperature, reducing the temperature will reduce $\mathrm{NO}_{\mathrm{x}}$. The penalty suffered for retarding the timing of fuel injection is a decrease in power output of the engine 
as well as an increase in hydrocarbons and particulate matter in the exhaust. The compromise between $\mathrm{NO}_{\mathrm{x}}$ and $\mathrm{PM}$ minimization is termed the $\mathrm{NO}_{\mathrm{x}} / \mathrm{PM}$ trade-off [20].

Exhaust gas recirculation (EGR) has also been an effective way to decrease $\mathrm{NO}_{\mathrm{x}}$. EGR reduces available oxygen in the cylinder and introduces $\mathrm{H}_{2} \mathrm{O}$ and $\mathrm{CO}_{2}$ into the cylinder, which increases the thermal capacity of the in-cylinder charge. The combination of less oxygen and added heat capacity decreases the combustion temperature. $\mathrm{NO}_{\mathrm{x}}$ reduction is achieved from the decrease in temperature as well as the presence of less oxygen in the exhaust gases. However, black smoke and fuel consumption increase with an increase in the rate of EGR [17].

$\mathrm{NO}_{\mathrm{x}}$ has been reduced with a control strategy termed injection rate shaping. Rate shaping involves injecting part of the diesel fuel into the cylinder to initiate combustion and injecting the remaining quantity of fuel after the combustion process begins. This reduces the pressure spike that occurs during the premix burn of the combustion, which decreases the in-cylinder temperature thus reducing $\mathrm{NO}_{\mathrm{x}}$. Ghaffarpour and Baranescu [9] report a $50 \%$ reduction of $\mathrm{NO}_{\mathrm{x}}$ at certain operating conditions using an intercooler and rate shaping without significant change in performance or PM production.

Some techniques used in decreasing PM are increasing in-cylinder charge motion (swirl), increasing fuel injection pressure, and using injectors with finer sprays. With PM formation being a function of unburned and partly burned fuel, anything that allows for a more complete combustion will decrease PM. An increase in swirl promotes better mixing between the air and fuel which achieves a more complete burn while the increase in injection pressure and finer injector sprays allow an increase in atomization of the fuel. The engine operating on lower sulfur fuel decreases sulfate formation thus lower PM. 


\subsection{Exhaust aftertreatment}

The emission reduction practices mentioned above have enabled engine manufacturers to meet the EPA's past and present emission standards. In the next few years, the regulated emissions for $\mathrm{NO}_{\mathrm{x}}$ and $\mathrm{PM}$ will be substantially reduced from current standards as demonstrated in Table 2.1. Current technologies applied to reduce emissions will not be enough to achieve the future standards. Exhaust aftertreatment along with diesel engine emissions reduction practices will have to be combined to satisfy the upcoming standards. Some aftertreatment devices proposed to assist in the emissions reduction are oxidation catalysts, lean- $\mathrm{NO}_{\mathrm{x}}$ catalysts, $\mathrm{PM}$ filters (traps), $\mathrm{NO}_{\mathrm{x}}$ adsorbers, and the injection of urea ahead of a catalyst, which is termed selective catalytic reduction (SCR). A brief description of each technology is given in Table 2.2.

Table 2.2: Description of aftertreatment technologies.

\begin{tabular}{|c|l|}
\hline Aftertreatment Device & \multicolumn{1}{|c|}{ Description } \\
\hline Oxidation Catalyst & $\begin{array}{l}\text { Oxidizes the exhaust species } \mathrm{HC}, \mathrm{CO} \text {, and } \mathrm{SO}_{2} . \mathrm{HC} \text { changes } \\
\text { to } \mathrm{H}_{2} \mathrm{O} \text { and } \mathrm{CO}_{2} \text {, which decreases } \mathrm{PM} \text {. The creation of } \\
\text { sulfates }\left(\mathrm{SO}_{3}\right) \text { from } \mathrm{SO}_{2} \text { is minimal. } \mathrm{CO} \text { becomes } \mathrm{CO}_{2} \text { in the } \\
\text { oxidation process [8]. }\end{array}$ \\
\hline Lean- $\mathrm{NO}_{\mathrm{x}}$ Catalyst & $\begin{array}{l}\text { Converts } \mathrm{NO}_{\mathrm{x}} \text { to nitrogen }\left(\mathrm{N}_{2}\right) \text { and oxygen }\left(\mathrm{O}_{2}\right) . \mathrm{HC} \text {, diesel } \\
\text { fuel, must be introduced upstream of the catalyst for the } \\
\text { reaction to occur which decreases fuel economy. These types } \\
\text { of catalysts operate only at certain temperatures [7]. }\end{array}$ \\
\hline $\mathrm{NO}_{\mathrm{x}}$ Adsorbers & $\begin{array}{l}\text { Collects PM for a period of engine operation. The } \\
\text { accumulated PM is then combusted with external thermal } \\
\text { energy such as an electric heating or the use of a catalyst [14]. }\end{array}$ \\
\hline $\begin{array}{l}\text { Stores } \mathrm{NO}_{\mathrm{x}} \text { under lean operation, which is reduced during rich } \\
\text { operation. NO is oxidized to form } \mathrm{NO}_{2} \text { that is adsorbed on an } \\
\text { oxide surface. Resulting nitrate decomposes to } \mathrm{O}_{2} \text { and NO } \\
\text { which is then reduced to } \mathrm{N}_{2} \text { and } \mathrm{O}_{2} . \text { Generally used in } \\
\text { gasoline engines [7]. }\end{array}$ \\
\hline Injection of Urea & $\begin{array}{l}\text { Similar to a lean-NO } \mathrm{x}_{\mathrm{x}} \text { catalyst except that urea serves as the } \\
\text { reductant injected instead of diesel fuel. In this system, urea is } \\
\text { injected upstream of a selective catalytic reduction catalytic } \\
\text { converter in the engine's exhaust [11]. }\end{array}$ \\
\hline
\end{tabular}


All of the catalysts mentioned suffer from sulfur poisoning. Sulfur is used in diesel fuel as a lubricant for the fuel system. Catalyst poisoning occurs when an undesired compound or ion occupies the active sites, which are locations in a catalyst where the reactants attach themselves to the catalyst wall to promote the chemical reaction. Other means of poisoning that may occur are changing the catalyst selectivity, physical blockage of the activation site, or changing the catalyst structure [19]. Once a poisoning compound or ion, sulfur in this case, attaches to the site, the compound or ion generally stays at that site which decreases the performance of the catalyst. When the catalyst stops functioning because the poisoning agent occupies all of the activation sites, the catalyst is termed dead. The solution to sulfur poisoning is to remove the sulfur from the diesel fuel. The EPA is doing exactly that with a proposal that will reduce the sulfur content in diesel fuel from $500 \mathrm{ppm}$ by weight to $15 \mathrm{ppm}$ by weight. This change has been estimated to increase the cost of diesel fuel by 3 to 4 cents per gallon and will take effect in June of 2006 [25]. Some contend that $15 \mathrm{ppm}$ is not low enough, particularly the engine and catalyst manufacturers. Also, the lubricating oil may contribute sulfur to the exhaust at a level equivalent to roughly $10 \mathrm{ppm}$ in the fuel.

\subsection{Review of mini-dilution tunnels}

Mini-tunnels are used to measure all regulated emissions by only analyzing part of the exhaust. They combine an exhaust slipstream with dilution air for analysis. Either mass flow controllers, valves or a combination of both control the dilution air flow and the exhaust sample flow. A mixing chamber and pumps for pulling the samples complete the basic design of a mini-tunnel. PM is collected on filters and measured gravimetrically while gaseous emissions are obtained through analyzing raw exhaust with no dilution. Carbon 
Dioxide is usually measured in the exhaust (raw $\mathrm{CO}_{2}$ ) and through the mini-tunnel (dilute $\mathrm{CO}_{2}$ ) to obtain the dilution ratio. The dilution ratio is used to determine the emissions produced by the engine since only a portion of the exhaust is being analyzed. Japanese and European sampling systems for the purpose of exhaust emissions certification consist of mini-dilution tunnels for non-United States diesel engines. Several mini-tunnels have been accepted as a means of measuring emissions but are limited to narrow engine-output ranges unless considerable modifications are made [10].

Hirakouchi, et al. [13] determined that a 37-tube mini-tunnel and a full flow dilution tunnel had the same measurement characteristics on steady-state testing as well as transient operation. The number of tubes determines the amount of dilution that takes place in the mini-tunnel. Mini-tunnels with 61 tubes and 91 tubes where compared to the 37 tube minitunnel with good correlation with negligible effects of performance. The authors concluded that multi-tube type mini-dilution tunnels would be an excellent exhaust emissions measurement apparatus. This type of tunnel was capable of changing dilution ratios easily and at low cost enabling emissions measurement on any size engine without modification to any existing facilities.

A major advantage to mini-tunnels is portability while full flow dilution tunnels are generally stationary. Also, mini-tunnels cost approximately one third, are physically smaller, and require less capital to operate than that of full flow tunnels [13]. Graze discusses a minitunnel that is intensive of engine size and points out that size constraints limit full flow dilution tunnels to evaluate engines up to approximately 500 horsepower (hp) maximum. Graze's mini-tunnel was designed and developed to measure particulates for Caterpillar's entire line of engines, which range from $60 \mathrm{hp}$ to $7,000 \mathrm{hp} \mathrm{[10].} \mathrm{Caterpillar's} \mathrm{mini-tunnel,}$ 
termed a fractional sampler, filtered and diluted the sample directly on the engine's exhaust stack. This fractional sampling system was correlated with full flow particulate measurements. Composite results of the International Organization of Standardization (ISO) $8178 \mathrm{C} 1$ steady-state cycle demonstrated that the mini-tunnel gave results that were within $1 \%$ of the full flow tunnel values with respect to particulate emissions.

The EPA began certifying off-highway heavy-duty diesel engines between 175hp to 750hp in 1996. The International Organization for Standardization introduced a universal procedure for exhaust measurement, ISO 8178, of these off-highway engines that was applied worldwide. The ISO 8178 allows the use of a full flow dilution tunnel for emissions measurement but prefers the use of a raw sampling system (mini-tunnel). Stotler and Human conducted an experiment to correlate a full flow sampling system and a raw sampling system. A $300 \mathrm{hp} \mathrm{Cummins} \mathrm{LTA-10} \mathrm{operating} \mathrm{on} \mathrm{off-highway} \mathrm{number} 2$ diesel fuel executed an 8-mode steady-state cycle (ISO $8178 \mathrm{C} 1$ ) with emissions measured via a minitunnel and a full flow dilution tunnel. Both measurement systems sampled gaseous and particulate emissions for 10 minutes following a 10-minute stabilization period for each mode. The correlation of gaseous emissions between the two sampling systems; $\mathrm{HC}, \mathrm{NO}_{\mathrm{x}}$, and $\mathrm{CO}$ were within $7.0 \%, 3.0 \%$, and $1.0 \%$ respectively. PM correlated within $2.5 \%$ between the mini-tunnel and the full flow tunnel [24].

Rankin [21] designed, developed, and evaluated a particulate filtration system with microwave regeneration using a split exhaust configuration. Exhaust from a MWM D916-6 mining engine was split into two branches. One branch bypassed the filtration unit going directly to a dilution tunnel while the other branch was passed through the filtration system prior to entering the dilution tunnel. Since the filter was not of sufficient volume to capture 
the entire exhaust, an automated throttling valve was placed on the bypass branch for flow adjustment. Critical flow orifices placed before the split and in the bypass leg measured the respective flows. Rankin's conclusion that microwave regeneration was an effective way to heat, and thus remove, the collected diesel PM would not have been possible without the use a split exhaust configuration.

\subsection{Flow measurement}

ASME/ANSI MFC-7M-1987 specifies the geometry requirements for measuring flow with critical flow venturies. This paper also provides the procedures for operation and the conditions required when measuring mass flow rate with venturies. The principle behind critical flow venturies is that the mass flow rate of gas through the device is maintained at a constant value once the gas flow reaches sonic conditions [23]. Explanations of flow and device parameters such as static pressure and discharge coefficients were discussed. Flow rate equations were presented for both the ideal case of one-dimensional isotropic flow and the real case that corrects for compressibility and viscous effects. Equation 2.1 determines the flow rate through a critical flow venturi operating under real conditions. Venturies possess a unique characteristic that flow is independent of downstream pressure if critical flow conditions are achieved [16].

$$
q_{m}=A^{*} C C_{R} \sqrt{Z_{O} P_{o} \rho_{O}}
$$

In Equation 2.1, $\mathrm{q}_{\mathrm{m}}$ represents the mass flow rate, $\mathrm{A}^{*}$ represents the area of the throat, $C$ represents the discharge coefficient for the device, $C_{R}$ represents the real gas critical flow coefficient, $Z_{0}$ represents the compressibility factor at stagnation temperature and pressure, $\mathrm{P}_{\mathrm{O}}$ represents the absolute stagnation pressure at the device inlet, and $\rho_{\mathrm{O}}$ represents the gas density at stagnation temperature and pressure at the device inlet [16]. 
Orifice meters of $6 \mathrm{~mm}$ to $40 \mathrm{~mm}$ line size are discussed in ASME MFC-14M-1995. This national standards paper specifies geometry requirements and operational procedures and conditions required when measuring flow rate with these devices. Only steady subsonic flow throughout the measuring section of the orifice was considered in the publication. Unlike critical flow venturies, orifices require the differential pressure across the primary device to calculate flow through the device. Equation 2.2 determines the flow rate through an orifice placed in subsonic flow [15].

$$
q_{m}=\frac{\pi}{4} C \varepsilon_{1} d^{2} \sqrt{\frac{2 \Delta p p_{f 1}}{1-\mathrm{B}}}
$$

In Equation 2.2, $\mathrm{q}_{\mathrm{m}}$ represents the mass flow rate, $\mathrm{C}$ represents the discharge coefficient for the device, $\varepsilon_{1}$ represents the expansion factor based on upstream pressure, $\mathrm{d}$ represents the diameter of the device, $\Delta \mathrm{p}$ represents the differential pressure across the device, $\mathrm{p}_{\mathrm{f} 1}$ represents the static pressure upstream of the device, and $\mathrm{B}$ represents a ratio of the orifice diameter to the upstream pipe diameter [15].

Laminar flow elements (LFE) function similarly to venturies and orifice meters in that the differential pressure across a flow obstruction is correlated to volume flow rate. The LFE obstruction is a honeycomb structure. A calibration curve provided by the manufacturer and differential pressure across the device obstruction determines the flow rate passing through the device. The calibration curve provided by Merium Instruments was a secondorder polynomial [21].

Annubars operate on the same principle as orifices in that differential pressure across the device can be related to flow rate. Diamond type II+ annubars contain a rigid multipletube structure that embodies dual averaging chambers with a diamond cross-section. This 
device has multiple ports on the upstream and downstream sides of the probe that is placed into the moving fluid. The upstream ports (high pressure side) correspond to the measurement of the stagnation pressure while the downstream ports (low pressure side) correspond to the measurement of the reference pressure [2]. Equation 2.3 determines the flow through the annubar [2].

$$
q_{m}=C^{*} K d^{2} y_{a} \sqrt{\Delta p p}
$$

In Equation 2.3, $\mathrm{q}_{\mathrm{m}}$ represents the mass flow rate, $\mathrm{C}^{*}$ represents the correction coefficient that contains device and flow parameter corrections [2], $\mathrm{K}$ represents the device coefficient, $d$ represents the diameter of pipe in which the fluid flowing, $y_{a}$ represents the expansion factor, $\Delta \mathrm{p}$ represents the differential pressure across the device, and $\mathrm{p}$ represents the static pressure downstream of the device. 


\section{Experimental Set-up and Procedures}

This chapter discusses the Engine and Emission Research Center (EERC) at West Virginia University and hardware used in this facility for emission measurement. Cycles used for the DECSE program and for the split exhaust validation are also presented. The exhaust system is described in detail along with procedures performed while conducting a split exhaust test run.

\subsection{Test engines}

A total of four diesel engines was used throughout the DESCE program. Two identical heavy-duty Cummins diesel engines and two identical medium-duty Navistar diesel engines aged and evaluated two types of aftertreatment technologies. One of each respective engine evaluated catalysts in the emissions test cell, which is described in Section 3.2, while the other respective engines were located in an adjacent room and used for catalyst aging. For the purpose of clarity in this thesis, engines used for catalyst aging will be called aging engines and engines performing the aftertreatment performance assessment will be termed the evaluation engines.

\subsubsection{Cummins ISM370 ESP}

Two direct-injected, turbocharged 1999 Cummins ISM370 ESP heavy-duty diesel engines were used for the high temperature catalyst aging and evaluations. Engine specifications are listed in Table 3.1. Figure 3.1 illustrates engine power and torque curves for the Cummins engine. The split exhaust system validation was completed with the Cummins evaluation engine. A photograph of the Cummins evaluation engine is shown in Figure 3.2. 
Table 3.1: Engine specifications.

\begin{tabular}{|c|c|c|}
\hline Engine & Cummins ISM370 ESP & Navistar T444E \\
\hline Displacement (l) & 10.8 & 7.3 \\
\hline Bore / Stroke (in) & $4.92 / 5.79$ & $4.11 / 4.18$ \\
\hline Power Rating (hp) & $370 @ 2100 \mathrm{rpm}$ & $210 @ 2300 \mathrm{rpm}$ \\
\hline Torque Rating (ft-lb) & 1350 @ 1200 rpm & 520 @ 1500 rpm \\
\hline Configuration & In-line 6 cylinder & V8 cylinder \\
\hline Compression Ratio & $16.3: 1$ & $16.1: 1$ \\
\hline
\end{tabular}

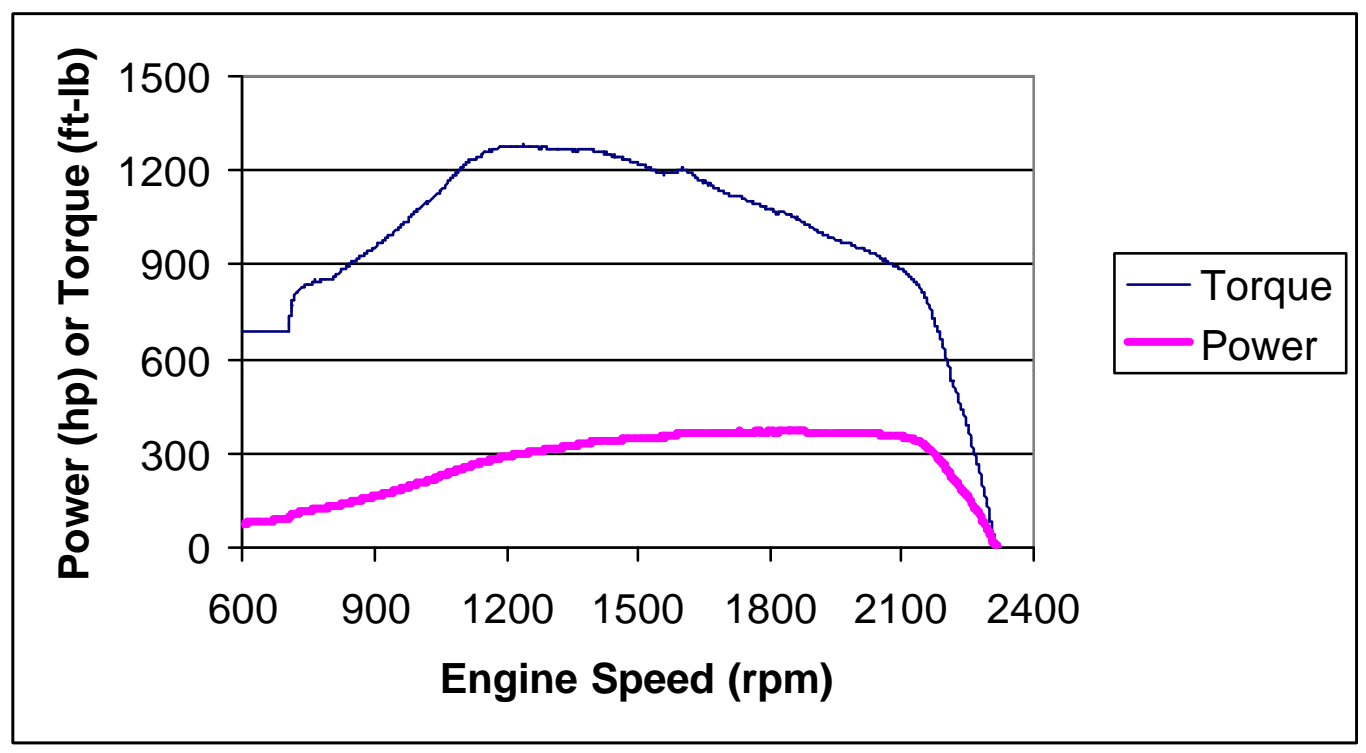

Figure 3.1: Cummins ISM370 ESP power torque map. 


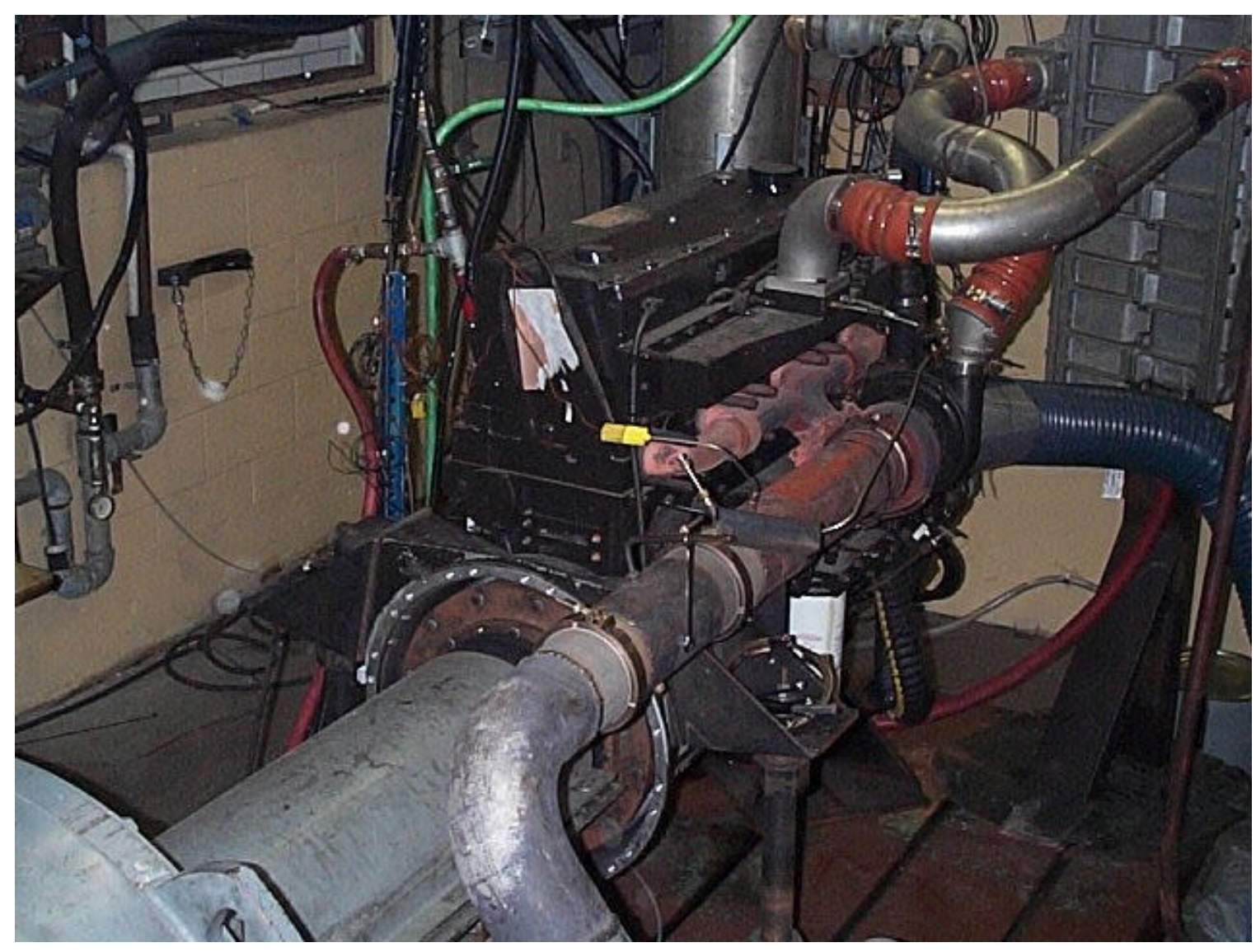

Figure 3.2: Cummins ISM370 connected to GE dynamometer.

\subsubsection{Navistar T444E}

Two direct-injected, turbocharged 1999 Navistar T444E medium-duty diesel engines were used for the low temperature catalyst aging and evaluations. Engine specifications are listed in Table 3.1. Figure 3.3 illustrates engine power and torque curves and a picture of the Navistar evaluation engine is shown in Figure 3.4. 


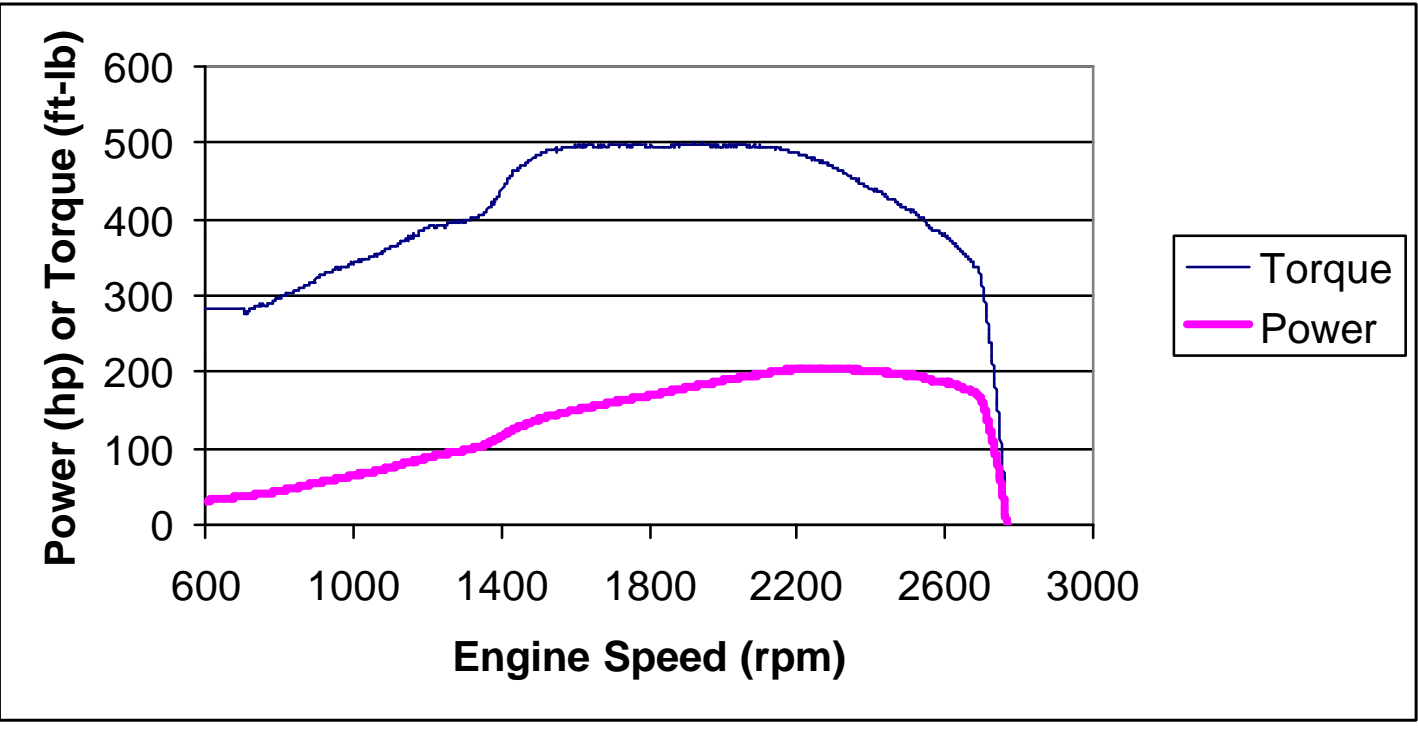

Figure 3.3: Navistar T444E power torque map.

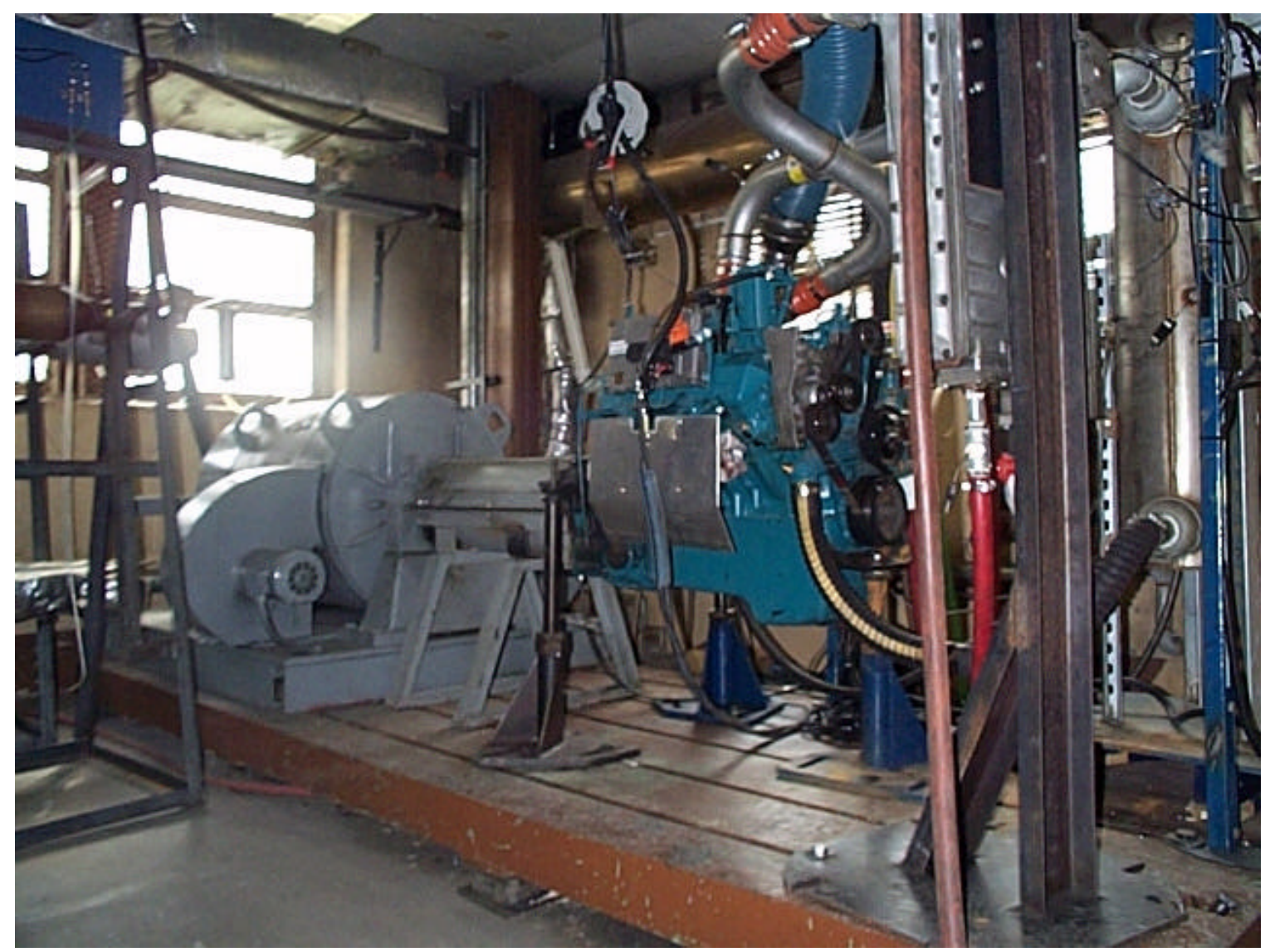

Figure 3.4: Navistar T444E connected to GE dynamometer. 


\subsection{Fuel specifications}

Number-2 diesel fuel, supplied by Phillips Petroleum Company, with four different levels of sulfur was used during the DECSE program. All of the fuel used was blended from the same base stock. A certain amount of sulfur additives was added to the base stock to yield the desired sulfur fuel level. Sulfur fuel concentration levels of approximately $3 \mathrm{ppm}$, 30ppm, 150ppm, and 350ppm were used throughout the DECSE program. The validation of the split exhaust system utilized 30ppm diesel fuel. Certificates of fuel analysis were provided by Phillips Petroleum can be seen in Appendix A.

\subsection{Catalyst specifications}

Two versions of a diesel oxidation catalyst and two versions of a lean- $\mathrm{NO}_{\mathrm{x}}$ catalyst were evaluated during the DESCE project. Catalyst geometry and properties of both catalyst technologies are given in this section. Table 3.1 includes specifications for both the diesel oxidation catalysts while Table 3.2 provides specifications for the lean- $\mathrm{NO}_{\mathrm{x}}$ catalysts [3]

Table 3.1: DOC catalyst specifications.

\begin{tabular}{|c|c|c|c|c|c|c|}
\hline Catalyst Type & Pt Loading & Substrate Size & Volume & \# of & Cell Density & Converter Size \\
\hline & $\left(\mathrm{g} \mathrm{Pt} / \mathrm{ft}^{3}\right)$ & $\mathrm{OD} \times$ Length $(\mathrm{cm})$ & $($ liters $)$ & Substrates & $(\mathrm{cpsi})$ & OD $\times$ Length $(\mathrm{cm})$ \\
\hline High Temperature & 2 & $19.1 \times 15.9$ & 4.5 & 1 & 400 & $20.3 \times 66.0$ \\
\hline Low Temperature & $>50$ & $17.8 \times 11.8$ & 2.92 & 1 & 400 & $19.1 \times 40.6$ \\
\hline
\end{tabular}

Table 3.2: Lean-NO catalyst specifications.

\begin{tabular}{|c|c|c|c|c|c|c|}
\hline Catalyst Type & Formulation & Substrate Size & Volume & \# of & Cell Density & Converter Size \\
\hline & $\left(\mathrm{g} \mathrm{Pt} / \mathrm{ft}^{3}\right)$ & $\mathrm{OD} \times$ Length $(\mathrm{cm})$ & $($ liters $)$ & Substrates & $(\mathrm{cpsi})$ & OD $\times$ Length $(\mathrm{cm})$ \\
\hline High Temperature & Zeolite Base & $26.7 \times 15.2$ & 8.5 & 1 & 400 & $27.3 \times 51.4$ \\
\hline Low Temperature & Precious Metals & $17.8 \times 12.7$ & 6.4 & 2 & 400 & $19.1 \times 55.9$ \\
\hline
\end{tabular}

\subsection{Emissions measurement}

Research grade gaseous emissions analyzers for $\mathrm{HC}, \mathrm{CO}, \mathrm{NO}_{\mathrm{x}}$, and $\mathrm{CO}_{2}$ are used in conjunction with a full-scale dilution tunnel which is described in Section 3.5.1. Analyzers 
were calibrated at the beginning of each set of tests, test series, as well as zeroed and spanned daily. A test series involved evaluation of both catalysts as well as engine-out emissions measured from full exhaust and split exhaust configurations described in Section 3.7.2. Zeroing analyzers entails passing a known gas that contains no chemical species that the instruments detects through the analyzers and setting the output of the analyzer to zero. Spanning analyzers is conducted in the same way except that the instrument detects the span gas, which represents the maximum concentration that the analyzer can detect for the current calibration, and the output is set to $100 \%$. A background bag of the dilution air used to dilute the exhaust was taken and analyzed for the regulated emissions with each engine test. The background was subtracted from the "cycle integrated" results to yield the gaseous emissions produced by the engine. PM was collected on fiberfilm filters as well as with a Tapered Element Oscillating Microbalance (TEOM). For an in-depth explanation of the gaseous emissions instruments used at the EERC, refer to Evans [6] and Shade [23].

\subsubsection{Gaseous emissions instruments}

Hydrocarbons were measured with the method of flame ionization used by a Rosemount Analytical model 402 heated FID analyzer. The exhaust sample pressure of the analyzer was set at $3 \mathrm{psi}$ and temperature at $375^{\circ} \mathrm{F}$, as required by the CFR 40 . The analyzer was zeroed using $\mathrm{HC}$ free air produced by a Balston 75-87 zero air generator and spanned with 15ppm propane which was also used in calibration of the FID. For evaluation of the high temperature lean- $\mathrm{NO}_{\mathrm{x}}$ catalyst with the Cummins evaluation engine, 100ppm propane was used as the HC span gas because of the extra hydrocarbons introduced from the catalyst reductant. The low temperature lean- $\mathrm{NO}_{\mathrm{x}}$ catalyst required 50ppm propane as the span gas. 
A "FID peak" which optimizes detector response was performed as needed to maximizes the efficiency of the combusting $40 \%$ hydrogen / $60 \%$ helium fuel required by the instrument.

A Rosemount Analytical model 955 analyzer was the instrument for measuring oxides of nitrogen of the diesel exhaust. The $955 \mathrm{NO}_{\mathrm{x}}$ analyzer uses chemiluminescence as the method of detection and operates in $\mathrm{NO}_{\mathrm{x}}$ mode with a sample pressure of $4 \mathrm{psi}$ and ozone pressure of 21psi. Ultra-pure nitrogen was used to zero the analyzer while 500ppm nitric oxide was utilized as the span gas for all catalyst and engine-out testing for the Cummins evaluation engine. The Navistar evaluation engine required $250 \mathrm{ppm} \mathrm{NO}_{\mathrm{x}}$ as the span gas for full flow testing and 175ppm $\mathrm{NO}_{\mathrm{x}}$ was utilized for all split exhaust testing. A periodic $\mathrm{NO}_{\mathrm{x}}$ converter efficiency test on the $\mathrm{NO}_{\mathrm{x}}$ analyzer was performed with Rosemount Analytical $\mathrm{NO}_{\mathrm{x}}$ efficiency tester.

Carbon monoxide measurements were taken via a Rosemount Analytical model 880A, which uses Non-Dispersive Infrared (NDIR) as its method of detection. The zero gas used for the $880 \mathrm{~A} \mathrm{CO}$ analyzer was ultra-pure nitrogen while $250 \mathrm{ppm}$ carbon monoxide was utilized as the span gas for testing conducted with the Cummins evaluation engine. All of the Navistar engine testing was performed with a span gas of 100ppm. Carbon monoxide of 490ppm concentration was required as the span gas for testing the high temperature lean- $\mathrm{NO}_{\mathrm{x}}$ catalyst due to $\mathrm{CO}$ generated from the catalyst injection system.

A Beckman Industrial model 868 instrument was used to measure carbon dioxide produced by the engine. This analyzer employs Non-Dispersive Infrared (NDIR) as its method of detecting $\mathrm{CO}_{2}$. During testing, the analyzer was zeroed with ultra-pure nitrogen and spanned with $5 \%(50,000 \mathrm{ppm})$ carbon dioxide $\left(\mathrm{CO}_{2}\right)$ for Cummins engine testing and full flow Navistar testing. Split exhaust testing with the Navistar engine utilized 3\% 
(30,000ppm) $\mathrm{CO}_{2}$ as the span gas. Figure 3.1 shows the analyzer bench at the EERC along with the pumps and mass flow controller for the PM sampling system.

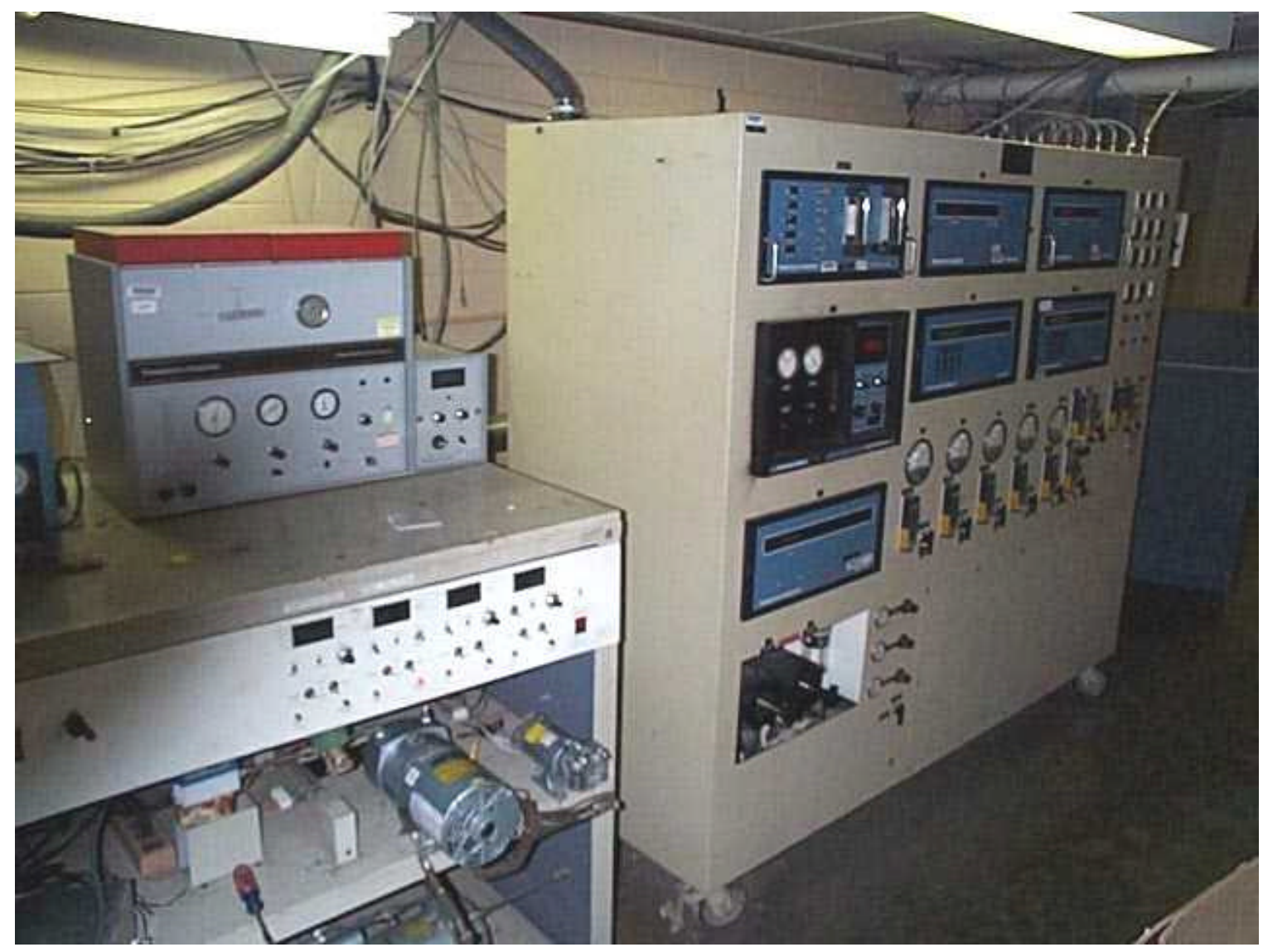

Figure 3.1: Gaseous emissions instruments.

\subsubsection{Particulate matter measurement}

PALLFLEX membrane filters made by Pall Gelman Sciences were used to collect PM during the testing. These filters were of the type fiberfilm T60A20 with a size of 70mm in diameter. Two filters were placed in series at the bottom of a secondary tunnel attached to the primary dilution tunnel. This secondary dilution tunnel is used to control the temperature of the sample at the filter face by further diluting the exhaust sample. The CFR 40 requires that the temperature at the filter may not exceed $125^{\circ} \mathrm{F}$. Dilution air was used in the 
secondary tunnel to decrease the temperature of the gas sample flowing through the filter during steady-state test cycles. Secondary dilution is generally not needed during transient test cycles.

The PM filters were conditioned in a Thermotron SM-80 chamber at $45 \%( \pm 8 \%)$ humidity and $22^{\circ} \mathrm{C}\left( \pm 3^{\circ} \mathrm{C}\right)$ for at least one hour before used to collect PM [1]. Once conditioned, the filter's weight was determined with a Cahn C-32 microbalance $( \pm 1 \mu \mathrm{g})$ and the filters were placed in filter holders for testing. After the emissions test, the filters were placed back into the conditioning chamber and recondition prior to measuring the post test weight. A background filter, a PM filter that collects PM only from the tunnel without the engine running, was taken at the end of each testing day. The background filter weight was subtracted from the test filter weights to yield PM produced by the engine during the cycle.

Certain cycles (ESC4, NAV4, and SSC which are described below) collected PM at the end of each steady-state mode, not on a continuos basis. This type of PM collection was required for two reasons: to avoid overloading the filter during the long modes and to allow for stabilization of catalyst temperatures prior to data collection. A bypass system was constructed to permit this type of PM collection. An electronic three-way valve allowed exhaust to either pass through the filter went collecting PM or to bypass the filter when allowing the exhaust to stabilize. Refer to Evans for a schematic of the bypass system used for collecting PM.

\subsection{Discussion of Engine and Emission Research Center at WVU}

Experiments were conducted at West Virginia University's Engine and Emission Research Center (EERC). The EERC maintains and operates a full flow dilution tunnel critical flow venturi (CFV) constant volume sampling (CVS) system. WVU's dilution tunnel 
meets all of the requirements provided by the Code of Federal Regulations 40 Part 86 Subpart N [1]. A description of various components used during emissions characterization at this facility is presented in this section.

\subsubsection{Full flow dilution tunnel}

Dilution tunnels combine engine exhaust and conditioned air to simulate what actually takes place in the real world if the test engine was in a truck driving down a road. The dilution tunnel at the EERC was 18 inches in diameter with a length of 40 feet and contains a mixing orifice 3 feet from the tunnel entrance. Sample probes that draw a small portion of the diluted exhaust for analysis were place 15 feet downstream of the tunnel inlet. A 75hp blower draws the air/exhaust mixture through the tunnel 23]. Flow rates were selected with four critical flow venturies (one nominal 400scfm and three nominal 1000scfm) that may be applied in any combination to yield nominal flow rates between 400 scfm and $3400 \mathrm{scfm}$. At the present time, the facility is capable of a maximum flow rate of $2400 \mathrm{scfm}$ due to the capacity of the blower. A secondary dilution tunnel, used to collect PM, was connected to the main dilution tunnel at the sampling plane. This smaller tunnel's capability for additional dilution provides temperature control during the collection of PM on the filters. Section 3.4.2 provides an in-depth description on the collection of particulates.

\subsubsection{Engine dynamometer}

Emissions testing entails loading and motoring the engine, which was accomplished via an engine dynamometer. The EERC dynamometer used for this testing was a direct current (DC) General Electric model DYC 243. This piece of equipment has the capability of absorbing 550-hp and motoring up to 500-hp. Engine speed was determined with a digital encoder. Torque was measured with a load cell that was attached to the housing of the 
dynamometer. The measured torque was also compensated for dynamometer inertia. The engine and dynamometer were directly connected together with a driveshaft and a rubber coupler.

\subsubsection{Critical flow venturies}

Principles of critical flow venturies were discussed in Section 2.5. The EERC at WVU contains four venturies; one designed to operate at $400 \mathrm{scfm}$ and three designed to operate at $1000 \mathrm{scfm}$. When testing with the Cummins engine, described in Section 3.1.1, a nominal flow rate of $2400 \mathrm{scfm}$ was used for full flow testing and nominal flow rate of 1400 scfm was used for split exhaust testing. The Navistar, described in Section 3.1.2, required a nominal flow rate of $1400 \mathrm{scfm}$ for full flow testing and $1000 \mathrm{scfm}$ for split exhaust testing. The criteria in selecting tunnel flow rates involve maximizing resolution associated with gaseous emissions instrumentation. Good engineering practice limits the maximum output of the gas analyzer to approximately $80 \%$ of full scale during the entire test run.

\subsubsection{Data acquisition}

Data collected during emissions testing, such as analyzer, thermocouple, and pressure transducer outputs, at the EERC were recorded using in-house software and data acquisition hardware. This hardware includes RTI-815 analog-to-digital acquisition boards attached to the computer and 3B modules made by Analog Devices for signal conditioning. During the testing, data was recorded as ADC code and converted to engineering units when data reduction was completed [23].

\subsubsection{Data reduction}

Data reduction for the DECSE program and the split exhaust validation was executed with in-house software on the EERC's reduction machine. Procedures and calculations were 
base from the CFR 40 for transient FTP test runs and from the Official Journal of the European Communities for steady-state test runs [1] [18]. split flow emissions results of $\mathrm{NO}_{\mathrm{x}}, \mathrm{HC}, \mathrm{CO}$, and $\mathrm{CO}_{2}$ were corrected with the reduction program to reflect full flow levels. This was accomplished by calculating a split ratio based on $\mathrm{CO}_{2}$ concentration, refer to Section 3.8.2, and applying the inverse of this ratio to the split flow data yielding "split flow corrected" results. The reasoning behind correcting the split flow data was to provide agreement with full flow data on a brake-specific basis. Equations 3.1 through 3.4 provide the equations used to correct the split flow gaseous data.

$$
\begin{aligned}
N O_{X(\text { corrected })} & =\frac{C O_{2(\text { full-flow })}}{C O_{2(\text { split-flow })}} \cdot N O_{X(\text { split-flow })} \\
H C_{(\text {corrected })} & =\frac{C O_{2(\text { full-flow })}}{C O_{2(\text { split-flow })}} \cdot H C_{(\text {split-flow })} \\
C O_{(\text {corrected })} & =\frac{C O_{2(\text { full-flow })}}{C O_{2(\text { split-flow })}} \cdot C O_{(\text {split-flow })} \\
C O_{2(\text { corrected })} & =\frac{C O_{2(\text { full-flow })}}{C O_{2(\text { split-flow })}} \cdot C O_{2(\text { split-flow })}
\end{aligned}
$$

\subsection{Cycles}

The FTP transient cycle and a modified European steady-state cycle called the ESC4 were used in evaluation of the high-temperature diesel oxidation catalyst with the Cummins ISM370 engine. The ESC4 was the only cycle used to evaluate the performance of the hightemperature lean- $\mathrm{NO}_{\mathrm{x}}$ catalyst. Only steady-state conditions were used in both lean- $\mathrm{NO}_{\mathrm{x}}$ catalysts evaluations which alleviated problems associated the injecting the reductant on a transient basis. Figure 3.2 provides an engine speed trace of the FTP cycle and a torque trace is provided in Figure 3.3. Set points and mode times for the ESC4 are listed in Table 3.3. 


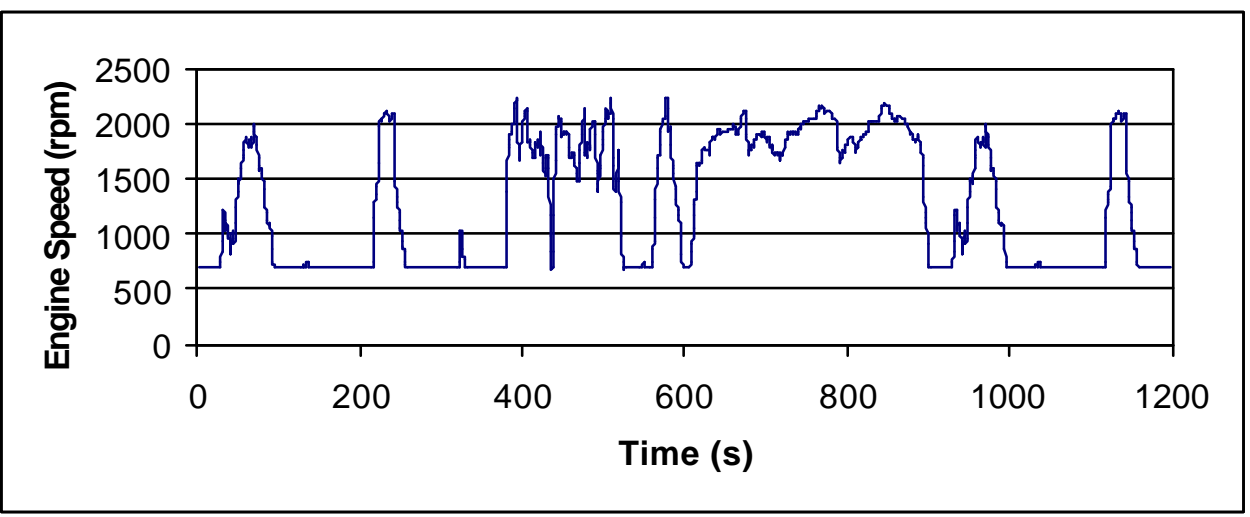

Figure 3.2: FTP engine speed.

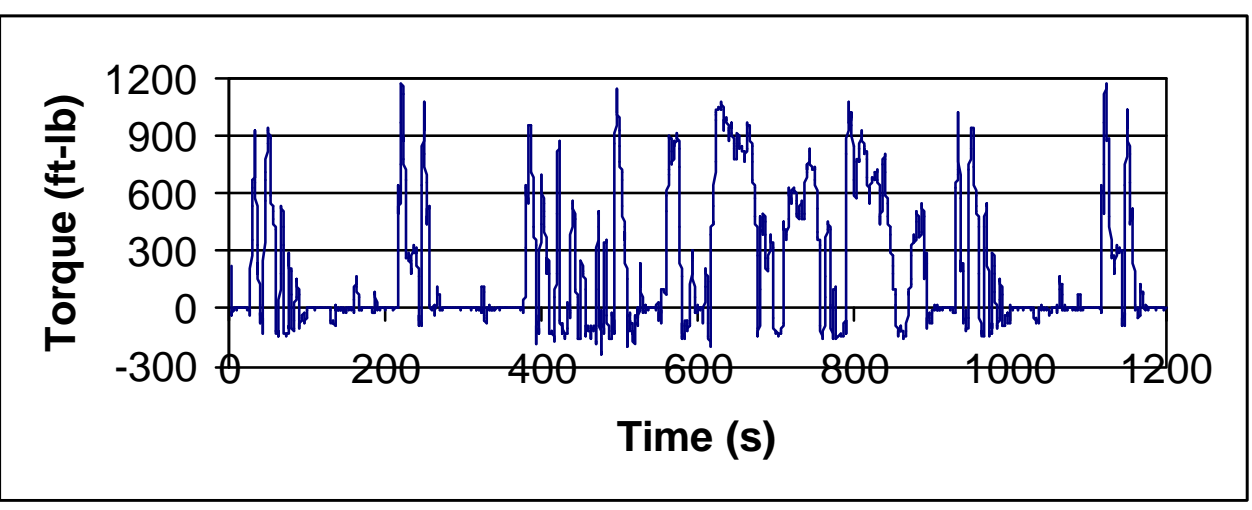

Figure 3.3: FTP engine torque.

Cycles performed by the Navistar T444E were a mimicked FTP75 and a steady-state test similar to the ESC4 termed the NAV4. The FTP75 cycle was derived from the Urban Driving Dynamometer Schedule (UDDS) chassis schedule that is commonly called the FTP75. Engine speed was obtained by taking the chassis schedule and applying the gear reductions (Table 3.5) that occur in the driveline of a Ford F-250 pick-up truck. The load trace of the mimicked FTP75 was determined by using the road load equation (3.1) and characteristics of the same F-250 pick-up truck, which are included in Table 3.5. 


$$
P=\left(\frac{\rho C_{d} A v^{3}}{2}\right)+(\mu m g v)+(m a v)
$$

For Equation 3.1, $\rho$ is air density, $C_{d}$ is the drag coefficient for the truck, $A$ is the frontal area of the truck, $v$ is the vehicle's velocity, $\mu$ is the rolling resistance of the truck, $m$ is the vehicle mass, $g$ is the acceleration due to gravity, and $a$ is the vehicle's acceleration. Figure 3.4 provides an engine speed trace of the mimicked FTP75 cycle while a torque trace is provided in Figure 3.5. The FTP75 and NAV4 cycles were used to test the performance of the low-temperature oxidation catalysts while only the NAV4 was performed to evaluate the low-temperature lean- $\mathrm{NO}_{\mathrm{x}}$ catalysts.

Table 3.3: Set-points of the ESC4 steady-state cycle performed.

\begin{tabular}{|c|c|c|c|c|}
\hline \multicolumn{5}{|c|}{ ESC4 (Cummins ISM) } \\
\hline Mode & Time (min) & Speed (rpm) & Torque (ft-lb) & Sample Time (s) \\
\hline 1 & 2 & 700 & 0 & 0 \\
\hline 2 & 20 & 1888 & 248 & 100 \\
\hline 3 & 20 & 1585 & 595 & 200 \\
\hline 4 & 20 & 1888 & 992 & 160 \\
\hline 5 & 20 & 1282 & 1244 & 160 \\
\hline 6 & 5 & 1200 & 0 & 0 \\
\hline
\end{tabular}

Table 3.4: Set-points of the NAV4 steady-state cycle performed.

\begin{tabular}{|c|c|c|c|c|}
\hline \multicolumn{5}{|c|}{ NAV4 (Navistar T444E) } \\
\hline Mode & Time (min) & Speed (rpm) & Torque (ft-lb) & Sample Time (s) \\
\hline 1 & 2 & 700 & 0 & 0 \\
\hline 2 & 20 & 1000 & 81 & 170 \\
\hline 3 & 20 & 1250 & 122 & 280 \\
\hline 4 & 20 & 2000 & 122 & 190 \\
\hline 5 & 20 & 2200 & 406 & 360 \\
\hline 6 & 5 & 1200 & 0 & 0 \\
\hline
\end{tabular}


Table 3.5: Parameters used in the development of the FTP75.

\begin{tabular}{|c|c|c|c|c|}
\hline Gear & Reduction & Parameter & Value & Unit \\
\hline \hline 1 & 5.79 & Mass & 3632 & $\mathrm{~kg}$ \\
\hline 2 & 3.31 & Tire Diameter & 0.8125 & $\mathrm{~m}$ \\
\hline 3 & 2.1 & Drag Coefficient & 0.88 & \\
\hline 4 & 1.31 & Rolling Resistance & 0.0098 & \\
\hline 5 & 1 & Air Density & 1.177 & $\mathrm{~kg} / \mathrm{m}^{3}$ \\
\hline 6 & 0.72 & Frontal Area & 5 & $\mathrm{~m}^{2}$ \\
\hline Differential & 3.73 & & & \\
\hline
\end{tabular}

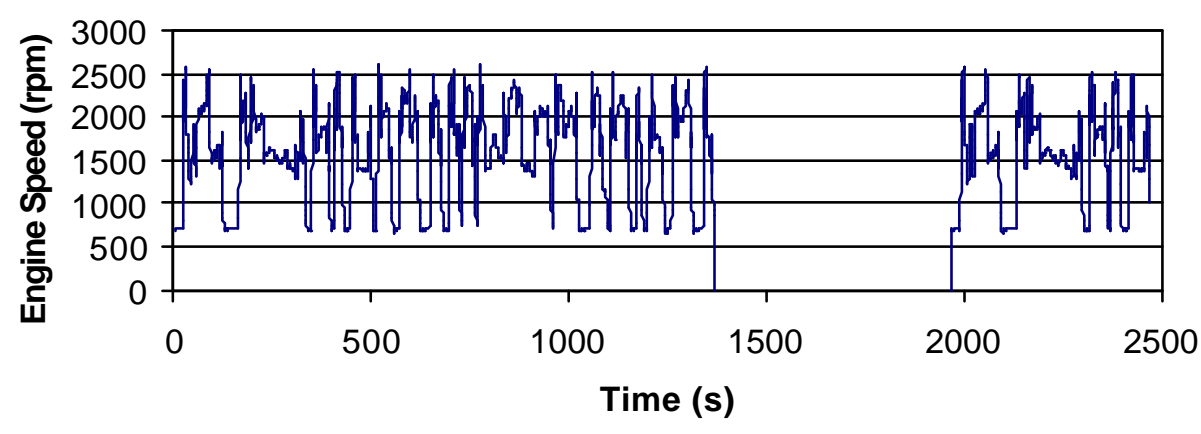

Figure 3.4: Mimicked FTP75 engine speed.

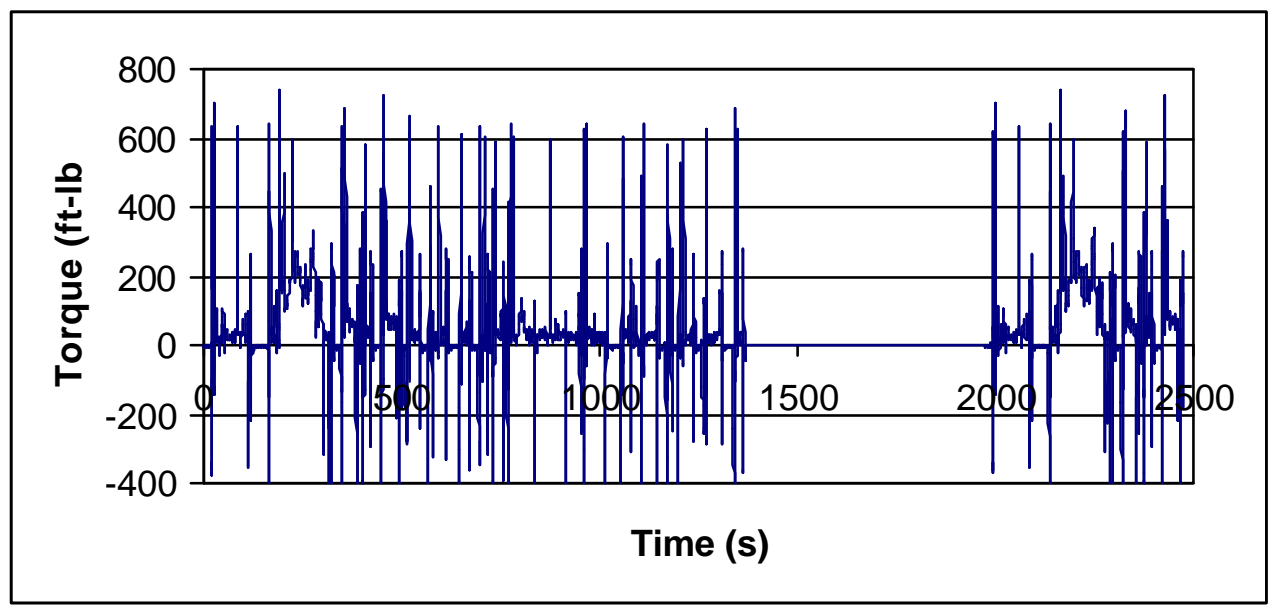

Figure 3.5: Mimicked FTP75 engine torque. 
Catalyst aging with the Navistar and the Cummins was completed by repeating a steady-state cycle with set points and mode times listed in Table 3.6 until the proper aging period was achieved. The aging cycles contain the same modes as the evaluation steady-state cycles but the evaluation cycles were performed in the order of increasing exhaust temperature. Modes 1 and 4 of the AgeISM cycle were switched to obtain the ESC4 cycle. The modes of the AgeNav were arranged in the order of increasing exhaust temperature therefore the NAV4 modes are in the same order.

Table 3.6: Steady-state cycles for catalyst aging.

\begin{tabular}{|c|c|c|c|c|c|c|}
\hline & \multicolumn{2}{|c|}{ AgeISM (Cummins ISM) } & \multicolumn{3}{c|}{ AgeNav (Navistar T444E) } \\
\hline Mode & Time (min) & Speed (rpm) & Torque (ft-lb) & Time (min) & Speed (rpm) & Torque (ft-lb) \\
\hline 1 & 24 & 1282 & 1244 & 12 & 1000 & 81 \\
\hline 2 & 6 & 1585 & 595 & 12 & 1250 & 122 \\
\hline 3 & 24 & 1888 & 992 & 12 & 2000 & 122 \\
\hline 4 & 6 & 1888 & 248 & 24 & 2200 & 406 \\
\hline
\end{tabular}

The validation of the split exhaust system was conducted on the Cummins evaluation engine. Only the FTP and an ad hoc steady-state cycle (SSC) were used for this validation. Set points, sampling times, and duration of the SSC modes are listed in Table 3.7.

Table 3.7: Steady-state cycle for split exhaust validation.

\begin{tabular}{|c|c|c|c|c|c|}
\hline Mode Number & Engine Speed & Load & Duration & Sample Time & Percent Load \\
\hline & $(\mathrm{rpm})$ & $(\mathrm{ft}-\mathrm{lb})$ & $(\mathrm{s})$ & $(\mathrm{s})$ & \\
\hline 1 & 700 & 0 & 240 & 90 & Idle \\
\hline 2 & 1200 & 640 & 240 & 90 & 50 \\
\hline 3 & 1800 & 1080 & 240 & 90 & 100 \\
\hline 4 & 1200 & 1280 & 240 & 90 & 100 \\
\hline 5 & 1800 & 540 & 240 & 90 & 50 \\
\hline 6 & 700 & 0 & 240 & 90 & Idle \\
\hline
\end{tabular}




\subsection{Split Exhaust Systems}

The DECSE program implemented a split exhaust configuration to accelerate the aging process by simultaneously aging the $\mathrm{DOC}$ and lean- $\mathrm{NO}_{\mathrm{x}}$ catalysts. The Cummins split exhaust systems for aging and evaluation were constructed of 5 inch diameter aluminized steel exhaust pipe. The same type of exhaust pipe was utilized for the Navistar split exhaust systems except with a pipe diameter of 4 inches. Flanges were welded onto the ends of all the components in the exhaust and attached together with exhaust clamps. Figure 3.6 illustrates the split exhaust configuration for simultaneous aging of both catalyst technologies.

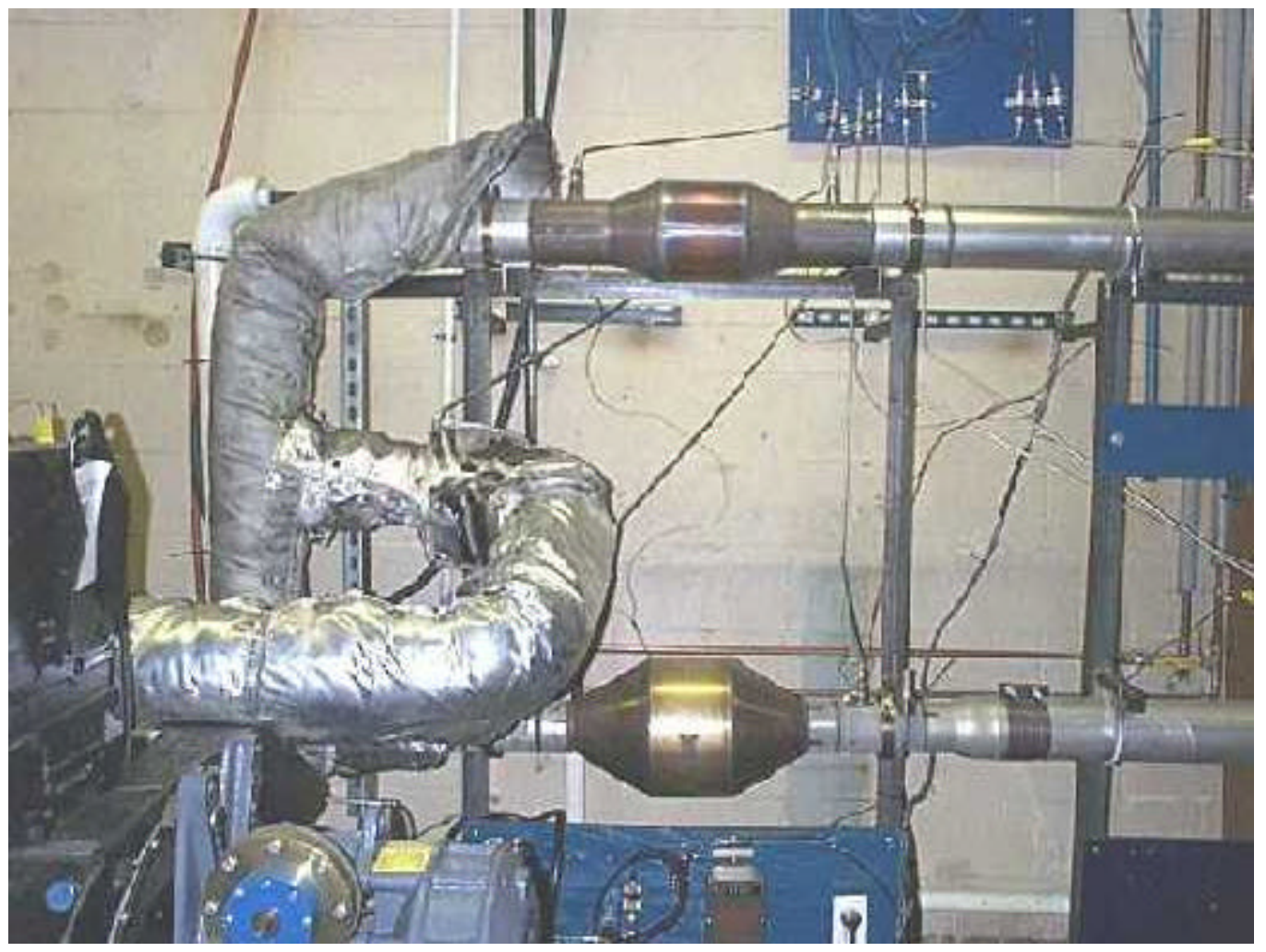

Figure 3.6: Picture of set-up for catalyst aging. 


\subsubsection{Aging engine's exhaust set-up}

A Go-Power Model DT-2000 water-break dynamometer was connected to both respective engines to provide load while conducting catalyst aging. Water required for the Go-Power dynamometers was provided from the building's water supply. The same water supply was utilized for the cooling system of the engine. The engine's exhaust was split into two branches. The DOC was placed in the top branch of the exhaust system while the lean$\mathrm{NO}_{\mathrm{x}}$ catalyst was placed in the lower branch. The lean- $\mathrm{NO}_{\mathrm{x}}$ branch was outfitted with injectors to supply the supplemental $\mathrm{HC}$ reductant required by the catalyst. A flow metering orifice and throttling value in each branch completes the hardware of the aging split exhaust system. Figure 3.7 illustrates the exhaust system used for aging the catalysts.

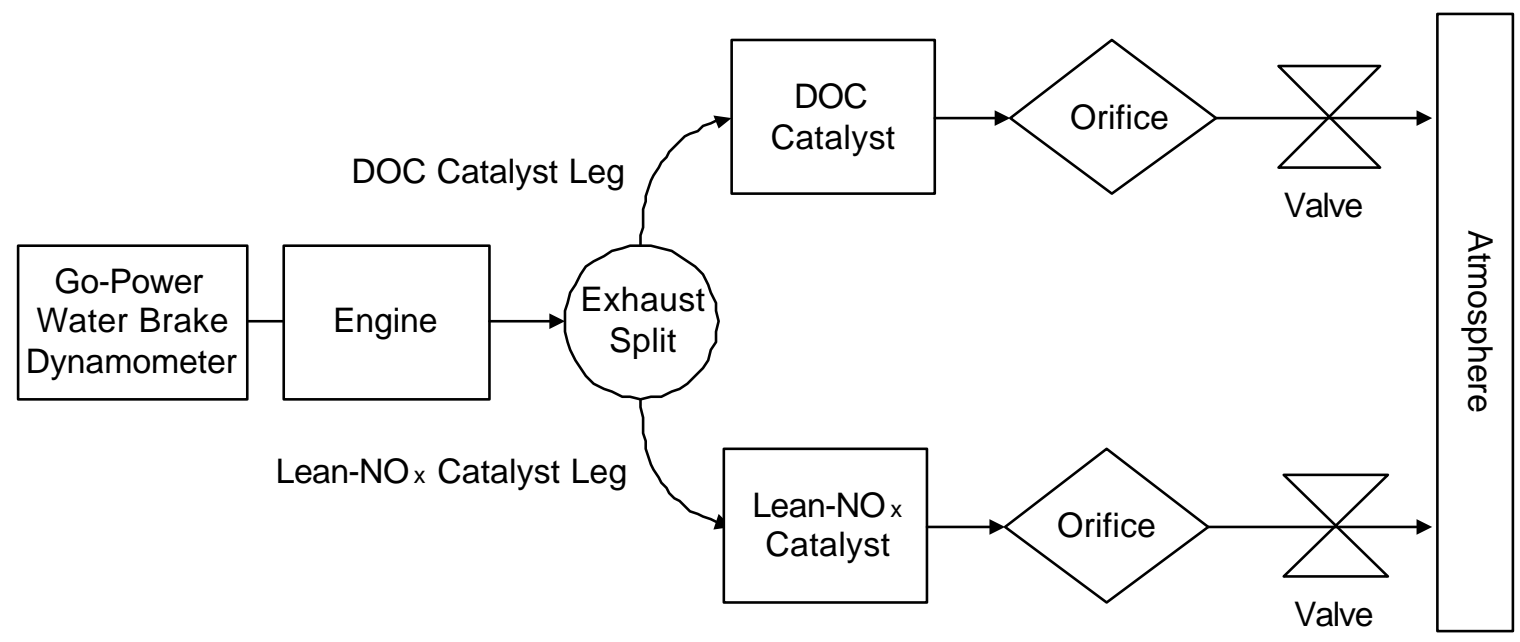

Figure 3.7: Exhaust configuration for aging the catalyst.

\subsubsection{Evaluation engine's exhaust set-up}

The DECSE program requires three types of testing. The first type involves typical engine dynamometer testing by introducing the entire engine exhaust stream into a dilution tunnel. This testing was named full flow because the entire exhaust flows into the dilution 
tunnel. split flow engine-out testing implies splitting the exhaust into two branches and passing one branch into the dilution tunnel while the other branch is discarded into the atmosphere. No aftertreatment occurs in the split flow engine-out tests. The last type of testing involves catalyst evaluation. The catalyst, either the oxidation catalyst or the lean$\mathrm{NO}_{\mathrm{x}}$ catalyst, was placed in the exhaust branch that was connected to the dilution tunnel while the other branch contained a bypass catalyst that provided similar flow restrictions as the active catalyst. The bypass catalyst contains the same honeycomb as the active catalyst but the honeycomb was not washcoated. This aided in balancing the flows between each exhaust branch of the split exhaust system. Refer to Section 3.8 for the procedure used to balance the exhaust flows in each branch. Metering orifices and throttling valves complete the set-up for the evaluation split exhaust system. Figure 3.8 is a schematic of the exhaust split system used for the catalyst evaluations.

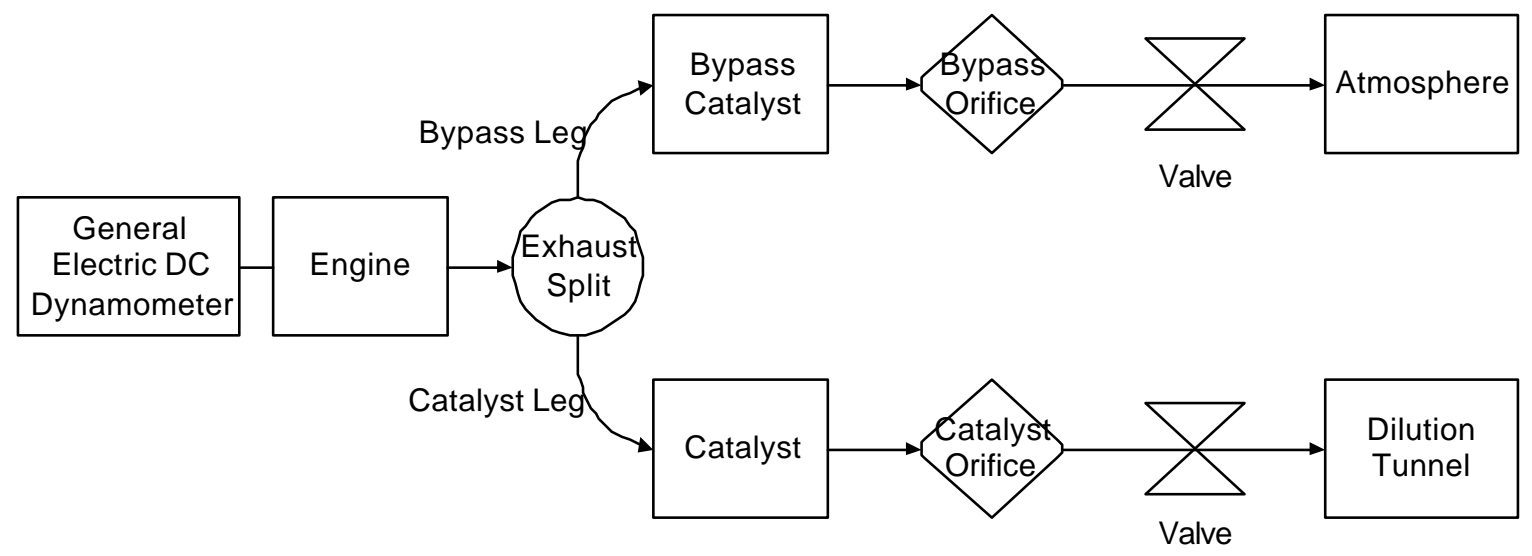

Figure 3.8: Exhaust configuration for evaluation of catalysts.

\subsubsection{Split flow validation exhaust set-up.}

The split exhaust system used for catalyst evaluation and described in Section 3.7.2 was used for the validation with some modifications. To increase accuracy, Diamond II+ 
Annubars, described in Section 2.5, replaced the flow metering orifices for exhaust flow measurement in each exhaust branch. An annubar place in a 5 inch diameter pipe was used to measure the flow in the catalyst branch while an annubar placed in a 4 inch diameter pipe was used to measure flow in the bypass branch. Due to size limitations in the engine test cell, the catalyst annubar was placed after the throttling value and the bypass annubar had to be placed before it's respective throttling value. Extra care was taken to prevent leaks when connecting the split exhaust system so annubar data from both instruments in the two different positions was reliable.

\subsection{Flow balancing procedures.}

Exhaust flows through each leg of the exhaust system were balanced before either an aging cycle or evaluation cycle was initiated. Throttling values were used as the hardware to change the flow in both aging and evaluation exhaust systems. Motorola model MPX5010DP pressure transducers were used to measure the differential pressure across the orifices.

\subsubsection{Procedure for balancing aging split exhaust configuration.}

Metering orifices are utilized to measure the exhaust flow in each branch of the split exhaust. These orifices where calibrated against a Meriam Instrument laminar flow element (LFE). A calibration curve for each orifice was created to relate flow through the orifice to differential pressure across the orifice. The flow in each branch was balanced with the engine operating at rated speed and full load while measuring the differential pressure across the orifice. Flow was inferred from the orifice calibration curve produced from the LFE comparison. The butterfly values were position so that the differential across each orifice

corresponded to approximately the same flow in each leg while maintaining the specified 
engine backpressure (32in. $\mathrm{H}_{2} \mathrm{O}$ for the Navistar and 41 in. $\mathrm{H}_{2} \mathrm{O}$ for the Cummins) at the rated power conditions. Two calibration curves for the Navistar aging split exhaust system are shown in Figure 3.9. Similar calibration curves were produced for the Cummins aging orifices.
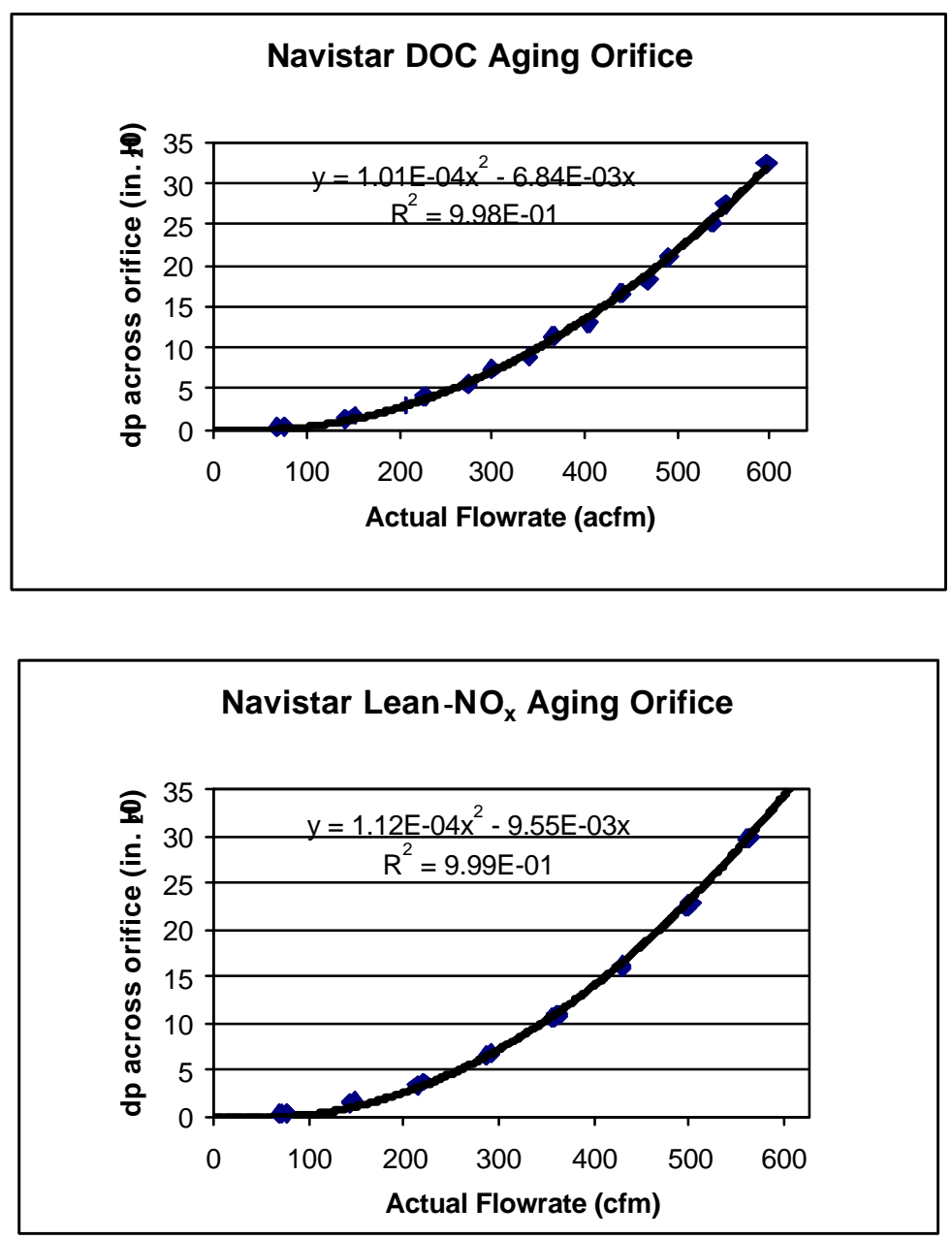

Figure 3.9: Calibrations of orifices for the Navistar aging set-up.

\subsubsection{Procedure for balancing evaluation split exhaust configuration.}

Having the same exhaust flow in each leg was essential considering the active catalyst was designed for half the engine exhaust flow and catalyst performance was being evaluated. Instead of orifices as a means of balancing the flow, $\mathrm{CO}_{2}$ concentration was used 
to balance the split exhaust system. The first step in balancing the exhaust system was to determine the amount of $\mathrm{CO}_{2}$ generated by the diesel engine. This was the full flow part of the engine testing in the testing series. All full flow tests where conducted at the same engine back pressure of roughly 32 inches of water for the Navistar and 41 inches of water for the Cummins at rated speed (1800rpm for the Cummins, 2300rpm for the Navistar), and full load. Engine backpressure was controlled with a throttling valve in the full exhaust and measured with Smar LD301 pressure transmitter. The primary purpose of the full flow testing was to obtain the $\mathrm{CO}_{2}$ concentration produced by the engine so that half of that value was flowing through the catalyst during evaluation.

The engine's exhaust was then connected to the split exhaust system with the dilution tunnel operating at the same nominal flow rate as the full flow case. The engine was then brought up to a selected operating condition (1888 rpm, $998 \mathrm{ft}-\mathrm{lb}$ for Cummins and 2200 rpm, $406 \mathrm{ft}-\mathrm{lb}$ for Navistar) of the steady-state cycle that the engine performed in the full flow exhaust configuration. The throttling valves in each exhaust branch were positioned so the exhaust backpressure was specified by the manufacturer while the $\mathrm{CO}_{2}$ concentration was approximately half that of the full flow case. Refer to Figure 3.8 for a schematic of the split exhaust set-up.

The split ratio, Equation 3.6, was defined as the $\mathrm{CO}_{2}$ concentration for the split exhaust case divided by the $\mathrm{CO}_{2}$ concentration for the full flow case. For example, an emission test with an average split ratio of .50 would be a perfect split, the split exhaust flow was exactly half of the full exhaust flow based upon $\mathrm{CO}_{2}$. This split ratio was used to correct all split exhaust gaseous emissions to reflect full flow levels. During the duration of the DECSE program, the split ratio was kept as close to .50 as possible. For transient testing, an 
average split ratio was calculated over the entire cycle and applied to the integrated split flow results. During steady-state testing, a modal split ratio was determined for each set point and applied to each mode. These modal results were then combined to generate a weighted result for the entire test. Annubar split ratios were calculated in a similar manner. The calculated split ratio for the Annubar exhaust flow measurements, Equation 3.7, was flow measured in catalyst branch divided by the total flow in both branches. Refer to Figure 3.10 for a set of typical split ratios for the Cummins testing.

$$
\begin{gathered}
C \mathrm{O}_{2} \mathrm{SR}=\frac{C \mathrm{O}_{2(\text { SplitExhaist })}}{C O_{2(\text { FullFlow })}} \\
\text { AnnubarFR }=\frac{\text { Flow }_{(\text {CatalystBranch })}}{\text { Flow } w_{(\text {Catalyst+BypassBraich })}}
\end{gathered}
$$

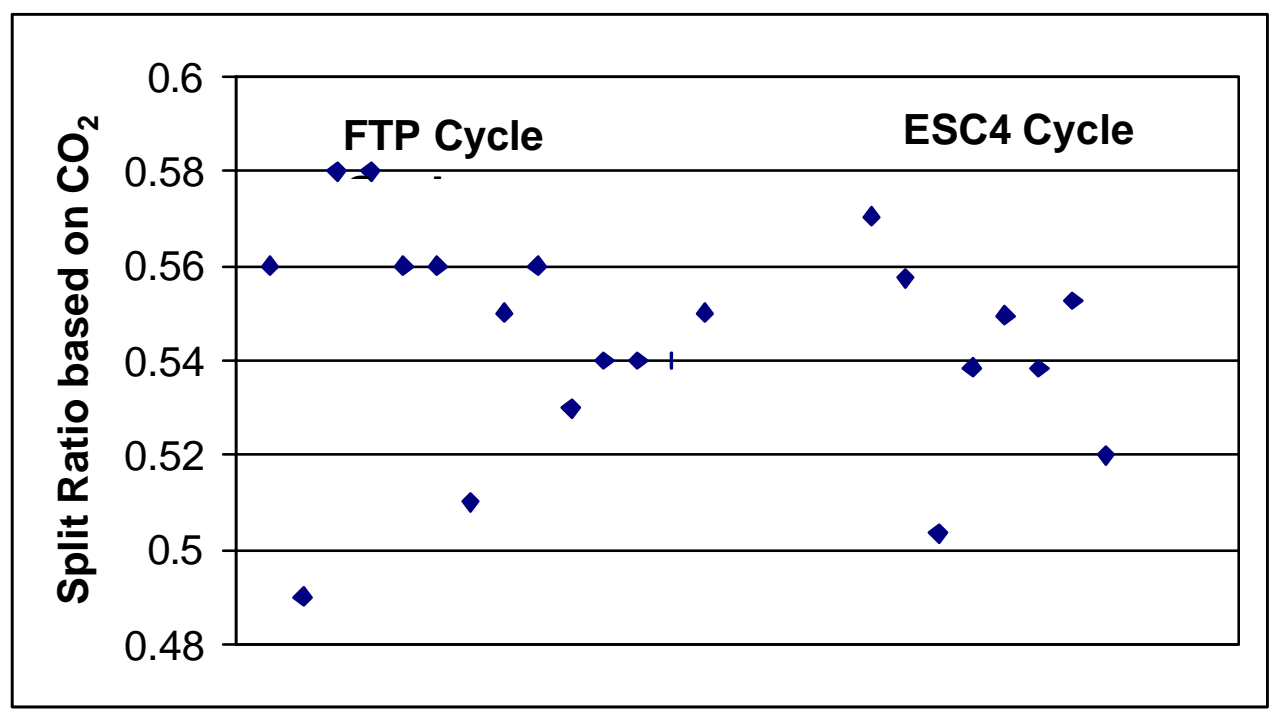

Figure 3.10: Typical split ratios for Cummins ISM370. 


\subsubsection{Procedure for balancing split exhaust validation set-up.}

Balancing the split exhaust system was completed in the same manner as described in Section 3.8.2 for catalyst evaluation. Additional balancing was required because the split exhaust validation not only examines flow rates that correspond to a .50 split ratio, but also examines exhaust flow rates that correspond to split ratios of approximately .30 and .60 respectively. It should be noted that a .30 split ratio has a lower flow rate in the catalyst branch of the split exhaust system than the bypass branch and vice versa for the .60 split ratio. When conducting the .30 and .60 split ratios test runs, the same procedure described in Section 3.8.2 were followed except only $30 \%$ or $60 \%$ of the full flow $\mathrm{CO}_{2}$ concentration was set with the throttling valve positions while maintaining the specified backpressure. 


\section{Results and Discussion}

The experimental results for the split exhaust validation are presented at the beginning of this chapter. Sections of this chapter are divided into tests performed with the different exhaust configurations described in Chapter 3 namely full flow tests and split flow tests with split ratios of 50/50,60/40, and 30/70. Catalyst performance data from the DECSE program will be discussed at the end of this chapter. Only data taken from a Cummins ISM370 ESP are presented.

$$
\% \text { difference }=\frac{\text { measured }- \text { reference }}{\text { reference }} * 100
$$

Equation 4.1 was applied when discussing error, percent difference, between two quantities. Measured full flow values were used as the reference in the calculation of errors between the split exhaust and full exhaust systems.

\subsection{Full flow results}

The first part of all split flow testing was to perform an engine baseline with the entire engine's exhaust directed to the dilution tunnel as prescribed by the CFR 40 . The engine exercised the FTP and SSC cycles described in Section 3.6. Data was taken and reduced as described in Chapter 3. Results of these full flow tests are presented in Table 4.1 for the transient cycles and Table 4.2 for the steady-state cycles. All values presented in both tables are either measured as full flow or corrected to full flow as described in Section 3.5.5 except

for the column labeled $\mathrm{CO}_{2}$ (split flow) which contains uncorrected $\mathrm{CO}_{2}$ concentration recorded during each split flow test run. This uncorrected quantity was compared to the full flow $\mathrm{CO}_{2}$ concentration and created the split ratio described in Section 3.8.2 for that particular test. This ratio was used to correct all other gaseous emissions to full flow levels. 
Table 4.1 and Table 4.2 also contain split flow exhaust data that will be discussed in each respective section. For example, the 50/50 result are presented with the full flow test results but will be explained in the 50/50 results section. Please note that the FTP full flow emissions levels of this 1999 model year engine are below the standards presented in Table 4.1.

Table 4.1: Split exhaust validation transient results.

\begin{tabular}{|c|c|c|c|c|c|c|c|}
\hline FTP Cycle & & & & & & & \\
\hline${ }^{* *}$ units are g/bhp-hr & Test & $\mathbf{H C}$ & $\mathbf{C O}$ & $\mathbf{C O}_{\mathbf{2}}$ (Full Flow) & $\mathbf{C O}_{\mathbf{2}}$ (Split Flow) & NOx & PM \\
\hline Full Flow & Ftp5 & 0.172 & 0.765 & 538.84 & NA & 3.998 & 0.05876 \\
\hline & Ftp6 & 0.181 & 0.757 & 541.76 & NA & 3.95 & 0.05584 \\
\hline & Ftp7 & 0.168 & 0.758 & 542.95 & NA & 3.924 & 0.05715 \\
\hline Average & & 0.174 & 0.760 & 541.18 & & 3.957 & 0.05725 \\
\hline Split Flow & & & & & & & \\
\hline $50 / 50$ & Ftp10 & 0.182 & 0.859 & $(546.91)$ & 278.92 & 3.933 & 0.05725 \\
\hline & Ftp11 & 0.153 & 0.83 & $(546.91)$ & 273.46 & 4.056 & 0.0644 \\
\hline Average & & 0.182 & 0.831 & $(542.9)$ & 271.45 & 4.192 & 0.06074 \\
\hline Percent Difference & & 0.172 & 0.840 & 545.57 & & 4.060 & 0.06080 \\
\hline
\end{tabular}

Table 4.2: Split exhaust validation steady-state results.

\begin{tabular}{|c|c|c|c|c|c|c|}
\hline Steady State Cycle & & & & & & \\
\hline${ }^{* *}$ units are g/bhp-hr & & $\mathrm{HC}$ & $\mathrm{CO}$ & $\mathrm{CO}_{2 \text { (Full Flow) }}$ & $\mathrm{CO}_{2 \text { (Split Flow) }}$ & NOx \\
\hline \multirow[t]{3}{*}{ Full Flow } & $\mathrm{SSC} 3$ & 0.103 & 0.207 & 476.24 & NA & 5.66 \\
\hline & SSC4 & 0.105 & 0.208 & 476.94 & NA & 5.621 \\
\hline & SSC5 & 0.103 & 0.206 & 477.38 & NA & 5.616 \\
\hline Average & & 0.104 & 0.207 & 476.85 & & 5.632 \\
\hline Split Flow & SSC13 & 0.102 & 0.231 & $(476.3)$ & 244.10 & 5.96 \\
\hline \multirow[t]{2}{*}{$50 / 50$} & SSC14 & 0.108 & 0.236 & $(476.31)$ & 245.53 & 5.917 \\
\hline & SSC15 & 0.108 & 0.235 & (476.32) & 248.40 & 5.899 \\
\hline Average & & 0.106 & 0.234 & 476.32 & & 5.925 \\
\hline Percent Difference & & 2.3 & 13.0 & 0.1 & & 5.2 \\
\hline Split Flow & SSC18 & 0.101 & 0231 & $(47631)$ & 28531 & 6535 \\
\hline \multirow[t]{2}{*}{$60 / 40$} & SSC19 & 0.101 & 0.231 & $(476.3)$ & 292.33 & 6.186 \\
\hline & SSC20 & 0.104 & 0.243 & $(476.3)$ & 291.14 & 6.238 \\
\hline Average & & 0.102 & 0.235 & 476.30 & & 6.320 \\
\hline Percent Difference & & 1.6 & 13.5 & 0.1 & & 12.2 \\
\hline & & & & & & \\
\hline Split Flow & SSC21 & 0.071 & 0.234 & $(476.31)$ & 143.96 & 5.965 \\
\hline \multirow[t]{2}{*}{$30 / 70$} & SSC22 & 0.082 & 0.24 & $(476.3)$ & 142.18 & 6.039 \\
\hline & SSC23 & 0.077 & 0.234 & $(476.3)$ & 141.70 & 6.072 \\
\hline Average & & 0.077 & 0.236 & 476.30 & & 6.025 \\
\hline Percent Difference & & 26.0 & 14.0 & 0.1 & & 7.0 \\
\hline
\end{tabular}




\section{$4.250 / 50$ split flow results}

The split exhaust system was connected to the Cummins engine. Balancing procedures were performed as described in Section 3.7.2. $\mathrm{CO}_{2}$ concentration was approximately half that of the full flow case upon the completion of the flow balancing process.

\subsubsection{FTP results}

The engine exercised three successive FTP cycles. Data was corrected as described in Section 3.5.5 yielding results presented in Table 4.1. Average values of emissions for the three test runs were determined and compared to the average of the three full flow test runs. Results from this comparison showed that corrected $\mathrm{HC}$ was within $1 \%$ of its corresponding full flow value, $\mathrm{CO}$ was within $11 \%$ of its respective full flow total, $\mathrm{NO}_{\mathrm{x}}$ was within $3 \%$ of the full flow level, and PM collected through the entire test was within $7 \%$ of the full flow PM quantity. Figures 4.1 through 4.4 provide $\mathrm{CO}_{2}, \mathrm{NO}_{\mathrm{x}}, \mathrm{CO}$, and $\mathrm{HC}$ with units of grams per second for a full flow FTP and a 50/50 split flow FTP. Please observe that the split flow curve for all four graphs is approximately half the respective full flow curve. An integrated $\mathrm{CO}_{2}$ split ratio was determined to be 0.51 which was used for split flow data correction. Figure 4.4 initially provides negative $\mathrm{HC}$ values. This was attributed to minimal $\mathrm{HC}$ produced by modern diesel engines, especially at idle which was where the negative values were measured. 


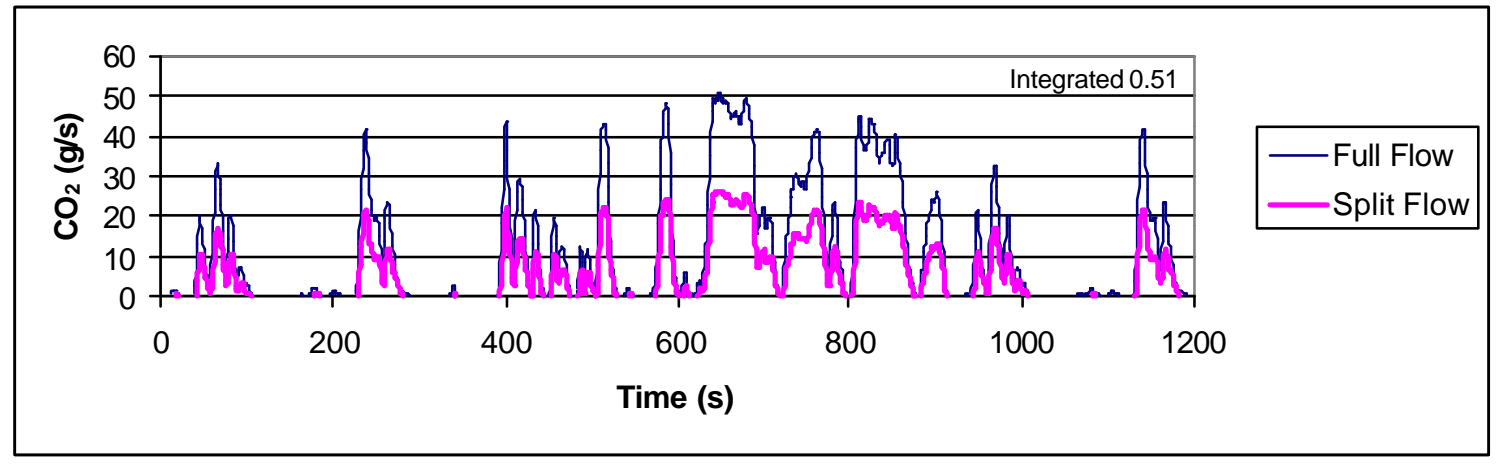

Figure 4.1: Continuous $\mathrm{FTP} \mathrm{CO}_{2}$ for full flow and 50/50 split flow exhaust configurations.

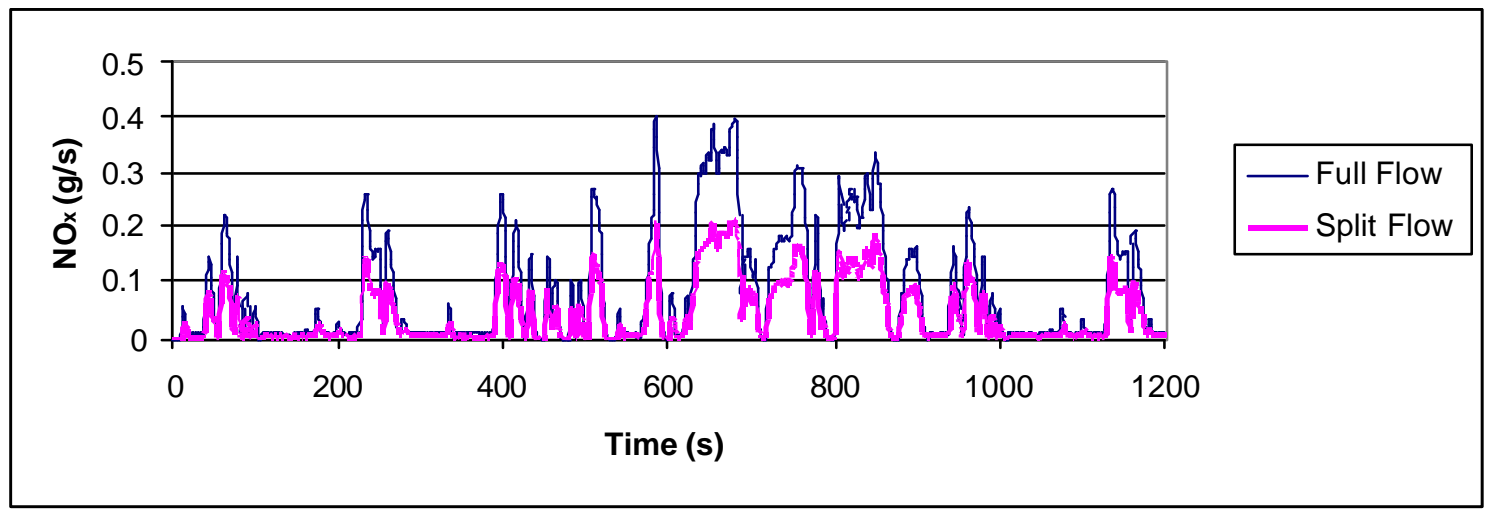

Figure 4.2: Continuous FTP $\mathrm{NO}_{x}$ for full flow and 50/50 split flow exhaust configurations.

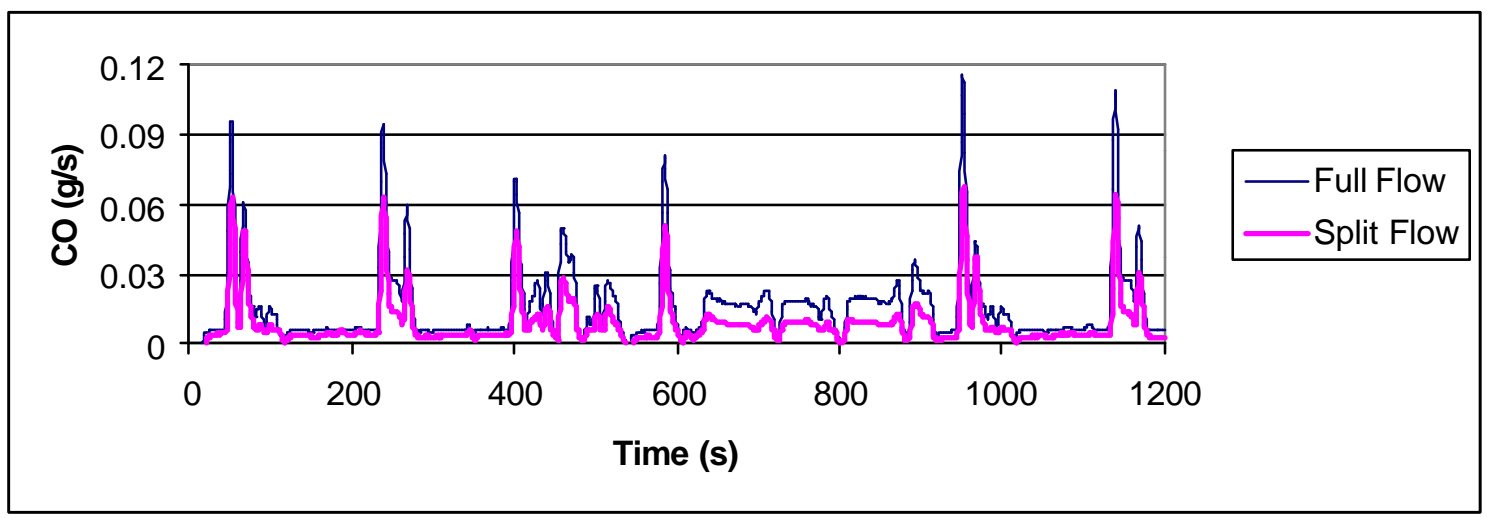

Figure 4.3: Continuous FTP CO for full flow and 50/50 split flow exhaust configurations. 


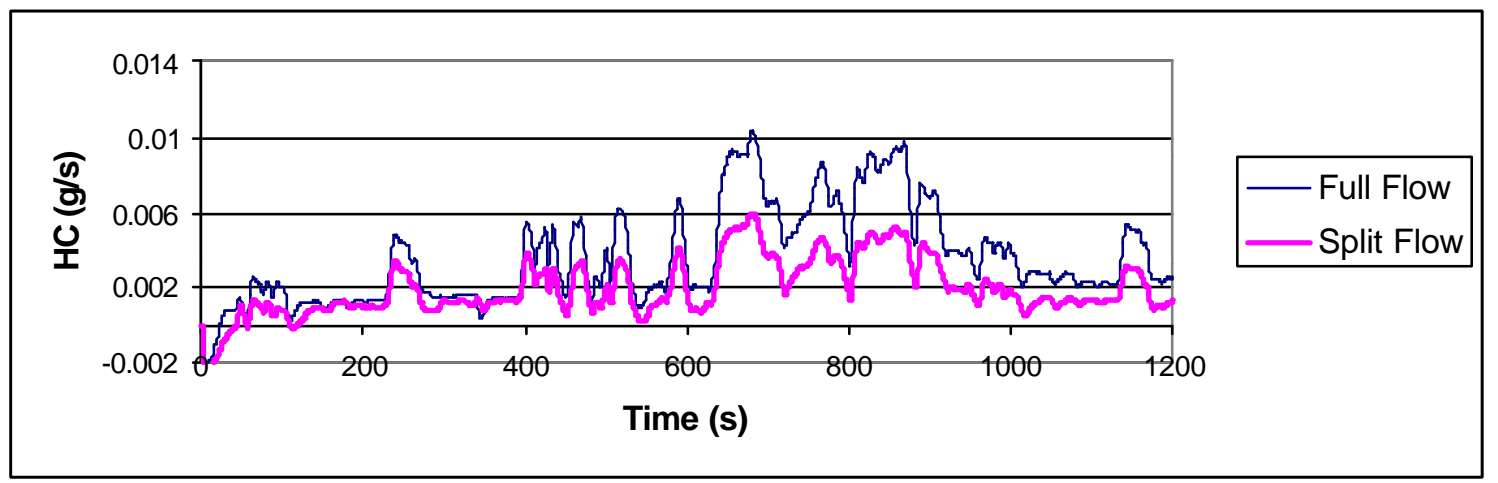

Figure 4.4: Continuous FTP HC for full flow and 50/50 split flow exhaust configurations.

Data obtained from one full flow and one 50/50 split flow FTP test were reduced and emissions are presented on an accumulation basis. The split flow test run data were corrected with the $\mathrm{CO}_{2}$ split ratio described in Section 3.8.2. This corrected result was compared to the full flow result and illustrated in Figure 4.5 for HC. The calculated split ratio applied was 0.51 which caused the corrected data to be approximately $8 \%$ larger than the amassed full flow data. A similar correlation was created for $\mathrm{CO}$ and is illustrated in Figure 4.6. The corrected $\mathrm{CO}$ demonstrated a $6 \%$ difference between the accumulated split flow and full flow data. Figure 4.7 shows a $6 \%$ difference in $\mathrm{NO}_{\mathrm{x}}$ between the accumulated split flow and full flow data.

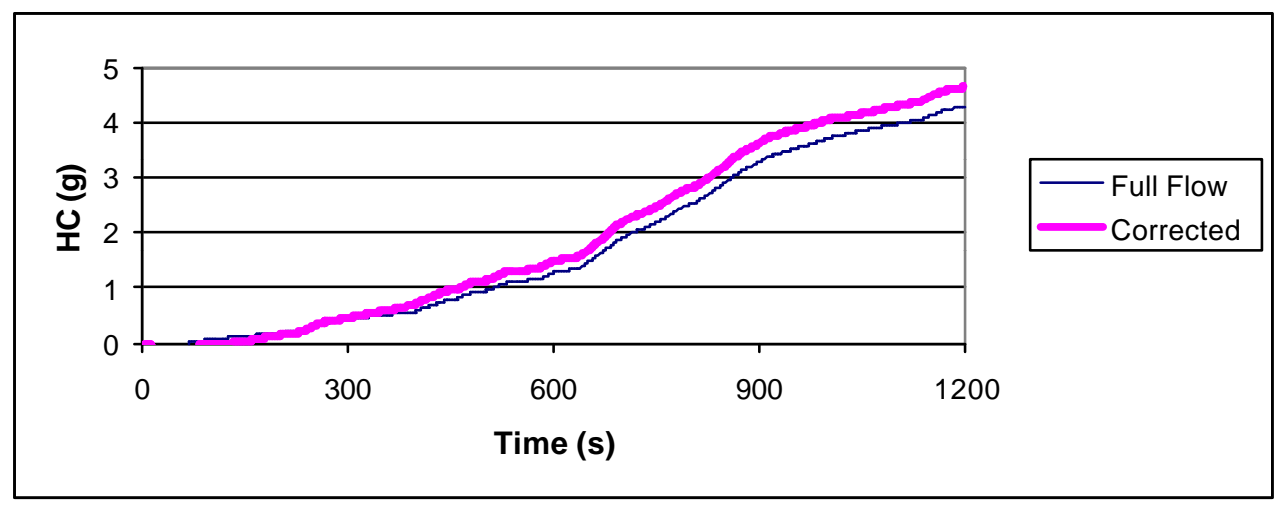

Figure 4.5: Accumulated $\mathrm{HC}$ during the FTP full flow and $\mathrm{CO}_{2}$ corrected 50/50 split flow. 


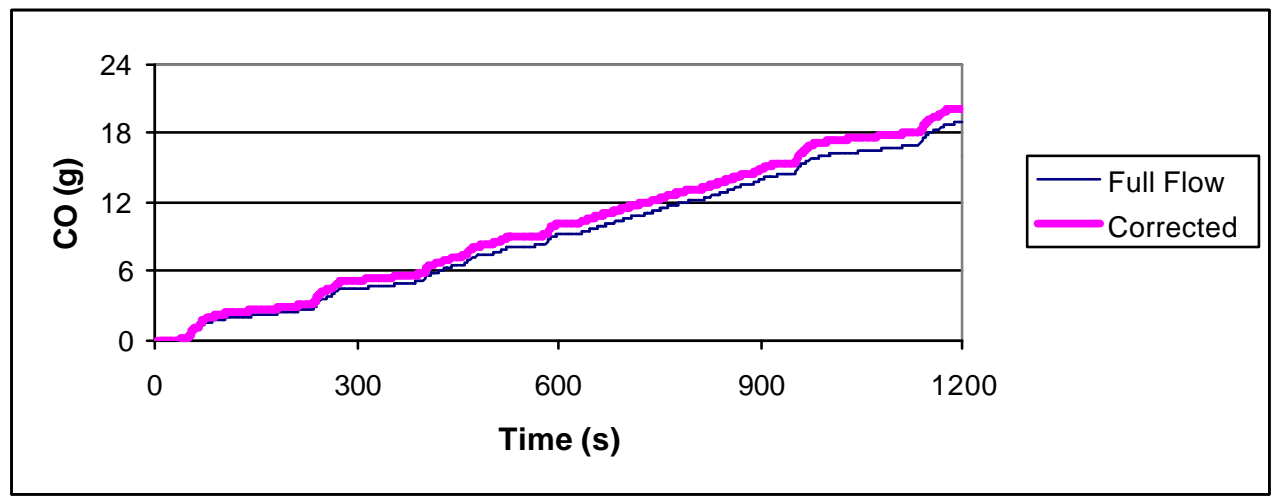

Figure 4.6: Accumulated $\mathrm{CO}$ during the FTP for full flow and $\mathrm{CO}_{2}$ corrected 50/50 split flow.

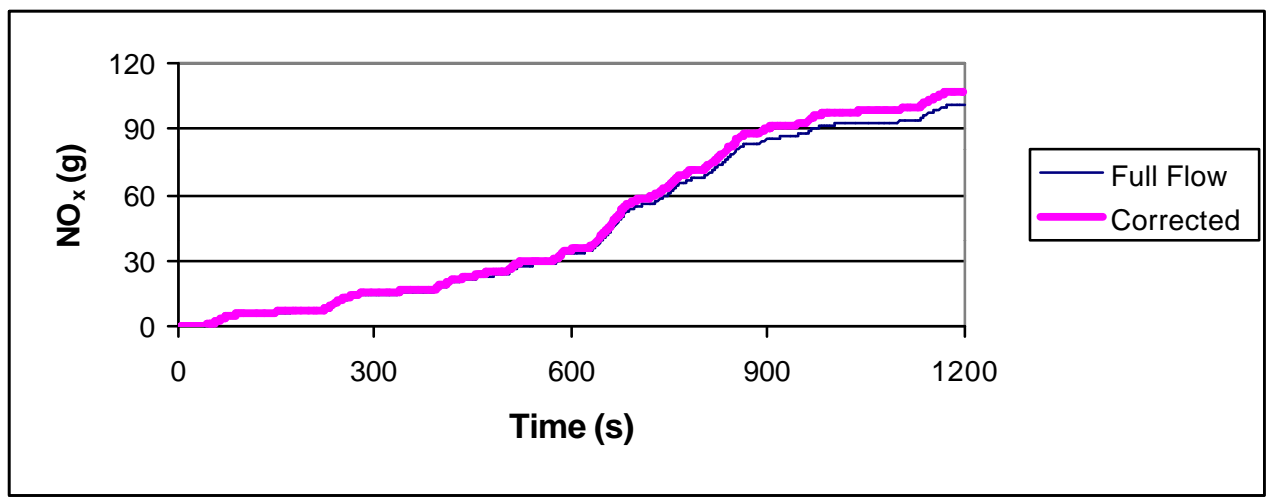

Figure 4.7: Accumulated $\mathrm{NO}_{x}$ during the FTP for full flow and $\mathrm{CO}_{2}$ corrected 50/50 split flow.

\subsubsection{Steady-state results}

The engine performed three successive SSC cycles. Data were collected only at the end of each mode as mentioned in Section 3.6 and corrected as described in Section 3.5.5. These corrected results are presented in Table 4.1. Average values of emissions for the three test runs were determined and compared to the average of the three full flow test runs. Results from this comparison showed that corrected $\mathrm{HC}$ was within $3 \%$ of its corresponding full flow value, $\mathrm{CO}$ was within $13 \%$ of its respective full flow total, and $\mathrm{NO}_{\mathrm{x}}$ was within $6 \%$ 
of the full flow level. These errors are similar to the errors observed during transient engine operation. PM was not collected during the steady-state test runs.

Figure 4.8 provides a comparison between full flow $\mathrm{CO}_{2}$ and 50/50 split flow $\mathrm{CO}_{2}$. Modal split ratios which range from 0.51 to 0.53 were calculated as discussed in Section 3.8.2. It is clear from Figure 4.8 that the split flow works successfully at high exhaust flow rates. This is because the split flow was adjusted to the desired ratio under similar conditions. However, at low flow rates, in particular at idle, deviation from the desired ratio is substantial. When determining an integrated split ratio for the entire test run, the idle conditions were omitted from the calculation.

The annubar flow measurement data show that the catalyst leg allowed $50 \%$ to $54 \%$ of the flow at high exhaust flow rates for the nominal 50/50 split as seen in Figure 4.9. However, at idle, the annubar data show $63 \%$ to $64 \%$ exhaust flow leaving via the catalyst leg. The $\mathrm{CO}_{2}$ data agree for the higher flow rates, but clearly show that almost all the flow is through the bypass leg during idle, in clear contradiction of the annubar data. Deviations from the desired split at low flow ratess may arise due to the small differential pressures available to control the flow split. However, the measurement techniques used are also challenged at low flow ratess. Differential pressures across the Annubar will decrease by about two orders of magnitude between full and idle flow conditions, so the differential pressure transducer errors become significant. In this study, the $\mathrm{CO}_{2}$ errors were certainly greater at idle than the annubar errors because dilution in the full-scale tunnel is high so that background (dilution air) $\mathrm{CO}_{2}$ mass flow can mask engine $\mathrm{CO}_{2}$ mass flow. It is therefore speculated that the annubar values of $63 \%$ to $64 \%$ catalyst flow are far more realistic than the $\mathrm{CO}_{2}$ split data for idle conditions, and that split ratios remain acceptable at idle. Since idle 
operation contributes only a small fraction of $\mathrm{NO}_{\mathrm{x}}$ and $\mathrm{PM}$ emissions, deviations at idle during test procedures will usually be acceptable.

An integrated flow ratio across the cycle of 0.53 was observed with the omission of the data collected at the idle conditions. This ratio, similar to the $\mathrm{CO}_{2}$ split ratio, was determined by Equation 3.7 given in Section 3.8.2. A $1 \%$ difference between $\mathrm{CO}_{2}$ ratio and flow ratio provides a accurate means of correcting partial flow exhaust streams to full flow exhaust levels without measuring the flow rate.

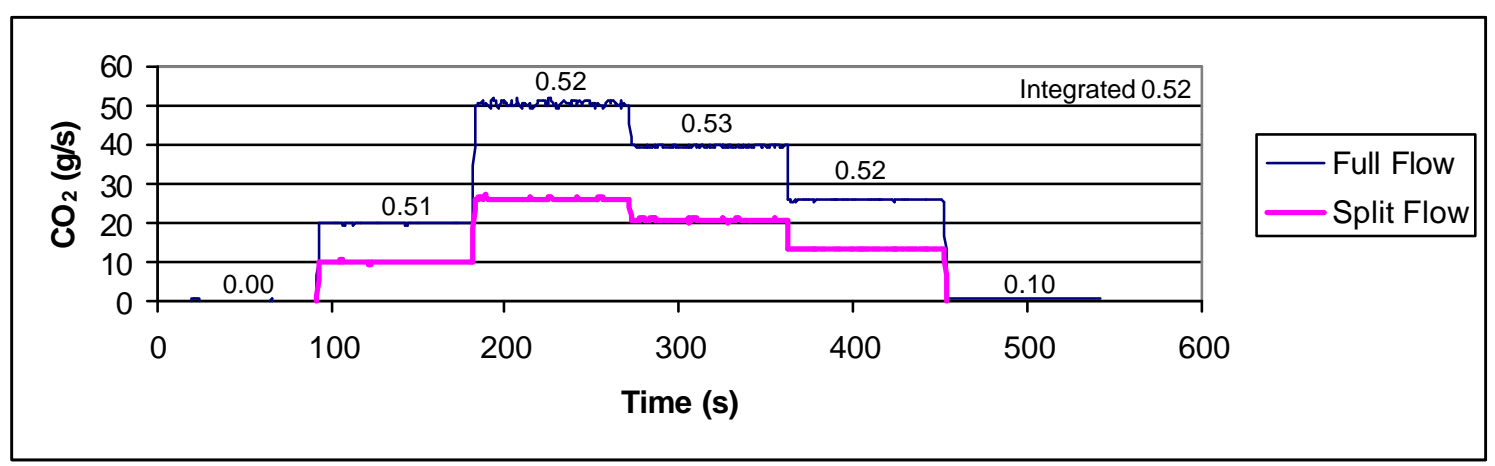

Figure 4.8: Comparison between full flow $\mathrm{CO}_{2}$ and 50/50 split flow $\mathrm{CO}_{2}$.

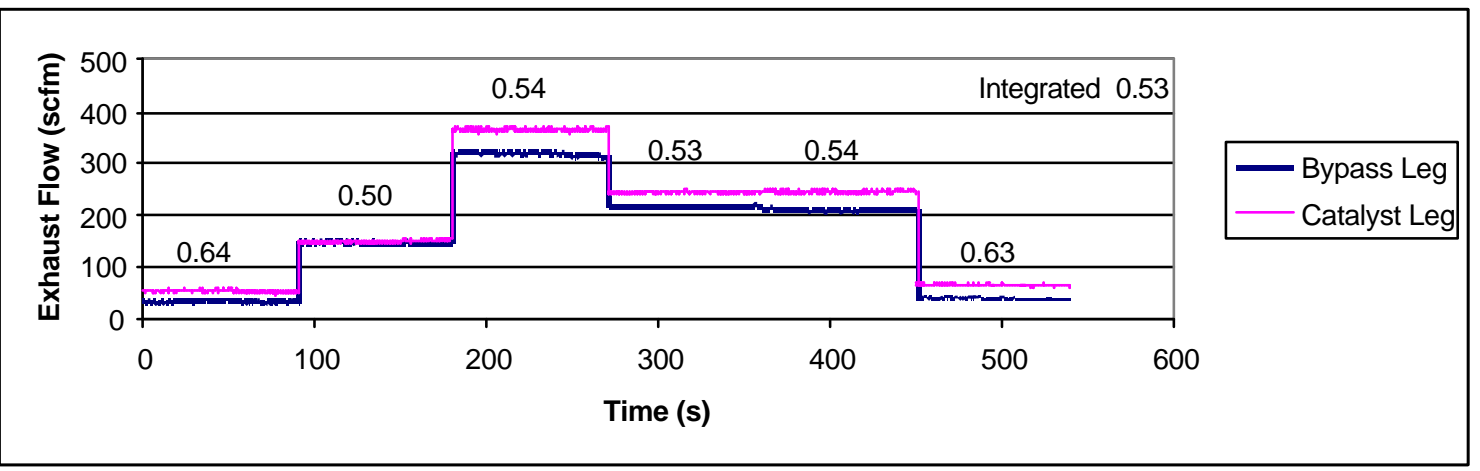

Figure 4.9: Measured exhaust flow during 50/50 SSC cycle. 


\section{$4.360 / 40$ split flow results}

The split exhaust system was connected to the Cummins engine. Balancing procedures were performed as described in Section 3.7.2. $\mathrm{CO}_{2}$ concentration was approximately $60 \%$ of the full flow case upon the completion of the flow balancing process.

The engine performed three successive SSC cycles. Data were collected only at the end of each mode as mentioned in Section 3.6 and corrected as described in Section 3.5.5. These corrected results are presented in Table 4.1. Average values of emissions for the three test runs were determined and compared to the average of the three full flow test runs. Results from this comparison showed that corrected HC was within $2 \%$ of its corresponding full flow value, $\mathrm{CO}$ was within $14 \%$ of its respective full flow total, and $\mathrm{NO}_{\mathrm{x}}$ was within $13 \%$ of the full flow level. PM was not collected during the steady-state test runs.

Figure 4.10 provides a comparison between full flow $\mathrm{CO}_{2}$ and 60/40 split flow $\mathrm{CO}_{2}$. Modal split ratios range from 0.61 to 0.62 (0.61 integrated) were calculated as discussed in Section 3.8.2. The deviations that occurred at the idle condition were discussed in Section 4.2.2. The section will only compare the $\mathrm{CO}_{2}$ split ratios and the calculated Annubar flow ratios, described in Section 3.8.2, for the middle four modes of the cycle. Calculated Annubar flow ratios varied from 0.61 to 0.65 (0.64 integrated) as presented in Figure 4.11. These results are consistent with the 50/50 results in that Annubar ratios are slightly larger than the $\mathrm{CO}_{2}$ ratios. 


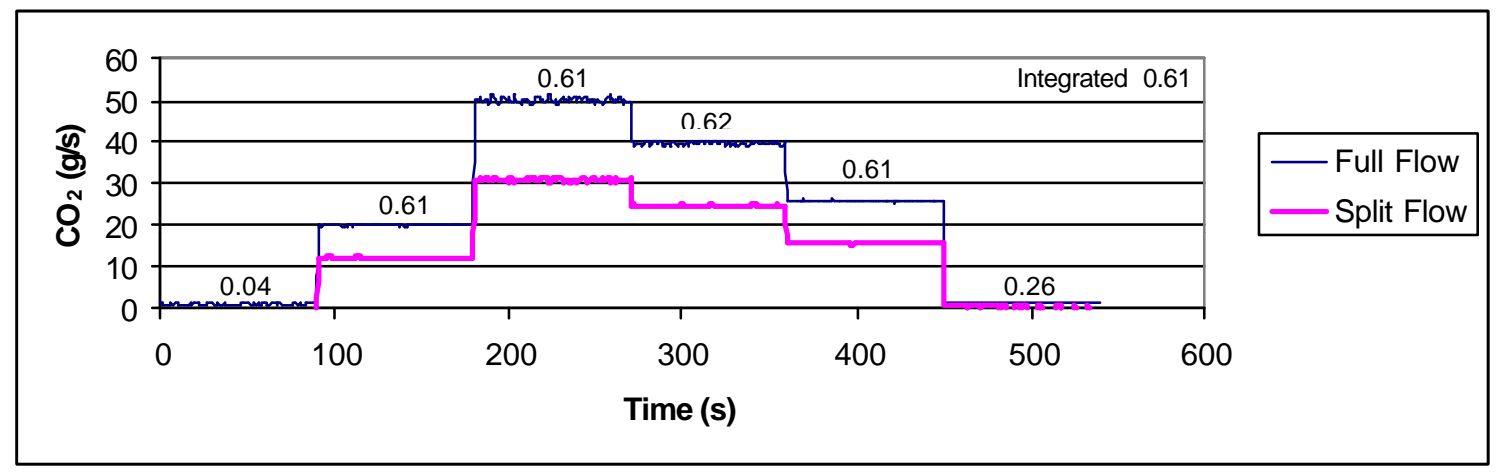

Figure 4.10: Comparison between full flow $\mathrm{CO}_{2}$ and 60/40 split flow $\mathrm{CO}_{2}$.

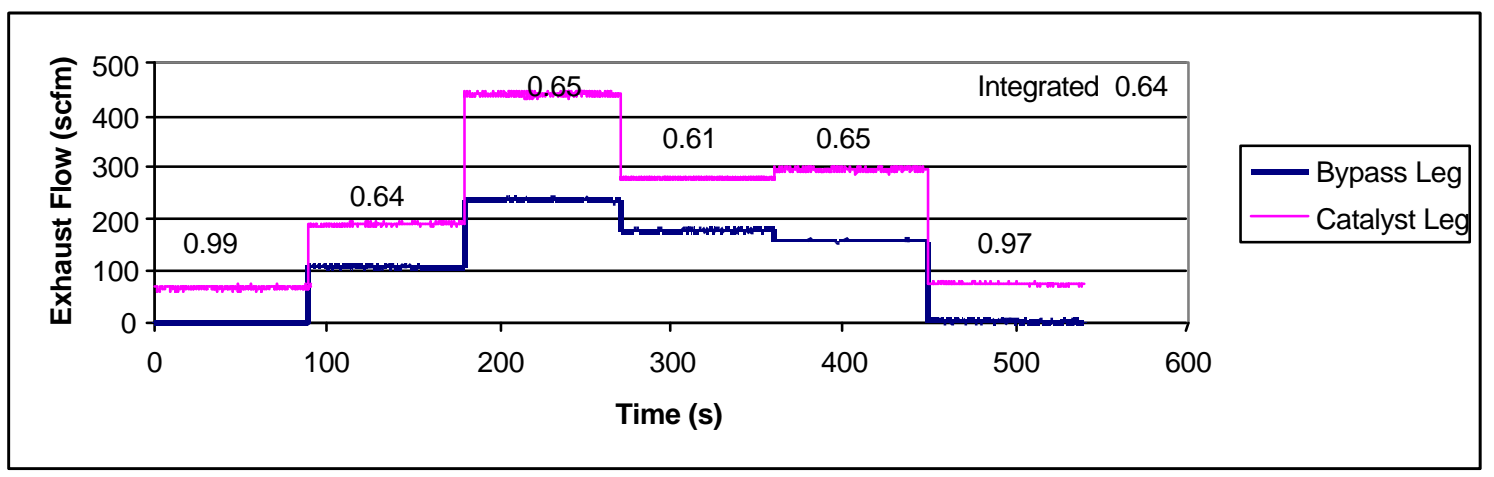

Figure 4.11: Measured exhaust flow during 60/40 SSC cycle.

\section{$4.4 \quad 30 / 70$ split flow results}

The split exhaust system was connected to the Cummins engine. Balancing procedures were performed as described in Section 3.7.2. $\mathrm{CO}_{2}$ concentration was approximately $30 \%$ that of the full flow case upon the completion of the flow balancing process.

The engine performed three successive SSC cycles. Data were collected only at the end of each mode as mentioned in Section 3.6 and corrected as described in Section 3.5.5. These corrected results are presented in Table 4.1. Average values of emissions for the three test runs were determined and compared to the average of the three full flow test runs. Results from this comparison showed that corrected $\mathrm{HC}$ was within $26 \%$ of its corresponding 
full flow value, $\mathrm{CO}$ was within $14 \%$ of its respective full flow total, and $\mathrm{NO}_{\mathrm{x}}$ was within $7 \%$ of the full flow level. PM was not collected during the steady-state test runs.

Figure 4.12 provides a comparison between full flow $\mathrm{CO}_{2}$ and 30/70 split flow $\mathrm{CO}_{2}$. Modal split ratios range from 0.27 to 0.31 (0.29 integrated) were calculated as discussed in Section 3.8.2. The deviations that occurred at the idle condition were discussed in Section 4.2.2. The section will only compare the $\mathrm{CO}_{2}$ split ratios and the calculated Annubar flow ratios, described in Section 3.8.2, for the middle four modes of the cycle. Calculated Annubar flow ratios varied from 0.33 to 0.34 (0.34 integrated) as presented in Figure 4.13. These results are consistent with pervious 50/50 and 60/40 results in that Annubar flow ratios are slightly larger than the $\mathrm{CO}_{2}$ split ratios. Also, the differences between the $\mathrm{CO}_{2}$ split ratios and the Annubar flow ratios increases as the difference in flows between the branches increase. Figure 4.14 provides modal split ratios results for all three of the split flow balanced conditions of the validation study.

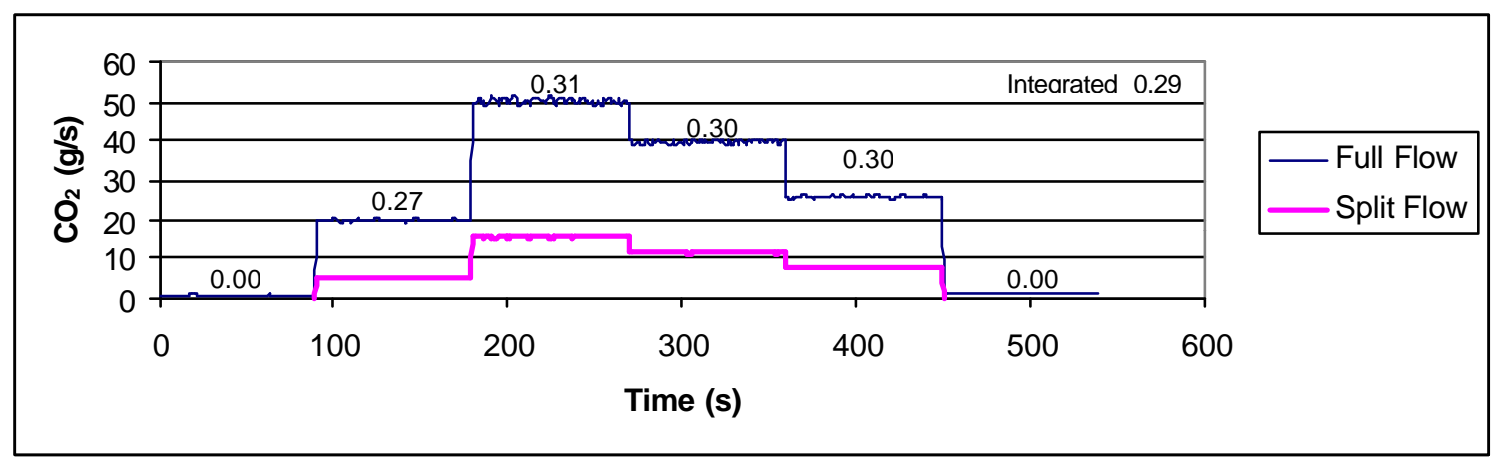

Figure 4.12: Comparison between full flow $\mathrm{CO}_{2}$ and 30/70 split flow $\mathrm{CO}_{2}$. 


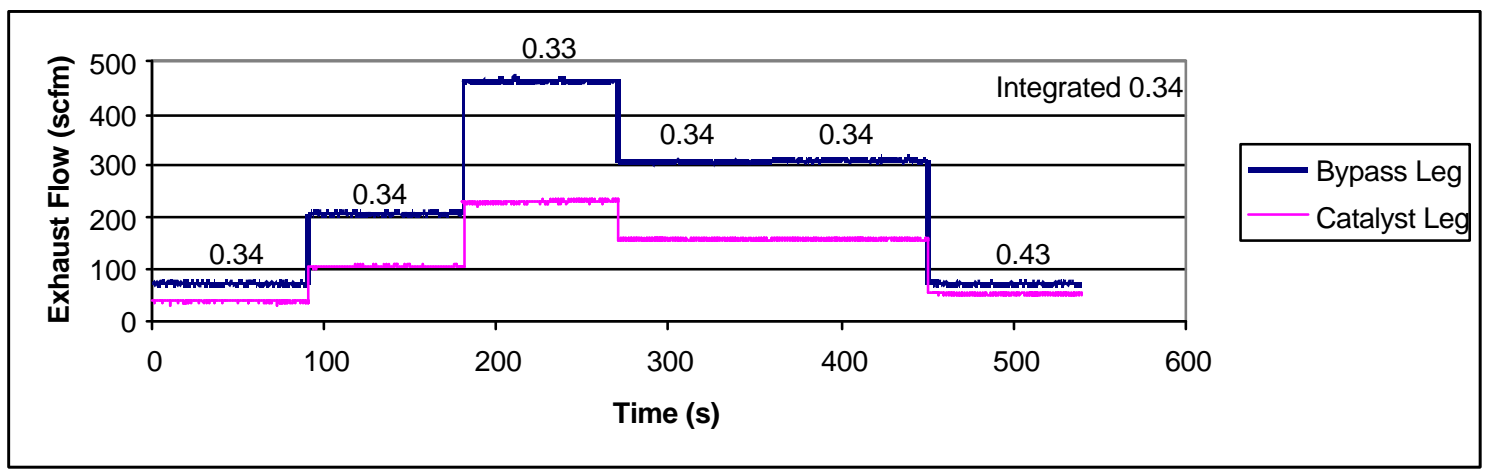

Figure 4.13: Measured exhaust flow during 30/70 SSC cycle.

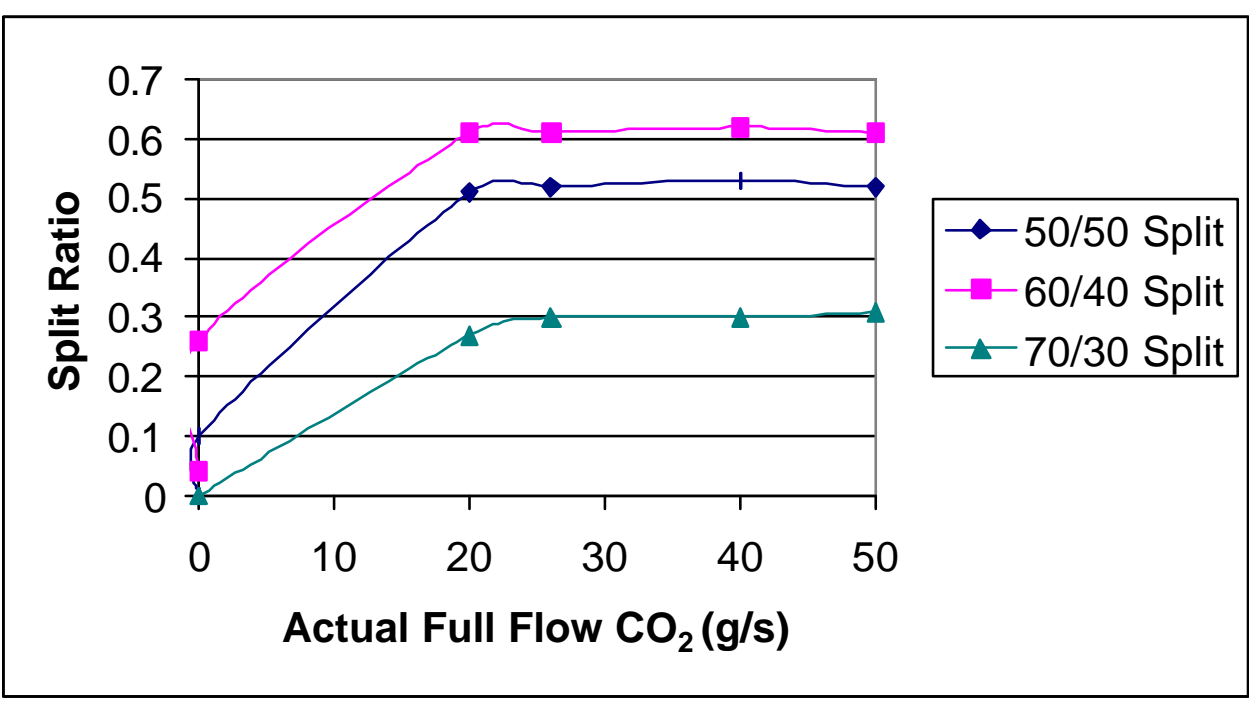

Figure 4.14: Modal split ratios for validation study.

\subsection{Oxidation catalyst results}

This section is divided up into four sub-sections to present results from the hightemperature diesel oxidation catalyst for the four different fuel sulfur levels used in the DECSE program. Both FTP and ESC4 results are presented by the accumulation of the constituents, $\mathrm{HC}, \mathrm{CO}, \mathrm{CO}_{2}$, and $\mathrm{NO}_{\mathrm{x}}$, throughout the cycle according to $\mathrm{CFR} 40$ and European regulations [1,18]. PM is presented on a continuous basis via TEOM and also 
presented as total PM mass collected from 70-mm filters. Gaseous emissions results are provided as engine-out split flow test with no aftertreatment and as catalyst out emissions recorded at various stages of catalyst aging. The oxidation of $\mathrm{HC}$ and $\mathrm{CO}$ during catalyst tests is presented as a percent reduction from the engine-out test. Figure 4.15 provides a temperature measured 6 inches before the oxidation catalyst termed precat and temperature measured 6 inches downstream of the catalyst called the postcat. Temperatures ranged between $\pm 25{ }^{\circ} \mathrm{C}$ of the two temperature traces provided in Figure 4.15 for the DECSE catalyst testing.

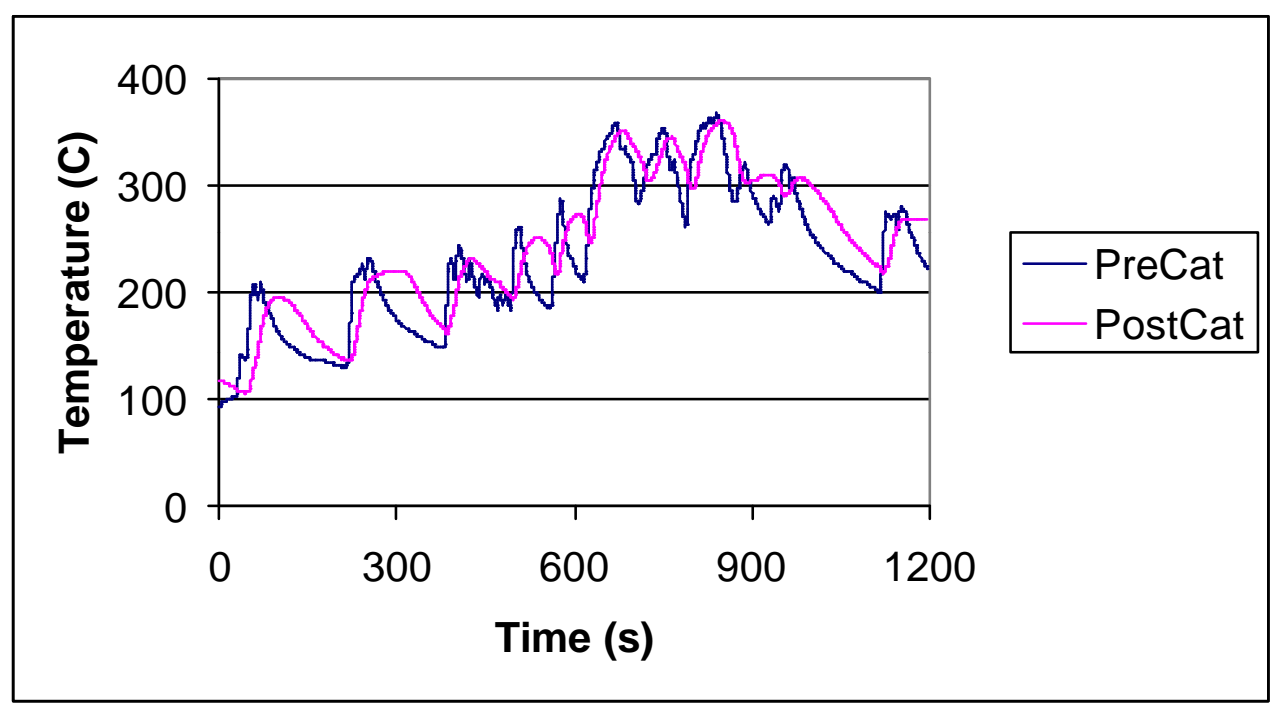

Figure 4.15: Oxidation catalyst temperatures.

\subsubsection{3ppm gaseous results}

Results were obtained from the Cummins ISM370 engine operating on 3ppm sulfur diesel fuel described in Section 3.2. Figure 4.16 shows the accumulated results of HC measured during the FTP cycle. This figure demonstrated that the catalyst oxidizes the majority of $\mathrm{HC}$ and 80 percent $\mathrm{HC}$ reduction is illustrated in Figure 4.17. Approximately 3 grams of $\mathrm{HC}$ amassed throughout the cycle without aftertreatment is small and hard to 
quantify. Thus, measurement difficulties occurred when catalyst evaluation was completed because the measured values were close to zero. The 0 and 150 hour data demonstrate a negative accumulation of $\mathrm{HC}$ across the cycle which is obviously measurement error because burning of a hydrocarbon fuel will generate gaseous $\mathrm{HC}$, not clean the atmosphere. The HC reductions greater than $100 \%$ seen in Figure 4.17 can be attributed to these measurement errors. Catalyst aging provided no significant effect on HC oxidation.

Figure 4.18 presents the amassed $\mathrm{CO}$ throughout the transient cycle. The catalyst appears to reach its "light-off" temperature and start functioning approximately halfway through the cycle. Light-off temperature is defined as the temperature required to initiate the catalytic reaction. At the beginning of the aging period, $\mathrm{CO}$ reduction is $50 \%$ and decreases over aging to roughly $30 \%$ as seen in Figure 4.19. The spike that occurs at the beginning of Figure 4.19 is attributed to a small difference in two small numbers, namely the engine-out accumulated value and the 250 hours accumulated value, that cause a large percentage difference (Refer to Equation 4.1). The catalyst has no effect on $\mathrm{CO}_{2}$ and $\mathrm{NO}_{\mathrm{x}}$ which is verified in Figure 4.20 and Figure 4.21.

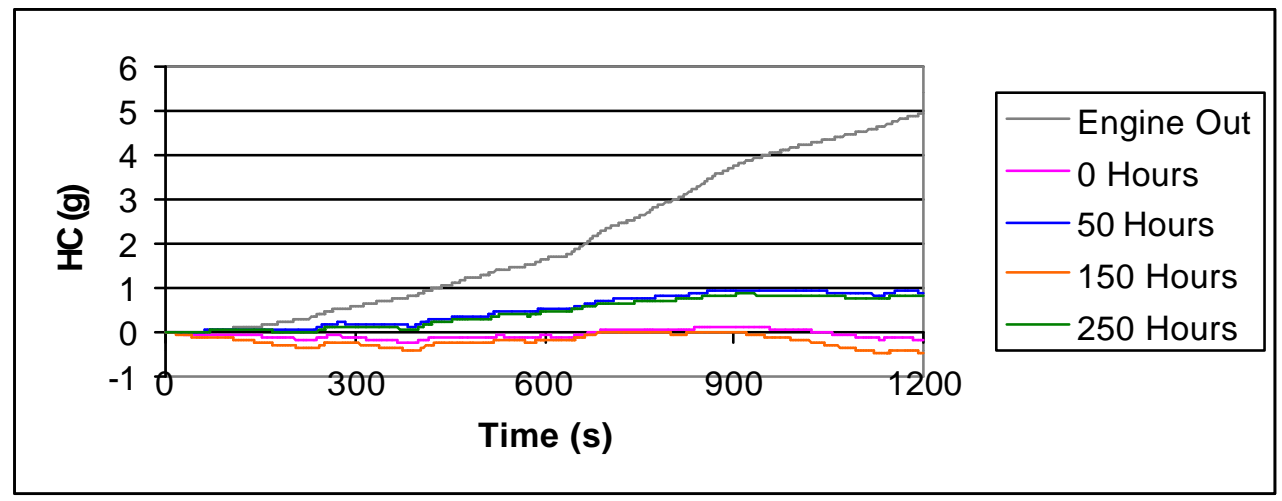

Figure 4.16: FTP accumulated HC for 3ppm oxidation catalyst through the aging period. 


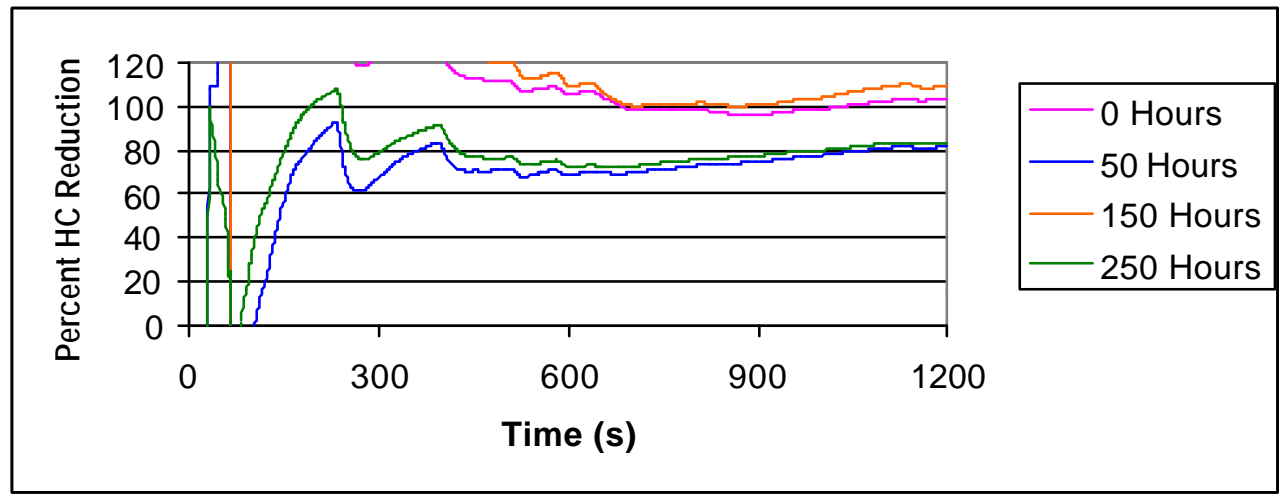

Figure 4.17: Percent reduction of HC for 3ppm oxidation catalyst.

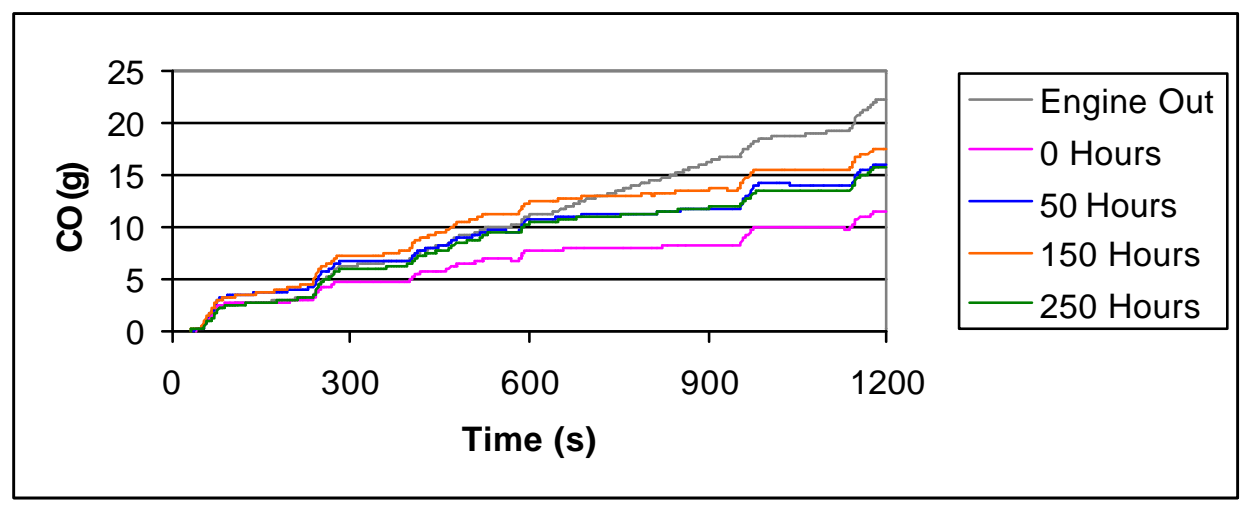

Figure 4.18: FTP accumulated CO for 3ppm oxidation catalyst through the aging period.

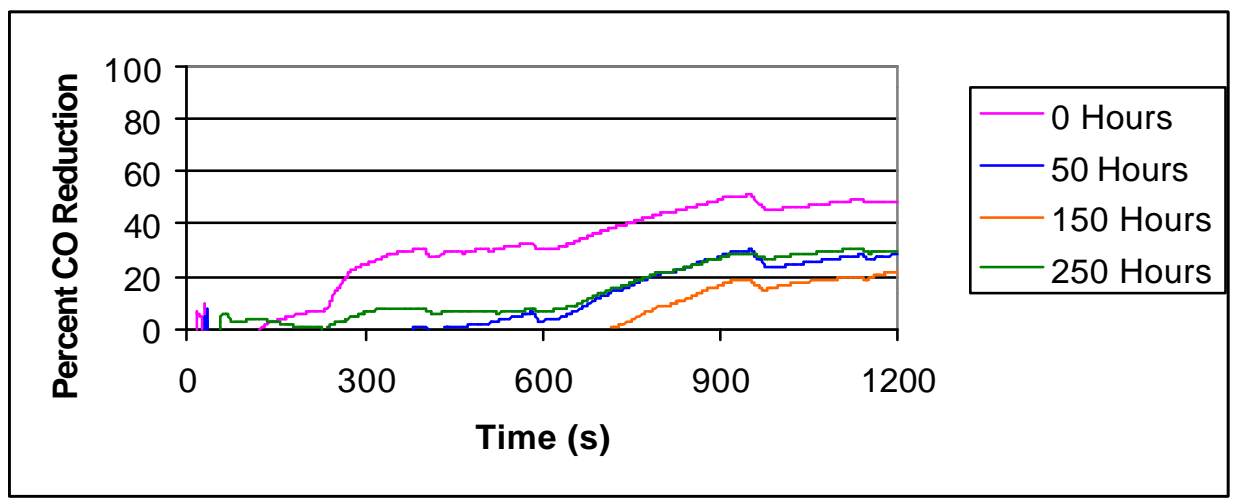

Figure 4.19: Percent reduction of CO for 3ppm oxidation catalyst. 


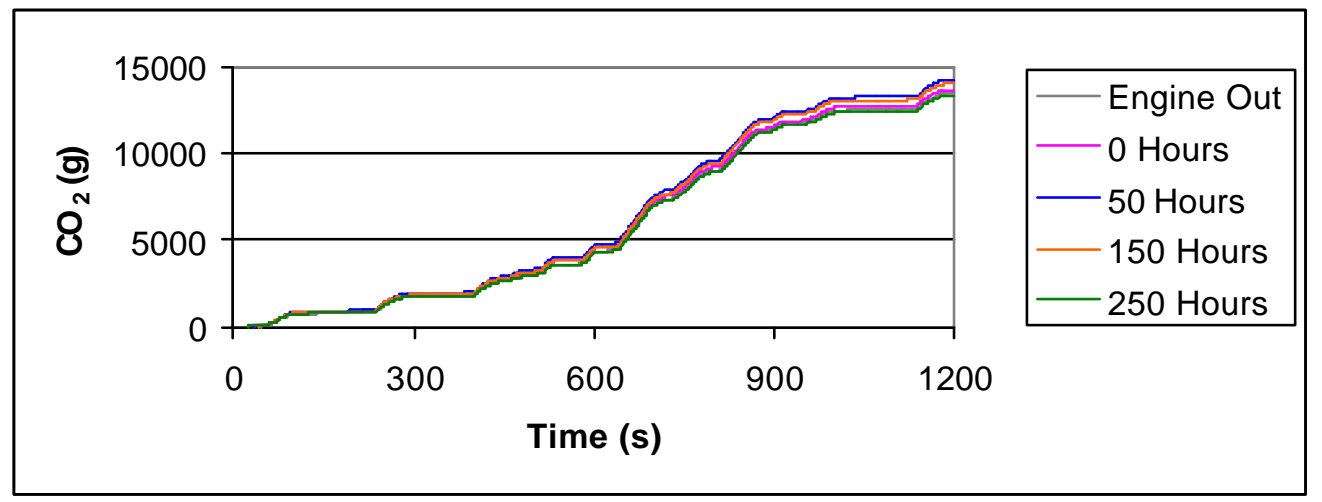

Figure 4.20: FTP accumulated $\mathrm{CO}_{2}$ for 3ppm oxidation catalyst through the aging period.

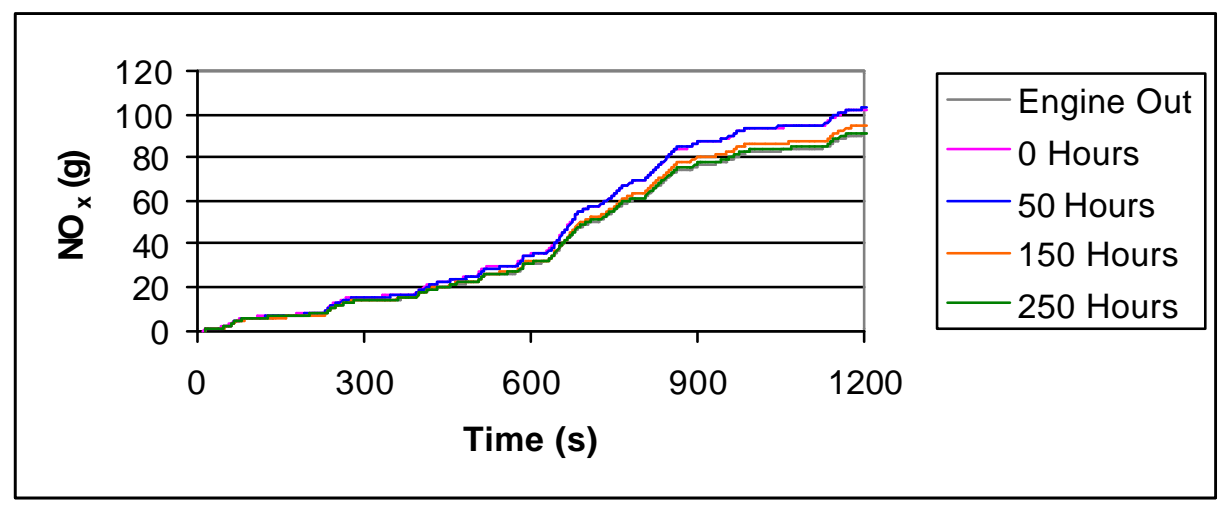

Figure 4.21: FTP accumulated $\mathrm{NO}_{x}$ for 3ppm oxidation catalyst through the aging period.

\subsubsection{0ppm gaseous results}

Results were obtained from the Cummins ISM370 engine operating on 30ppm sulfur diesel fuel as described in Section 3.2. Figure 4.22 shows the accumulated results of HC measured during the FTP cycle. Similar to the results obtained from the 3ppm oxidation catalyst, the 30ppm catalyst oxidizes approximately $75 \%$ of $\mathrm{HC}$ which is illustrated in Figure 4.23. Please observe that both the 3 and $30 \mathrm{ppm}$ oxidation catalysts seem to initially oxidize above $90 \%$ of the HC. After the first aging period, $\mathrm{HC}$ oxidation average reduction is $75 \%$.

Figure 4.24 presents the amassed CO throughout the transient cycle for the four aging points. The same phenomenon that occurred with the $3 \mathrm{ppm}$ oxidation catalyst of the catalyst 
not oxidizing $\mathrm{CO}$ until halfway through the cycle occurs with the $30 \mathrm{ppm}$ catalyst. $\mathrm{CO}$ reduction increases from $20 \%$ initially to $30 \%$ for the remaining amount of aging. The $20 \%$ $\mathrm{CO}$ reduction with no aging must be anomalous due to a significant increase initially in $\mathrm{CO}$ over the engine-out case. The 30\% CO reduction observed for the remaining aging hours corresponds to the results from the 3ppm oxidation catalyst. Figure 4.26 and Figure 4.27 support the same observation for the 30ppm oxidation catalyst that was made with the $3 \mathrm{ppm}$ oxidation catalyst which was the catalyst has no effect on $\mathrm{CO}_{2}$ and $\mathrm{NO}_{\mathrm{x}}$.
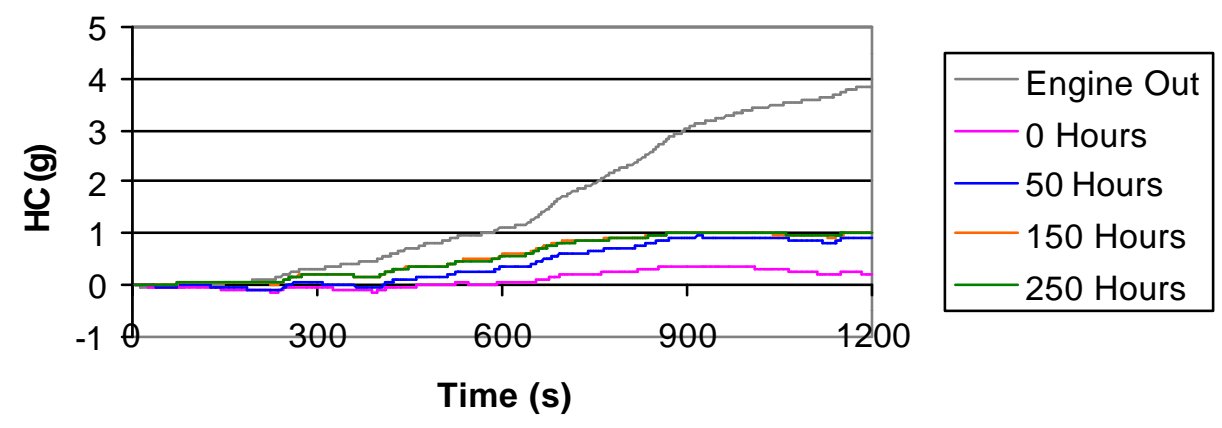

Figure 4.22: FTP accumulated HC for 30ppm oxidation catalyst through the aging period.

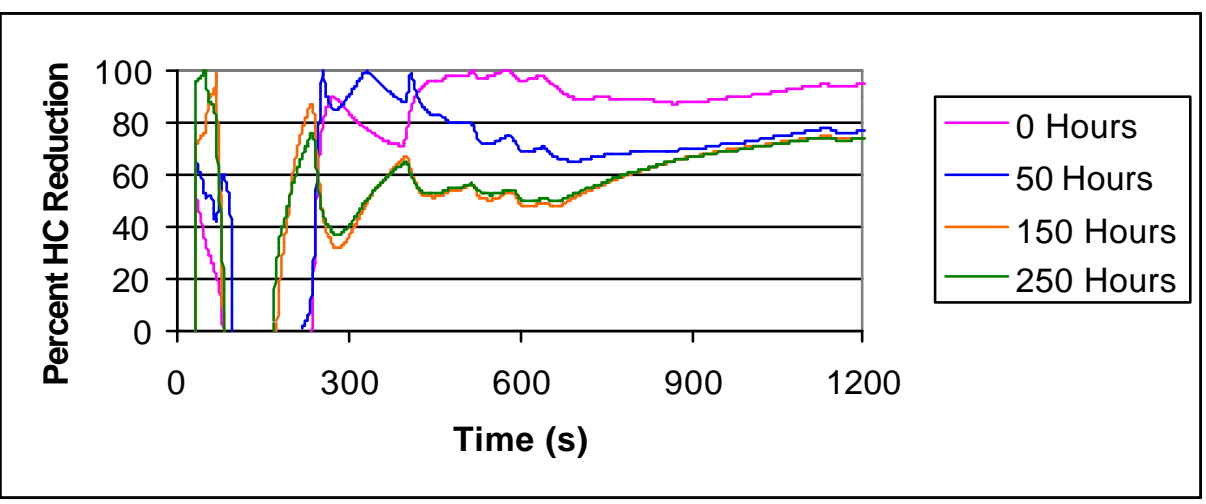

Figure 4.23: Percent reduction of HC for 30ppm oxidation catalyst. 


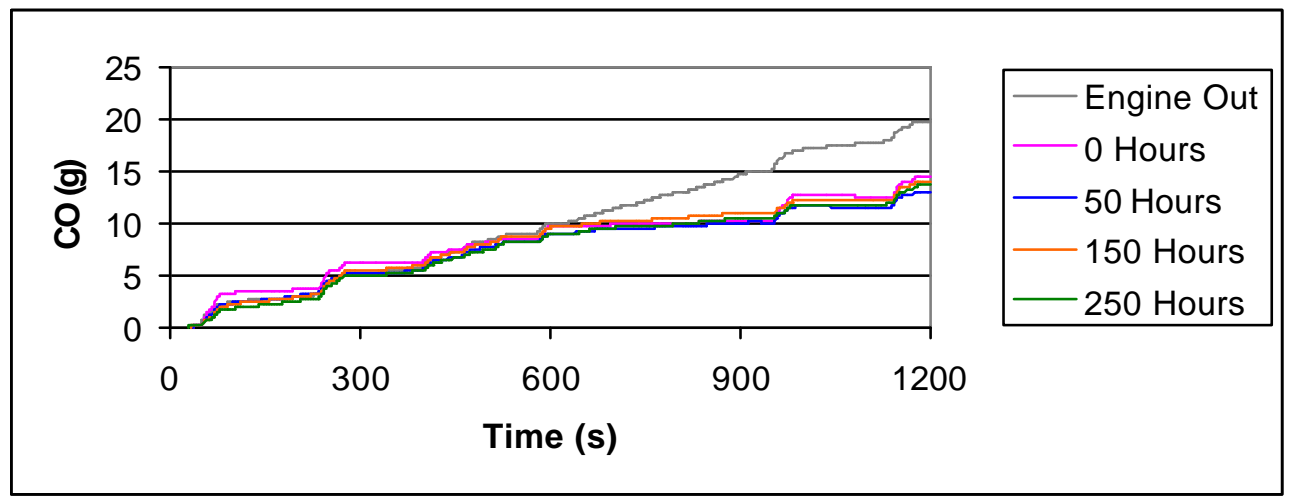

Figure 4.24: FTP accumulated CO for 30ppm oxidation catalyst through the aging period.

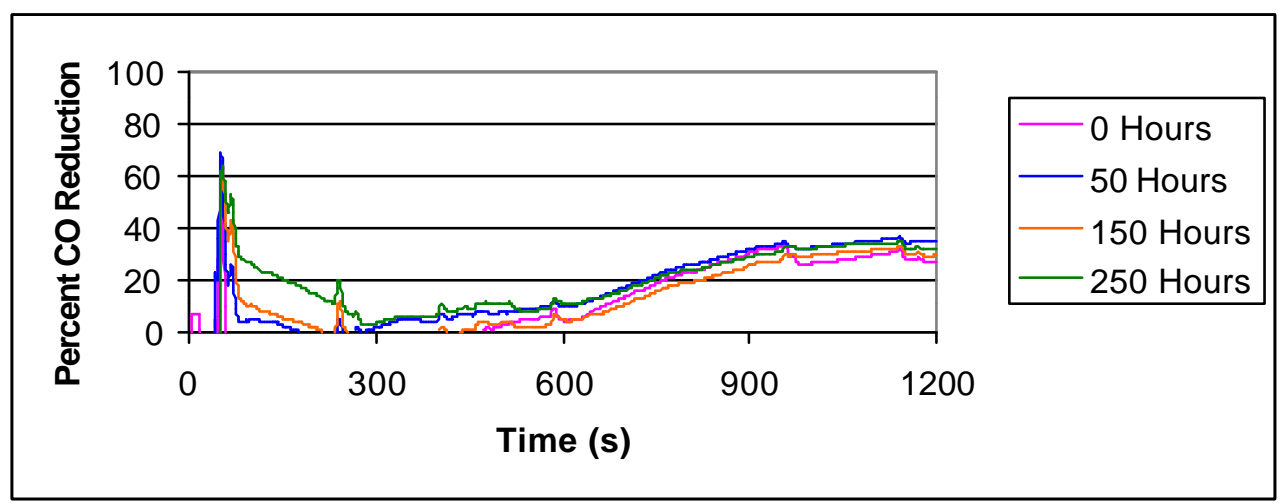

Figure 4.25: Percent reduction of CO for 30ppm oxidation catalyst.

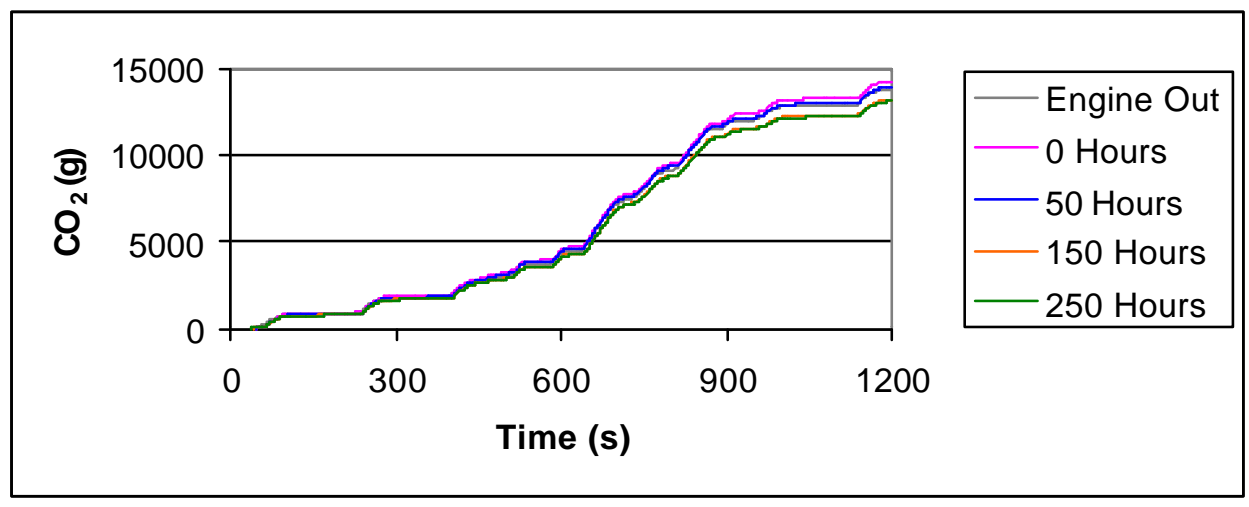

Figure 4.26: FTP accumulated $\mathrm{CO}_{2}$ for 30ppm oxidation catalyst through the aging period. 


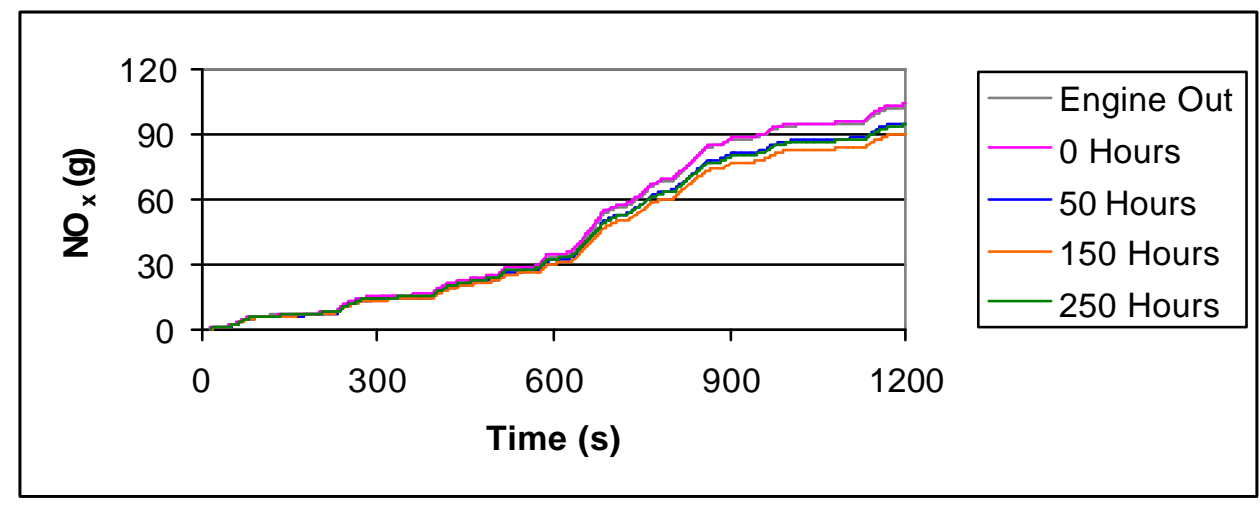

Figure 4.27: FTP accumulated $N O_{x}$ for 30ppm oxidation catalyst through the aging period.

\subsubsection{0ppm gaseous results}

Results were obtained from the Cummins ISM370 engine operating on 150ppm sulfur diesel fuel described in Section 3.2. Figure 4.28 shows the accumulated results of HC measured during the FTP cycle. Please disregard the 250 hour trace in Figure 4.28 due to measurement error as described in Section 4.5.1. 150ppm HC oxidation results are consistent with the 3 and $30 \mathrm{ppm}$ oxidation catalysts results of a large initial $\mathrm{HC}$ reduction and a decrease in performance after the first aging period. Figure 4.29 illustrates this decrease in performance that was more severe than the 3 and 30ppm results. The $\mathrm{HC}$ reduction was only $40 \%$ after the first 50 and 150 hours of aging. The 250 hour data could not support the loss in performance due to increased sulfur concentration in the diesel fuel because of below zero results.

Figure 4.30 presents the amassed $\mathrm{CO}$ throughout the transient cycle for the four aging points. The 150ppm catalyst does not function until halfway through the cycle consistent with the 3 and 30ppm results. A 33\% CO reduction for the first 150 aging hours is illustrated in Figure 4.31, which is a slight increase from the 3 and 30ppm results. In the last 100 hours of aging, CO reduction by the oxidation catalyst decreases to $20 \%$. This may be attributed to 
either thermal effects or catalyst poisoning from the increase in diesel fuel sulfur concentration. There was no decline in performance between the 150 and 250 hour evaluations in the $3 \mathrm{ppm}$ or $30 \mathrm{ppm}$ results, so it is speculated that the decline is due to fuel sulfur concentration. No effect on $\mathrm{CO}_{2}$ and $\mathrm{NO}_{\mathrm{x}}$ was observed from the oxidation catalyst or the increase in diesel fuel sulfur concentration as illustrated with Figure 4.32 and Figure 4.33.

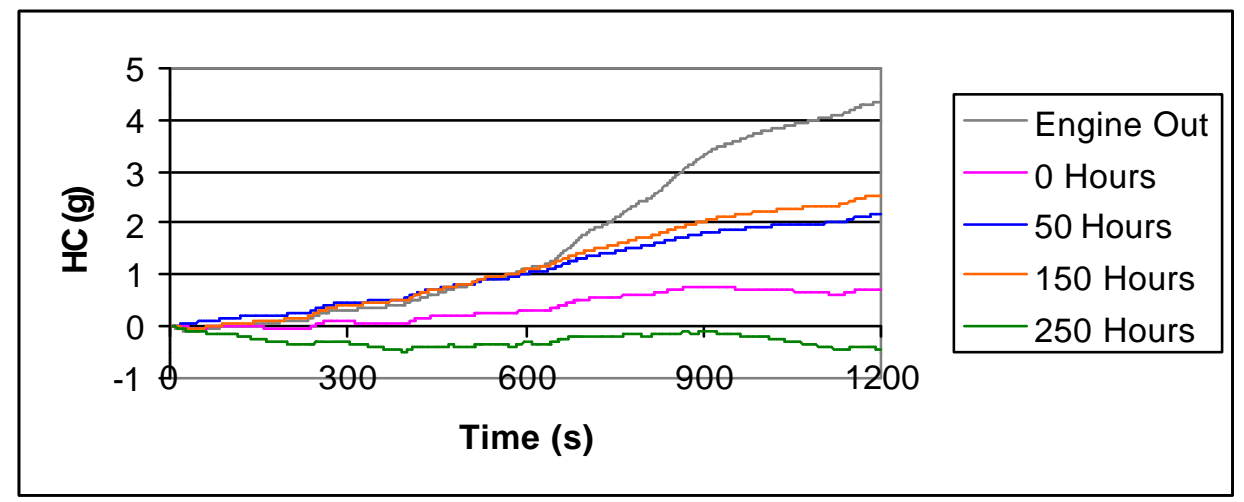

Figure 4.28: FTP accumulated HC for 150ppm oxidation catalyst through the aging period.

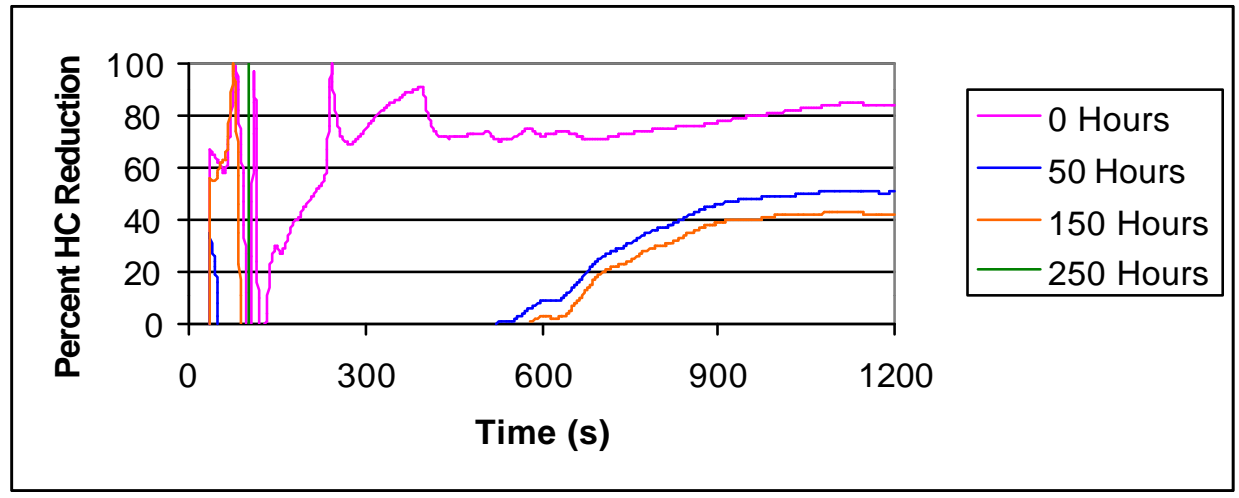

Figure 4.29: Percent reduction of HC for 150ppm oxidation catalyst. 


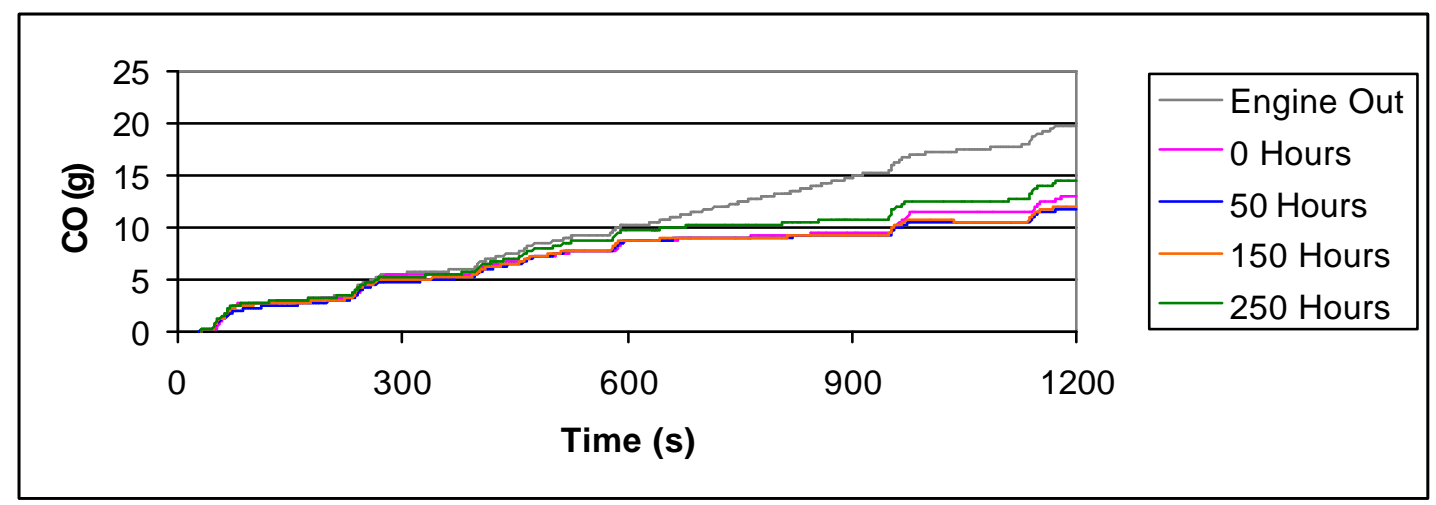

Figure 4.30: FTP accumulated CO for 150ppm oxidation catalyst through the aging period.

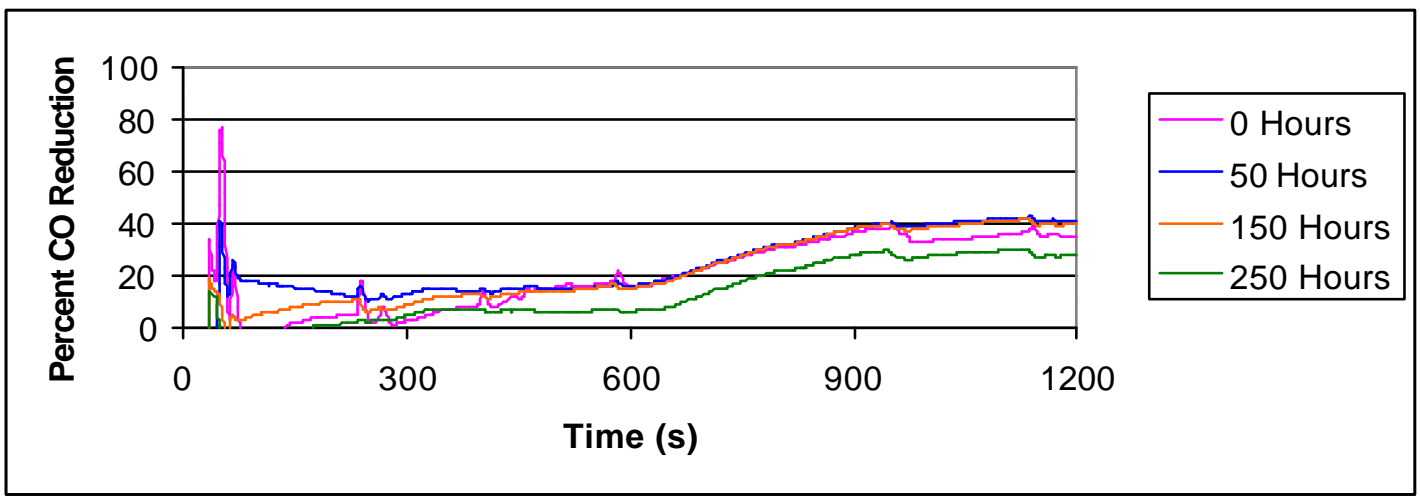

Figure 4.31: Percent reduction of CO for 150ppm oxidation catalyst.

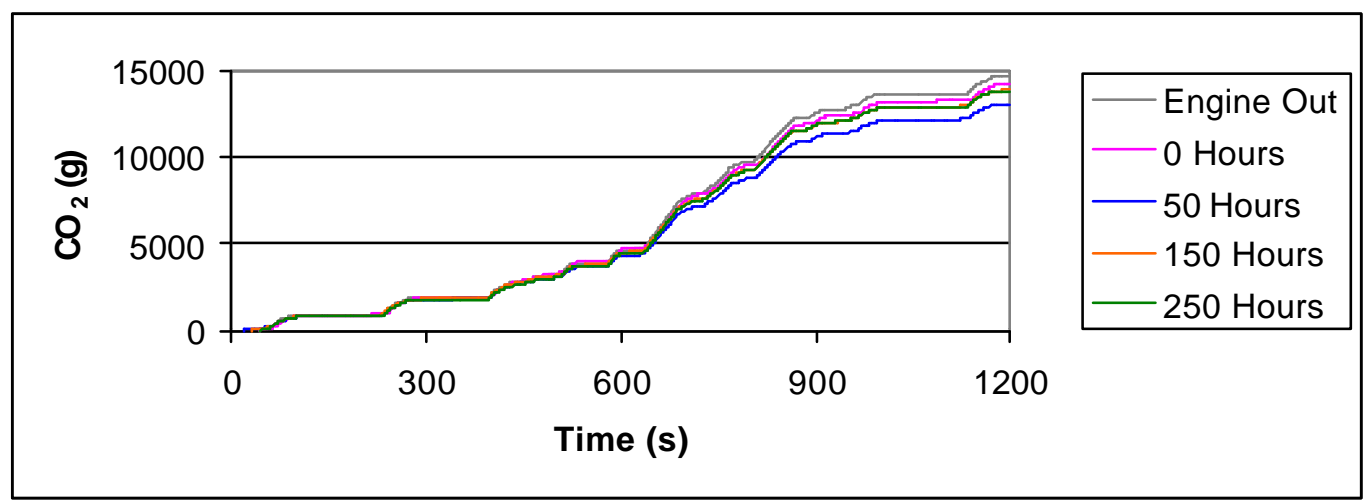

Figure 4.32: FTP accumulated $\mathrm{CO}_{2}$ for 150ppm oxidation catalyst through the aging period. 


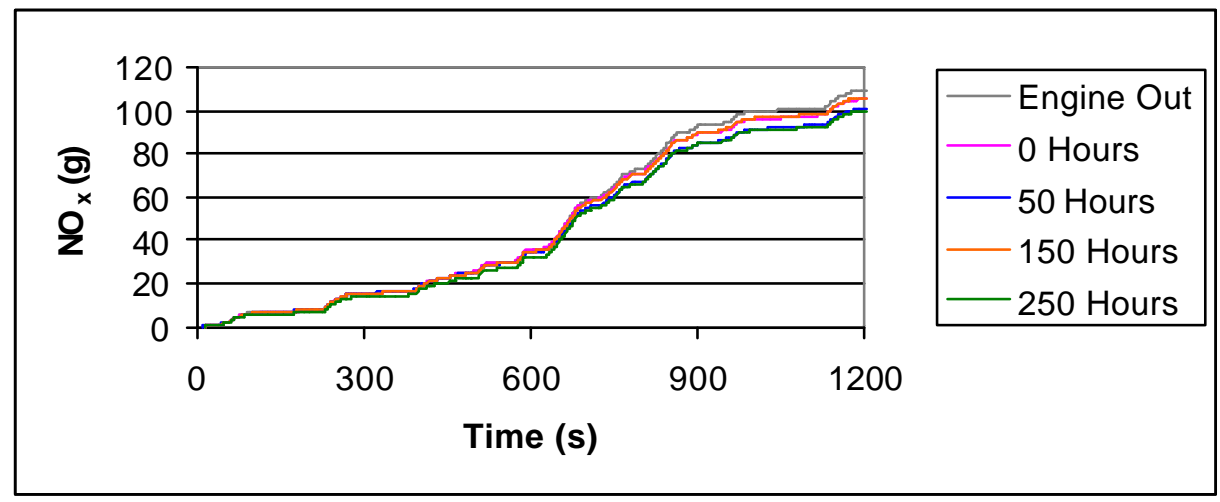

Figure 4.33: FTP accumulated $N O_{x}$ for 150ppm oxidation catalyst through the aging period.

\subsubsection{0ppm gaseous results}

Results were obtained from the Cummins ISM370 engine operating on 350ppm sulfur diesel fuel described in Section 3.2. Figure 4.34 shows the accumulated results of HC measured during the FTP cycle. The 350ppm HC oxidation results are at the $80 \%$ reduction level observed with the 3 and 30ppm oxidation catalysts which is displayed in Figure 4.35. Diesel fuel sulfur concentration has no significant effect on the reduction of $\mathrm{HC}$ with an oxidation catalyst as speculated in the $150 \mathrm{ppm}$ results.

Figure 4.36 presents the amassed $\mathrm{CO}$ throughout the transient cycle for the four aging points. All four sulfur fuel levels were consistent that $\mathrm{CO}$ oxidation does not initiate until halfway through the FTP cycle. A 40\% CO reduction was observed at the beginning and after 50 aging hours which is $10 \%$ increase from the 3 and $30 \mathrm{ppm}$ results and a $7 \%$ increase from the $150 \mathrm{ppm}$ results. A decline of $10 \%$ in $\mathrm{CO}$ reduction was observed earlier in the catalyst life due to catalyst poisoning from the high sulfur levels in the diesel fuel. After this $10 \%$ decline illustrated in Figure 4.37, the oxidation catalyst still reduced CO by $30 \%$ which was at the level of the other three oxidation catalysts. No effect on $\mathrm{CO}_{2}$ and $\mathrm{NO}_{\mathrm{x}}$ was 
observed from the 350ppm oxidation catalyst as displayed in Figure 4.38 and Figure 4.39 which was consistent in the other fuel level results.

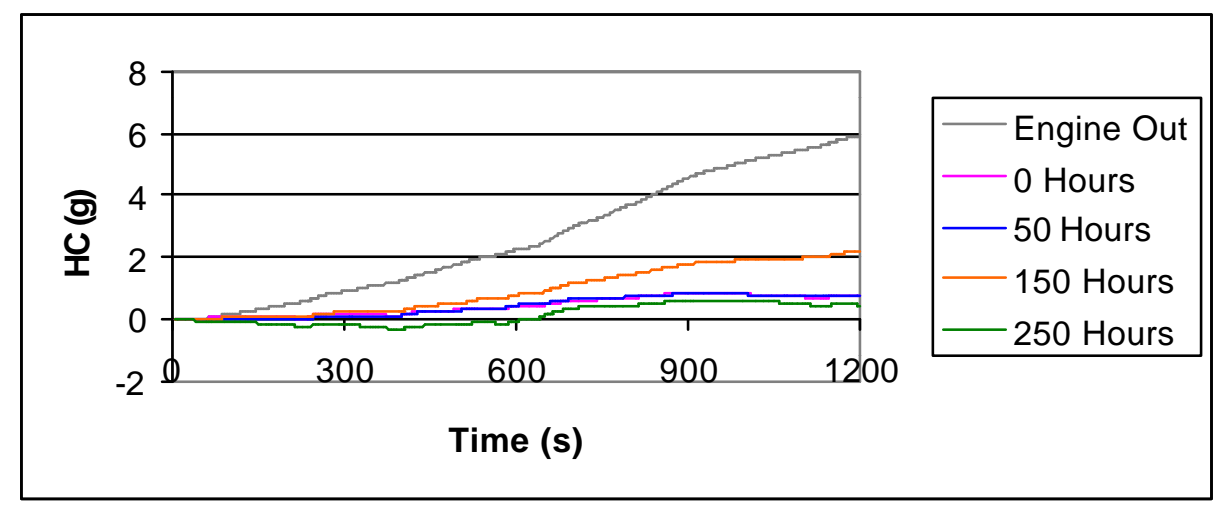

Figure 4.34: FTP accumulated HC for 350ppm oxidation catalyst through the aging period.

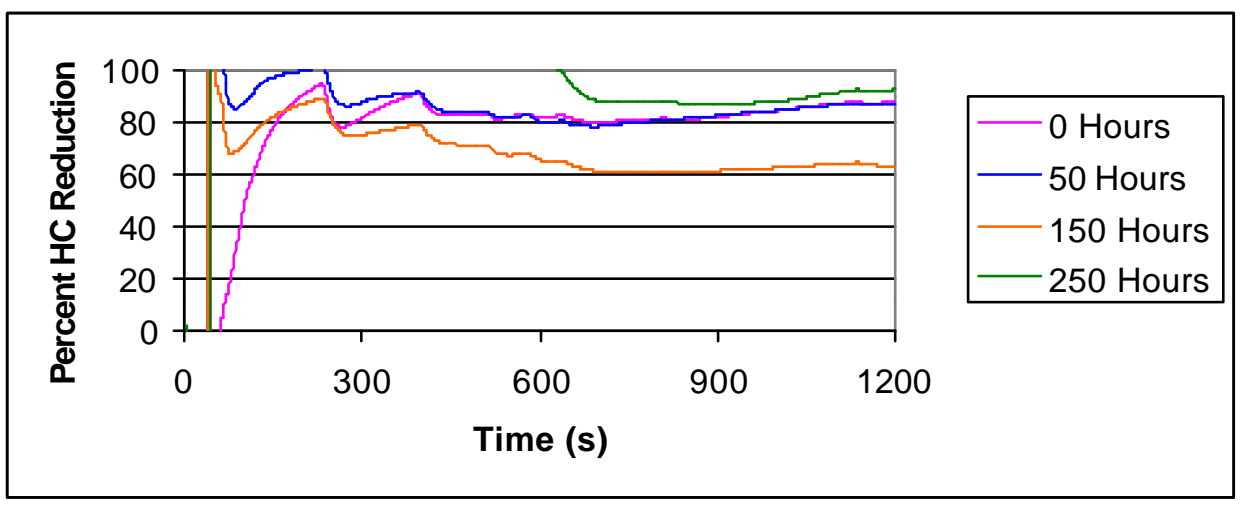

Figure 4.35: Percent reduction of HC for 350ppm oxidation catalyst.

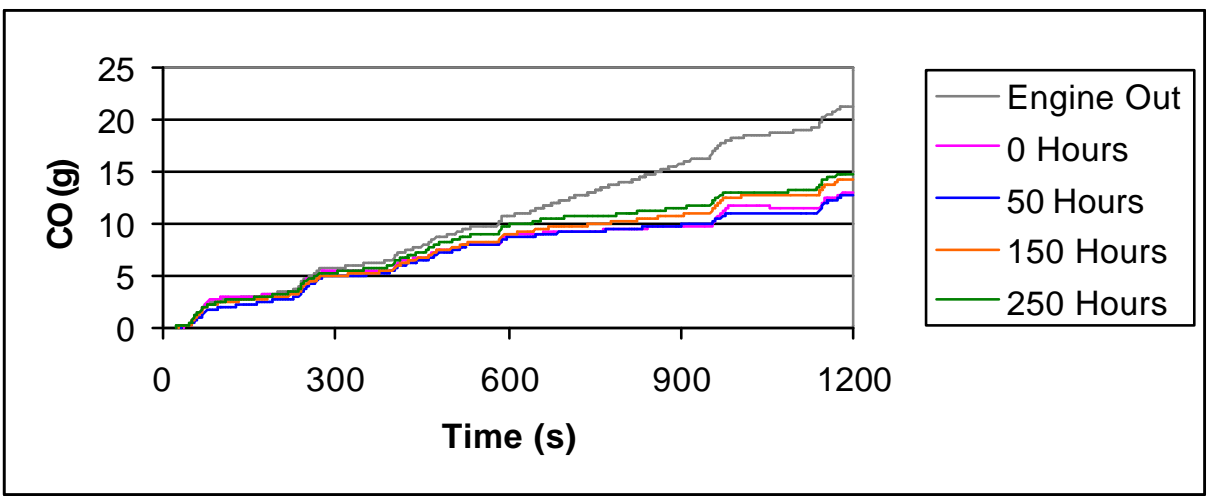

Figure 4.36: FTP accumulated CO for 350ppm oxidation catalyst through the aging period. 


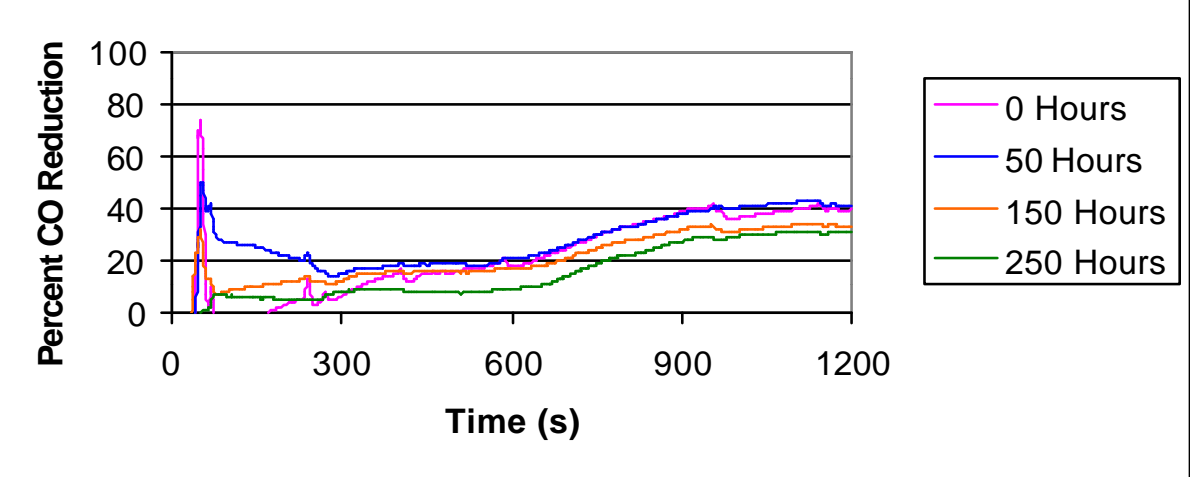

Figure 4.37: Percent reduction of CO for 350ppm oxidation catalyst.

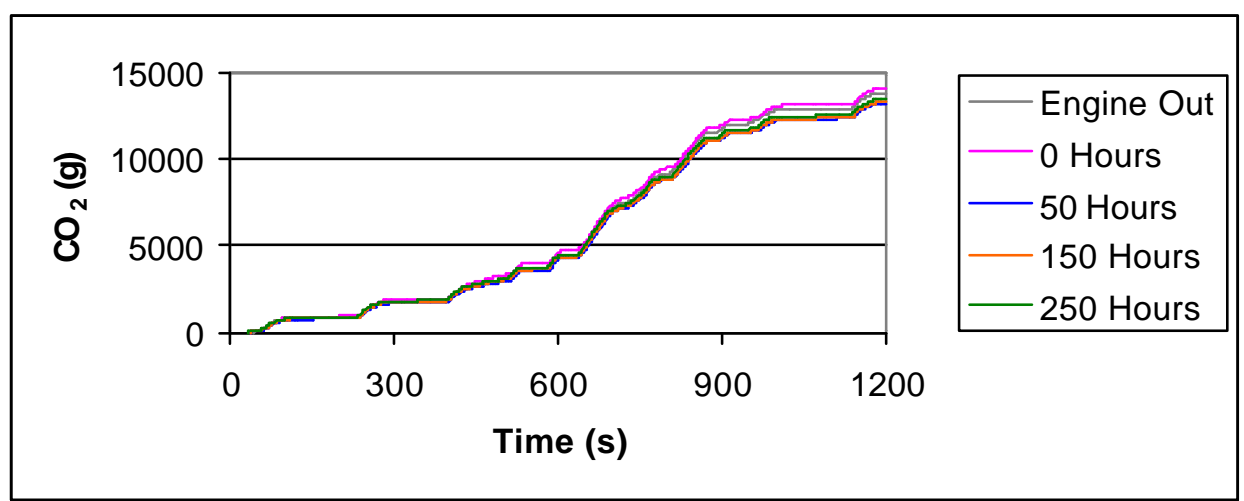

Figure 4.38: $\mathrm{FTP}$ accumulated $\mathrm{CO}_{2}$ for 350ppm oxidation catalyst through the aging period.

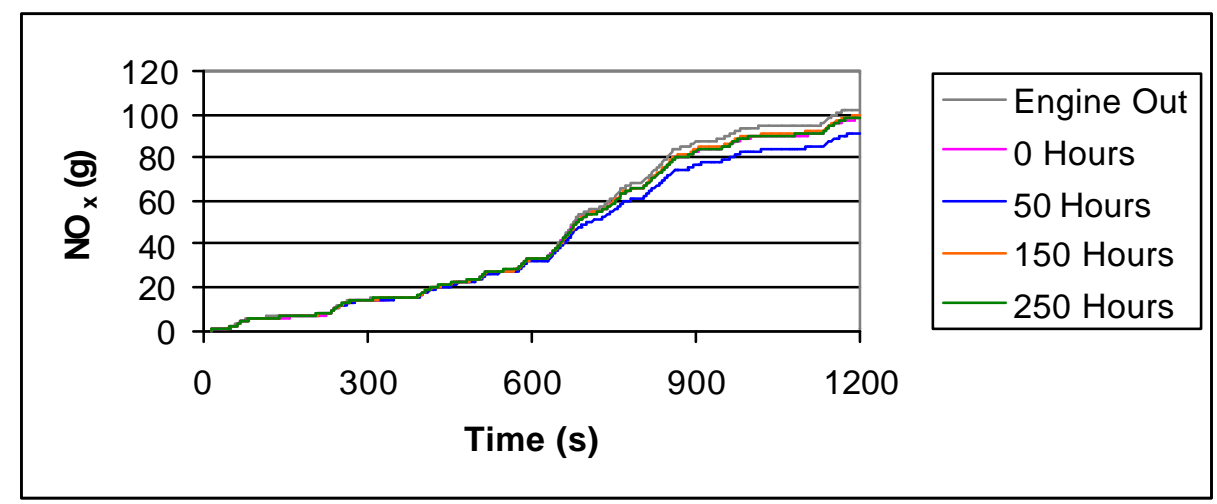

Figure 4.39: FTP accumulated $N O_{x}$ for 350ppm oxidation catalyst through the aging period. 


\subsubsection{PM results}

Total particulate matter is presented on a brake-specific basis and on a continuous basis. PM was collected on filters as required by the CFR [1]. The process used to collect PM was described in Section 3.4.2. Measured PM was converted to units of $\mathrm{g} / \mathrm{bhp}-\mathrm{hr}$ for each catalyst evaluation. PM results of the oxidation catalysts for the four sulfur fuel levels are presented in Figure 4.40. Equation 4.1 was used to determine the difference between initial and final measured PM during the aging process with initial data used as the reference. The 3ppm fuel provided a 7\% increase in PM over the aging process. This was the only fuel for which an increase in PM was observed. The remaining 30ppm, 150ppm, and 350ppm fuels demonstrated PM reductions of $16 \%, 4 \%$, and $21 \%$ respectively.

Figure 4.41 presents continuous PM measured with the TEOM for the four different fuels. An increase in sulfur in the diesel fuel increases the amount of sulfate present in the exhaust. These sulfates attach to particles which affect the weight of total particulate matter. Therefore, an increased concentration of sulfur in the diesel fuel should increase the measured PM. This was not the case for both the PM collected on filter and PM collected by the TEOM. The highest sulfur fuel produced the least amount of PM and the smallest quantity of sulfur in the fuel provided the most PM by both methods of measurement.

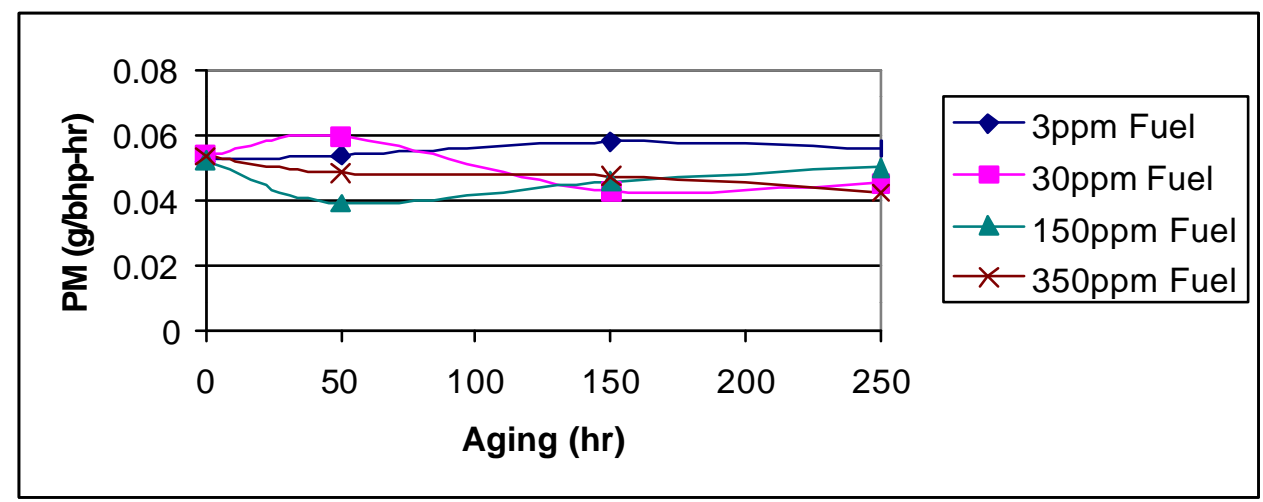

Figure 4.40: Total PM collected during oxidation catalyst evaluations. 


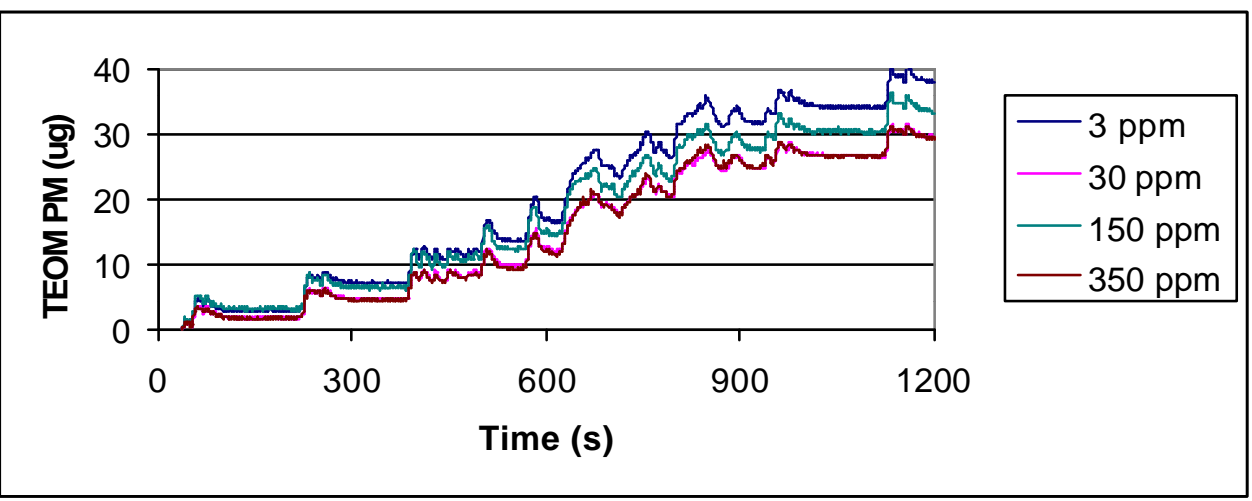

Figure 4.41: Continuous accumulated PM from TEOM for the oxidation catalysts.

\subsection{Lean- $\mathrm{NO}_{\mathrm{x}}$ catalyst results}

This section is divided up into four subsections to present the results from the hightemperature lean- $\mathrm{NO}_{\mathrm{x}}$ catalyst for the four different sulfur fuel levels. The results are presented by the accumulation of the constituents, $\mathrm{HC}, \mathrm{CO}, \mathrm{CO}_{2}$, and $\mathrm{NO}_{\mathrm{x}}$, throughout the steady-state cycle. This lean- $\mathrm{NO}_{\mathrm{x}}$ catalyst required a reductant injected upstream of the device for $\mathrm{NO}_{\mathrm{x}}$ reduction. Reductant was only injection in modes 4 and 5 of the ESC4 cycle because injection in modes 2 and 3 provided minimal $\mathrm{NO}_{\mathrm{x}}$ reduction. Gaseous emissions results are provided as engine-out split flow test with no aftertreatment and as catalyst out emissions recorded at various stages of catalyst aging. Equation 4.1 was used to determine $\%$ increase of $\mathrm{HC}$ and $\mathrm{CO}$ with the engine-out value used as the reference value. Figure 4.42 provides a temperature measured 6 inches before the oxidation catalyst termed precat and temperature measured 6 inches downstream of the catalyst called the postcat. Temperatures ranged between $\pm 20{ }^{\circ} \mathrm{C}$ of the two temperature traces provided in Figure 4.42 for the DECSE catalyst testing. 


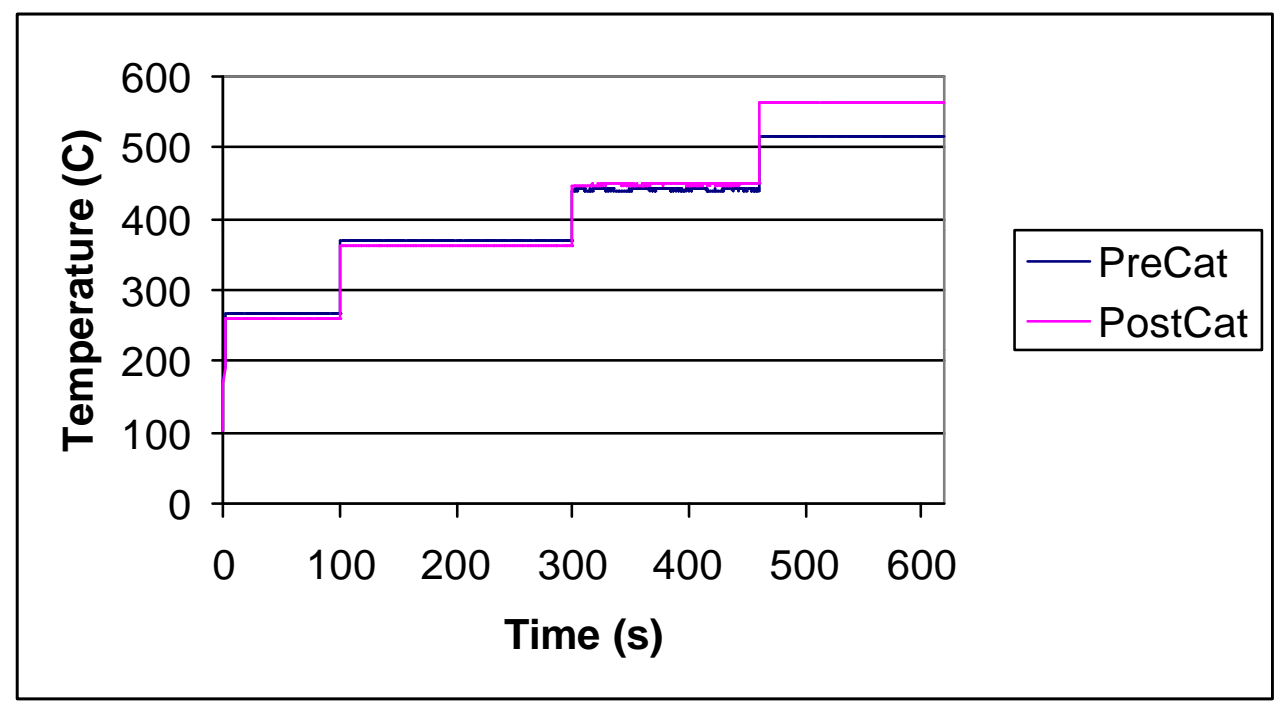

Figure 4.42: Lean-NOx catalyst temperatures.

\subsubsection{3ppm gaseous results}

Results were obtained from the Cummins ISM370 engine operating on 3ppm sulfur diesel fuel described in Section 3.2. Figure 4.43 presents the accumulated results of HC measured during the ESC4 cycle, which was described in Section 3.6. This figure illustrates that a large increase of $\mathrm{HC}$ was reported during the last two modes from the reductant injection. Figure 4.44 shows an $800 \%$ increase in $\mathrm{HC}$ from reductant injection at the final aging evaluation. The percent $\mathrm{HC}$ increase due to the reductant injection seems to increase as the catalyst ages.

$\mathrm{CO}$ accumulated throughout the ESC4 is shown in Figure 4.45. CO, just like HC, was generated during the reductant injection. Figure 4.46 provides $\mathrm{CO}$ generated from the reductant injection as a percentage of the engine-out $\mathrm{CO}$ with no reductant injection. The catalyst had minimal effect on $\mathrm{CO}_{2}$ as seen in Figure 4.47.

Accumulated $\mathrm{NO}_{\mathrm{x}}$ from the steady-state cycle is illustrated in Figure 4.48. Some $\mathrm{NO}_{\mathrm{x}}$ reduction occurred before the reductant injection as seen in Figure 4.49. This reduction 
could be attributed to the presence of $\mathrm{HC}$ introduced from the diesel combustion, not the injection system. The catalyst initially reduces $\mathrm{NO}_{\mathrm{x}}$ by approximately $12 \%$ which decreases to $7 \%$ after the first aging period. The 150 hours evaluation provided a $4 \% \mathrm{NO}_{\mathrm{x}}$ reduction and increased back up to $7 \%$ after the final aging was completed. It seems that the reductant injection system was not working properly during the 150 hour evaluation.

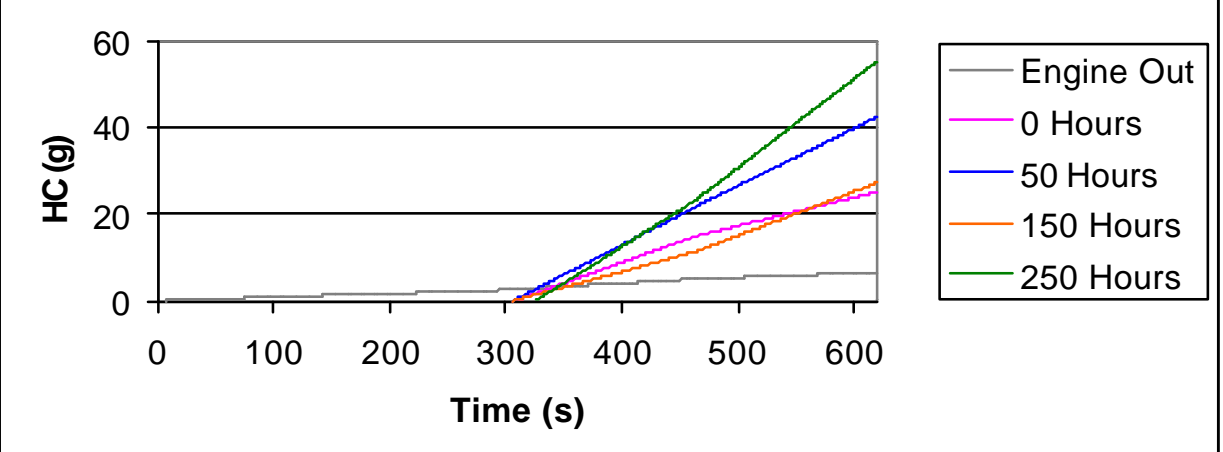

Figure 4.43: ESC4 accumulated $\mathrm{HC}$ for 3ppm lean-NO catalyst through the aging period.
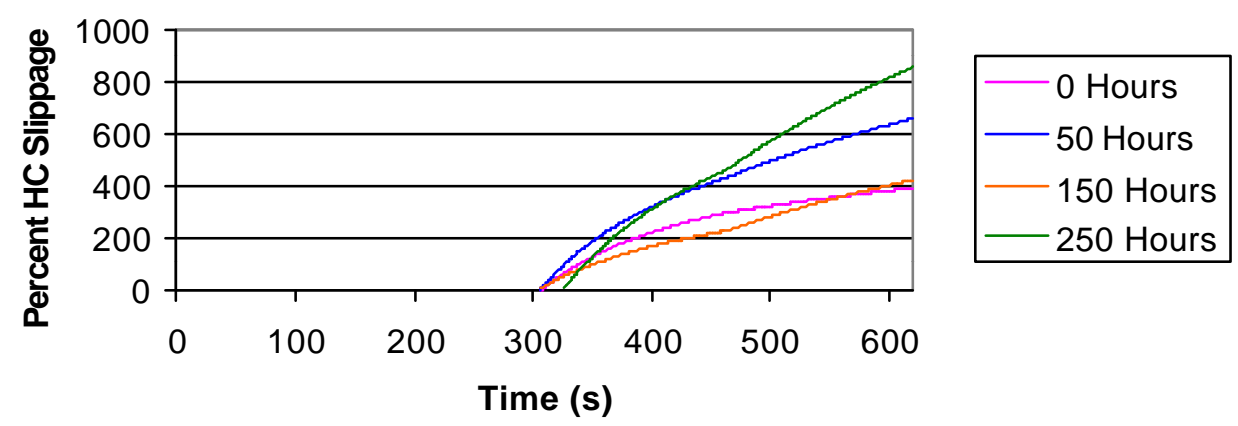

Figure 4.44: Percent increase of $\mathrm{HC}$ for $3 p p m$ lean-NO catalyst. 


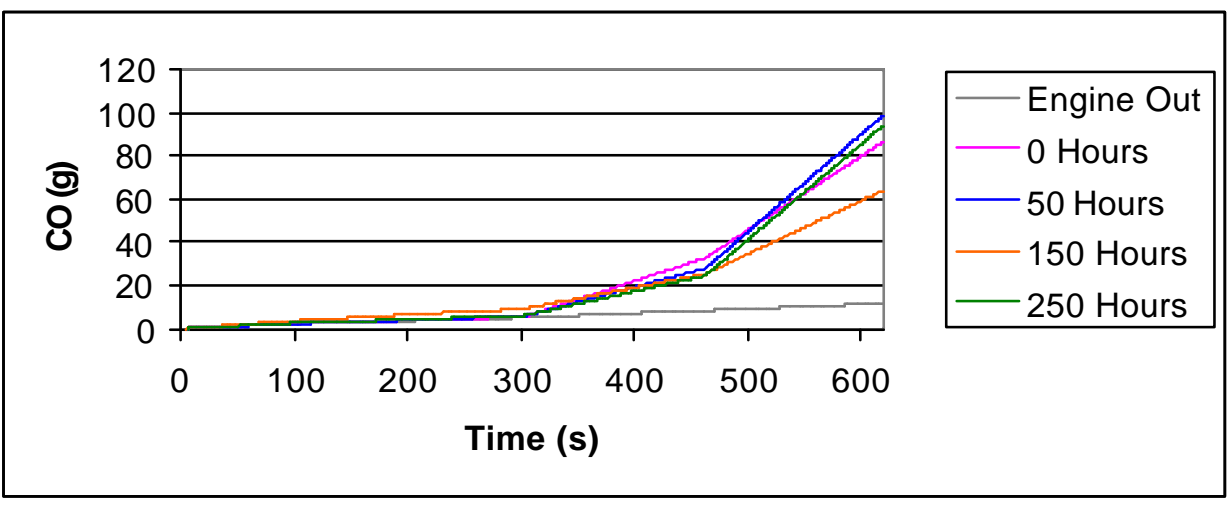

Figure 4.45: ESC4 accumulated CO for 3ppm lean-NO $O_{x}$ catalyst through the aging period.

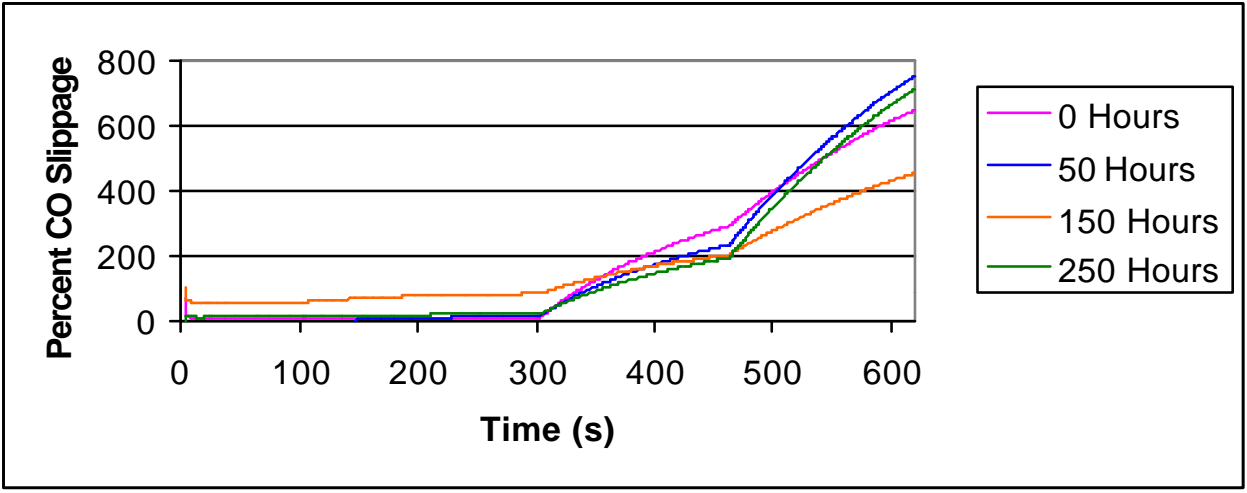

Figure 4.46: Percent increase of CO for 3ppm lean-NO $\mathrm{O}_{x}$ catalyst.

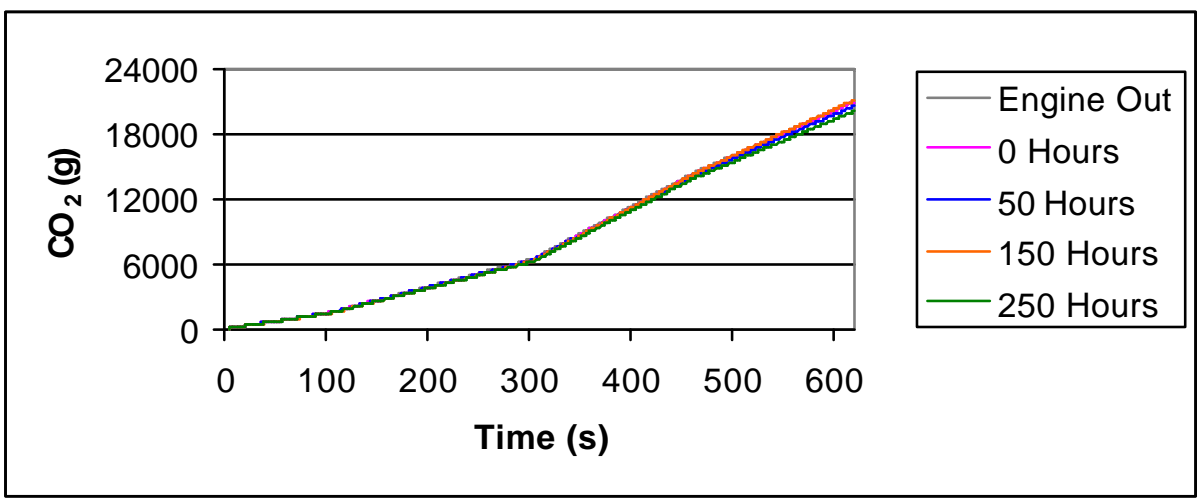

Figure 4.47: ESC4 accumulated $\mathrm{CO}_{2}$ for 3ppm lean-NO $\mathrm{O}_{x}$ catalyst through the aging period. 


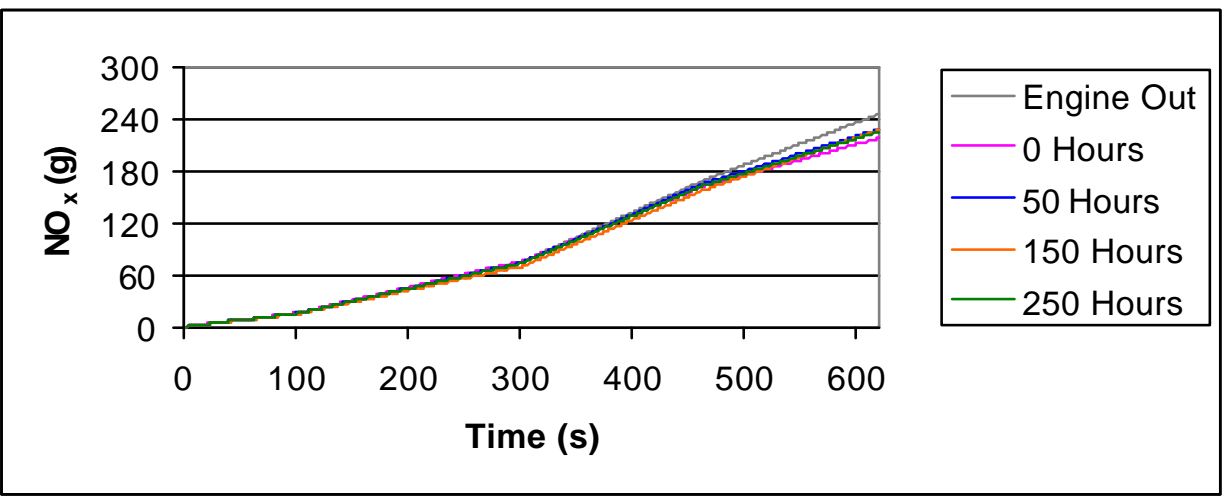

Figure 4.48: ESC4 accumulated $\mathrm{NO}_{x}$ for 3ppm lean-NO $\mathrm{O}_{x}$ catalyst through the aging period.

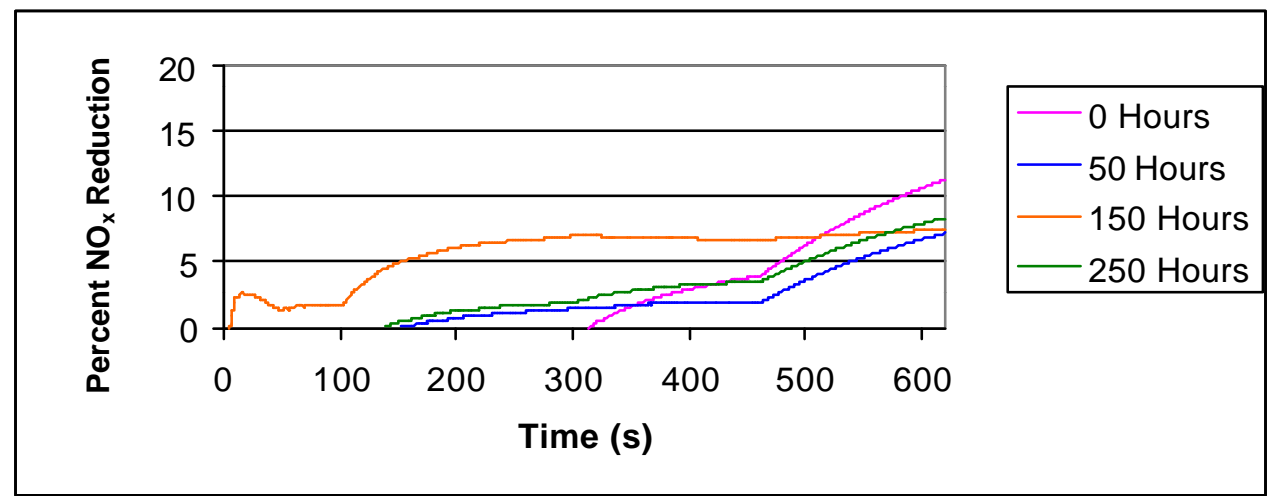

Figure 4.49: Percent reduction of $\mathrm{NO}_{x}$ for $3 p p m$ lean- $\mathrm{NO}_{x}$ catalyst.

\subsubsection{0ppm gaseous results}

Results were obtained from the Cummins ISM370 engine operating on 30ppm sulfur diesel fuel described in Section 3.2. Figure 4.50 presents accumulated results of HC measured during the ESC4 cycle. A large increase of $\mathrm{HC}$ was observed during the last two modes consistent with the $3 \mathrm{ppm}$ lean- $\mathrm{NO}_{\mathrm{x}}$ results. Figure 4.51 showed approximately a $700 \%$ increase in $\mathrm{HC}$ at the final aging evaluation. As speculated in the $3 \mathrm{ppm}$ results, $\mathrm{HC}$ increased from the reductant injection increased as the catalyst aged. 
$\mathrm{CO}$ accumulated throughout the ESC4 is shown in Figure 4.52. Figure 4.53 illustrates approximately $800 \% \mathrm{CO}$ generation from the reductant injection. The $\mathrm{CO}$ increase from the reductant increased as the catalyst was aged. Figure 4.54 shows that the catalyst had no effect on $\mathrm{CO}_{2}$ which is consistent with the $3 \mathrm{ppm}$ results.

Accumulated $\mathrm{NO}_{\mathrm{x}}$ from the steady-state cycle is illustrated in Figure 4.55. As was the case with the $3 \mathrm{ppm}$ results, some $\mathrm{NO}_{\mathrm{x}}$ reduction occurred before the reductant was injected. Figure 4.56 provides percent $\mathrm{NO}_{\mathrm{x}}$ reduction for the cycles executed during the four aging points. The data shows that $\mathrm{NO}_{\mathrm{x}}$ reduction increased to $12 \%$ for the 250 hour evaluation. 3ppm results do not support this result of increased catalyst performance while aged.

Please note that the 50 hour evaluation experienced lower increases in $\mathrm{HC}$ and $\mathrm{CO}$ with less $\mathrm{NO}_{\mathrm{x}}$ reduction. This may be attributed to a reductant injection malfunction introducing not enough reductant.

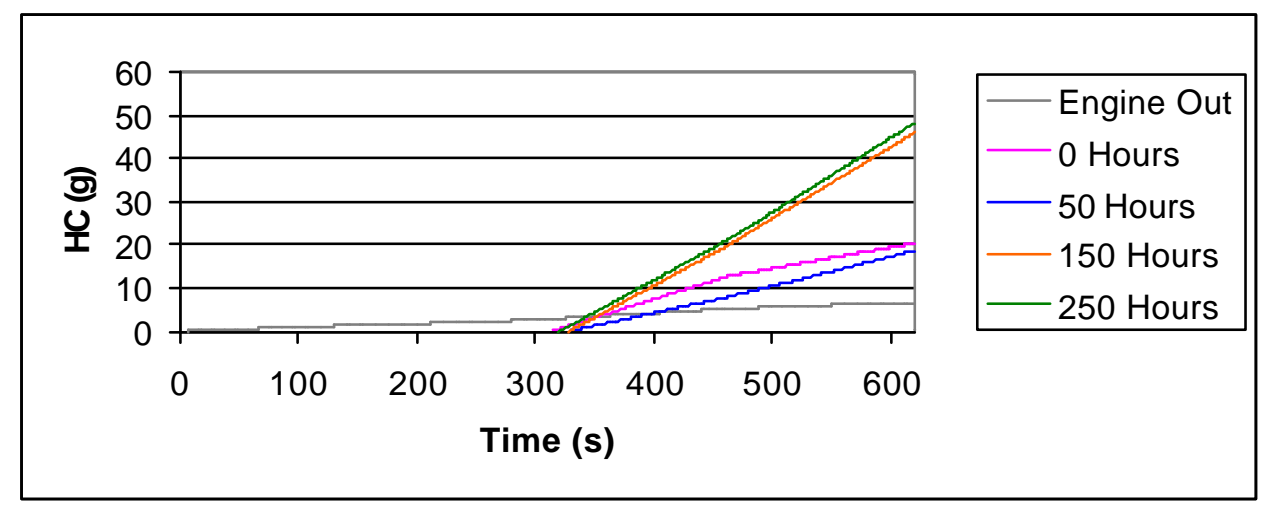

Figure 4.50: ESC4 accumulated HC for 30ppm lean-NO $O_{x}$ catalyst through the aging period. 


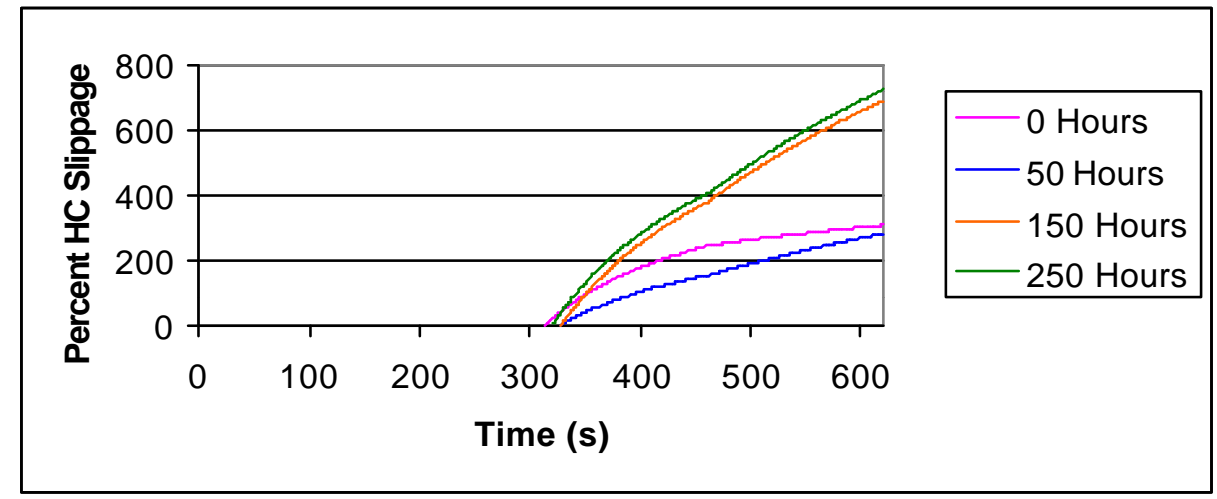

Figure 4.51: Percent increase of HC for 30ppm lean-NO $\mathrm{O}_{x}$ catalyst.

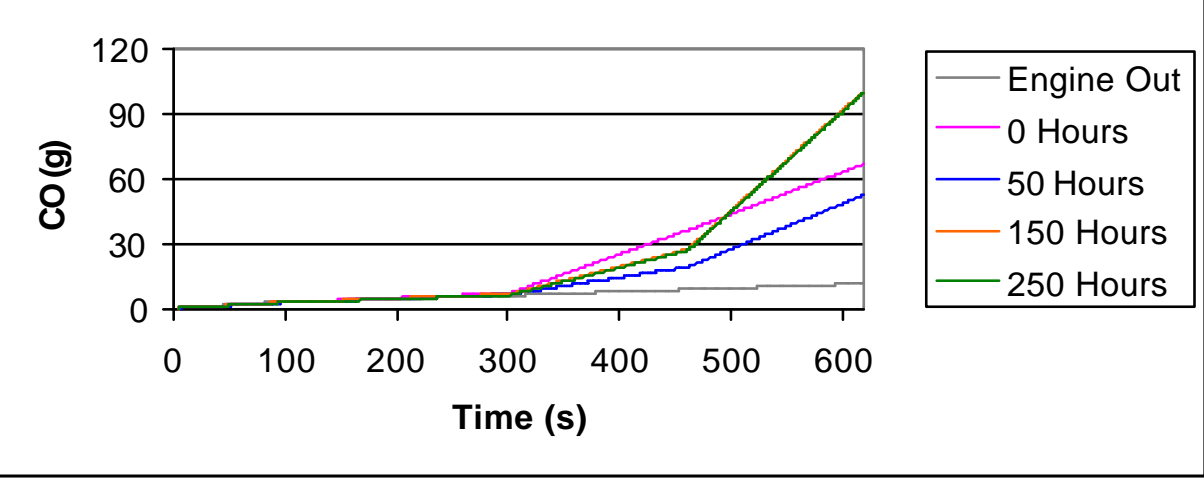

Figure 4.52: ESC4 accumulated CO for 30ppm lean-NOx catalyst through the aging period.

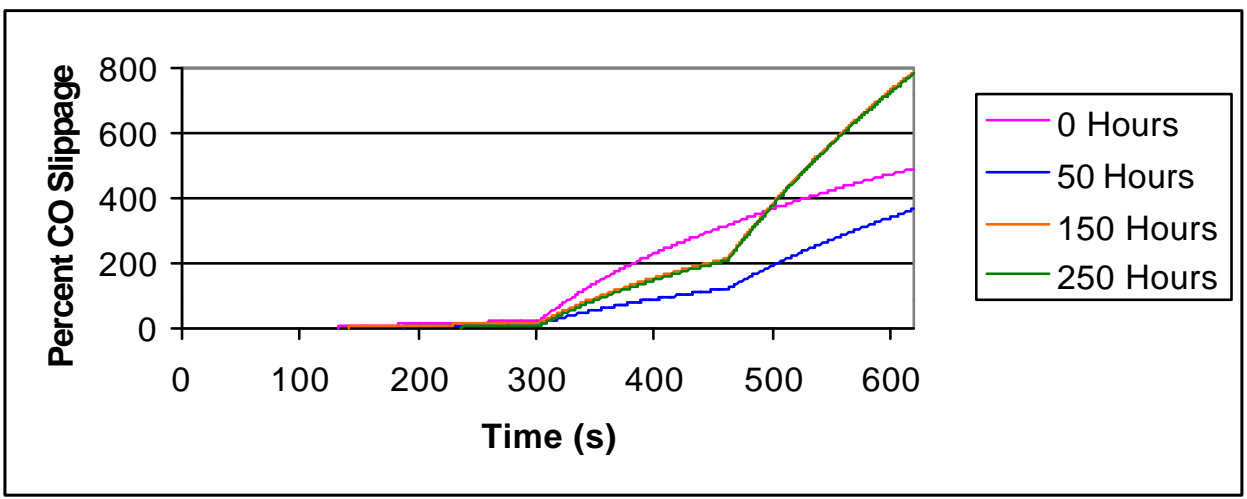

Figure 4.53: Percent increase of CO for 30ppm lean- $\mathrm{NO}_{x}$ catalyst. 


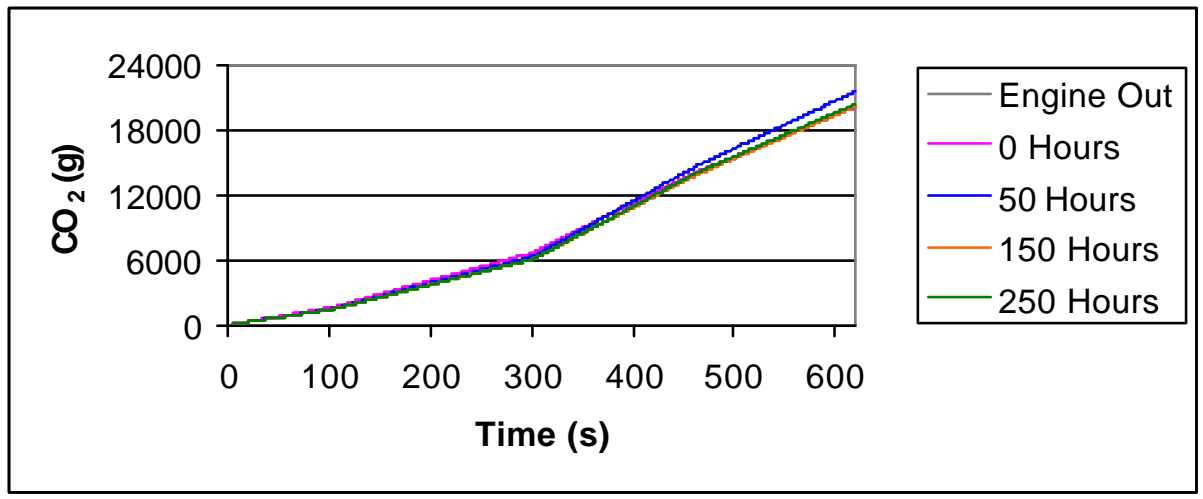

Figure 4.54: ESC4 accumulated $\mathrm{CO}_{2}$ for 30ppm lean-NO catalyst through the aging period.

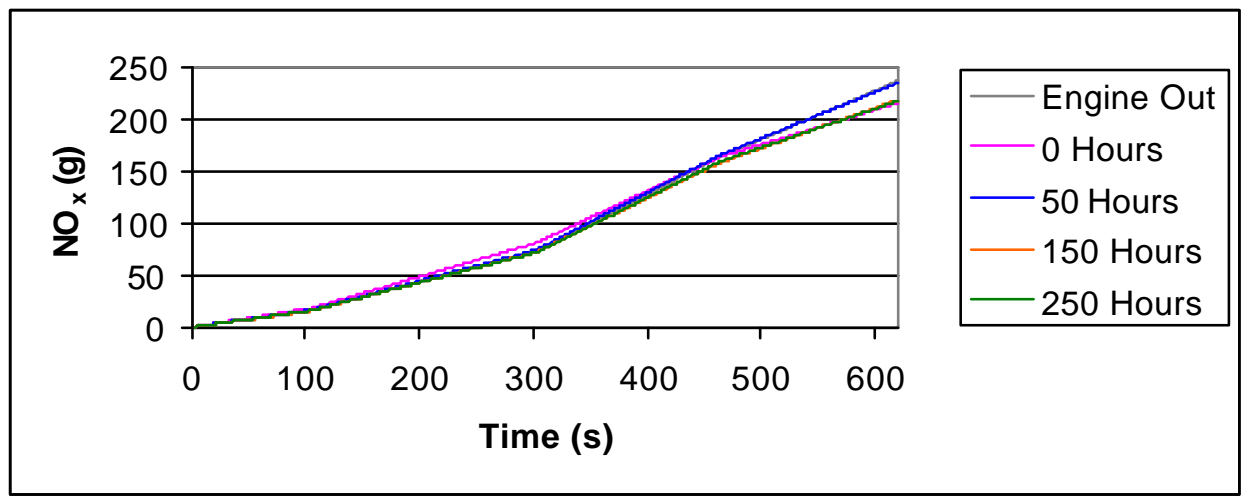

Figure 4.55: ESC4 accumulated $\mathrm{NO}_{x}$ for 30ppm lean-NO catalyst through the aging period.

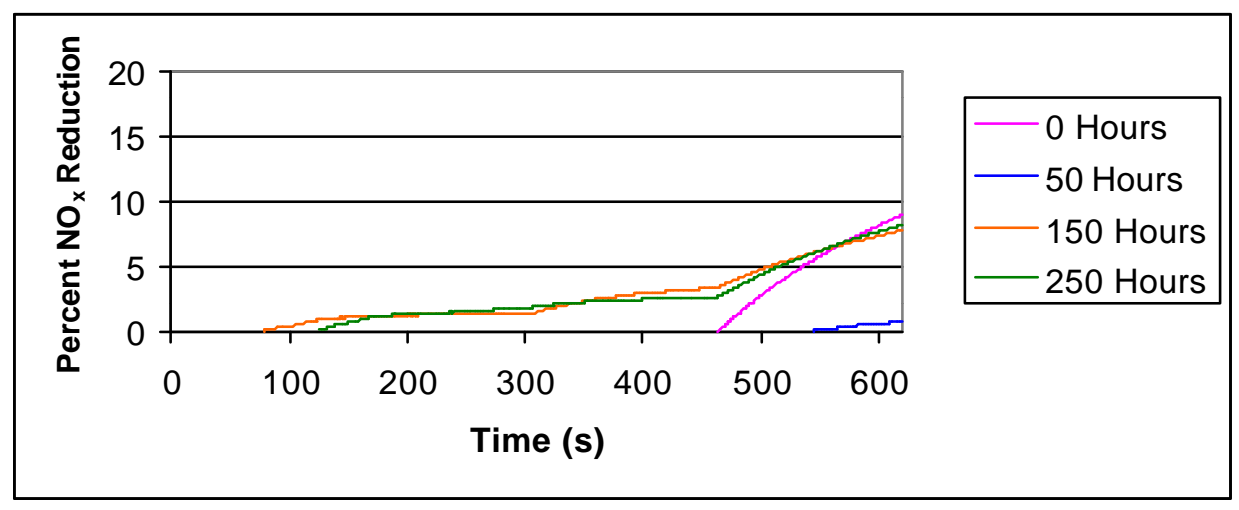

Figure 4.56: Percent reduction of $\mathrm{NO}_{x}$ for 30ppm lean-NO $\mathrm{O}_{x}$ catalyst. 


\subsubsection{0ppm gaseous results}

Results were obtained from the Cummins ISM370 engine operating on 150ppm sulfur diesel fuel described in Section 3.2. Figure 4.57 presents accumulated results of HC measured during the ESC4 cycle. A $1000 \%$ increase in $\mathrm{HC}$ was observed at the final aging evaluation as illustrated in Figure 4.58. This increase in $\mathrm{HC}$ was larger than the increase observed in the 3 and $30 \mathrm{ppm}$ results but the 150ppm results supported the previous results that $\mathrm{HC}$ increase from the reductant injection increase as the catalyst aged.

$\mathrm{CO}$ accumulated throughout the ESC4 is shown in Figure 4.59 which illustrates a CO generation of approximately $1200 \%$ from the reductant injection which is a significant increase from the $3 \mathrm{ppm}$ and $30 \mathrm{ppm}$ results. The $\mathrm{CO}$ increase from the reductant injection increased as the catalyst was aged except for the 250 hours result. Figure 4.61 shows that the catalyst had no effect on $\mathrm{CO}_{2}$ which is consistent with the $3 \mathrm{ppm}$ and 30ppm results.

Accumulated $\mathrm{NO}_{\mathrm{x}}$ from the steady-state cycle is illustrated in Figure 4.62. Figure 4.63 provides percent $\mathrm{NO}_{\mathrm{x}}$ reduction for the cycles executed during the four aging points. The data shows initial $\mathrm{NO}_{\mathrm{x}}$ reduction of $17 \%$ but declines to $5 \%$ for the 250 hour evaluation.

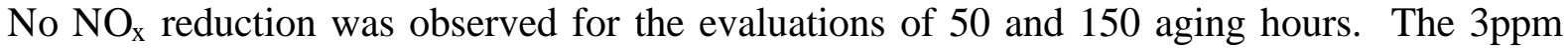
results are consistent with the result that $\mathrm{NO}_{\mathrm{x}}$ reduction decreases as the catalyst ages but the 30ppm results do not support this outcome. 


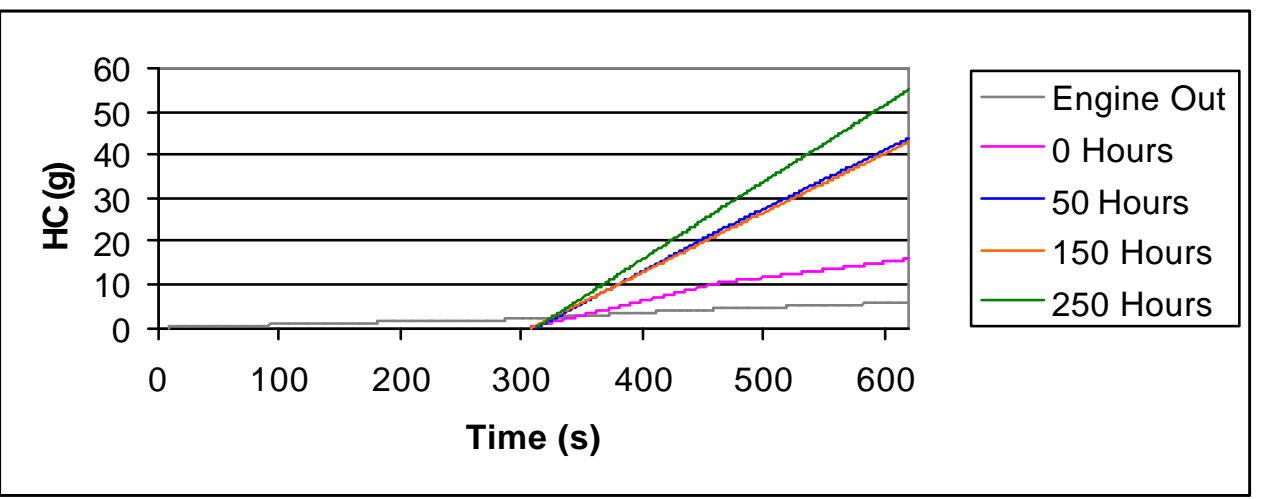

Figure 4.57: ESC4 accumulated HC for 150ppm lean-NO $\mathrm{O}_{x}$ catalyst through the aging period.

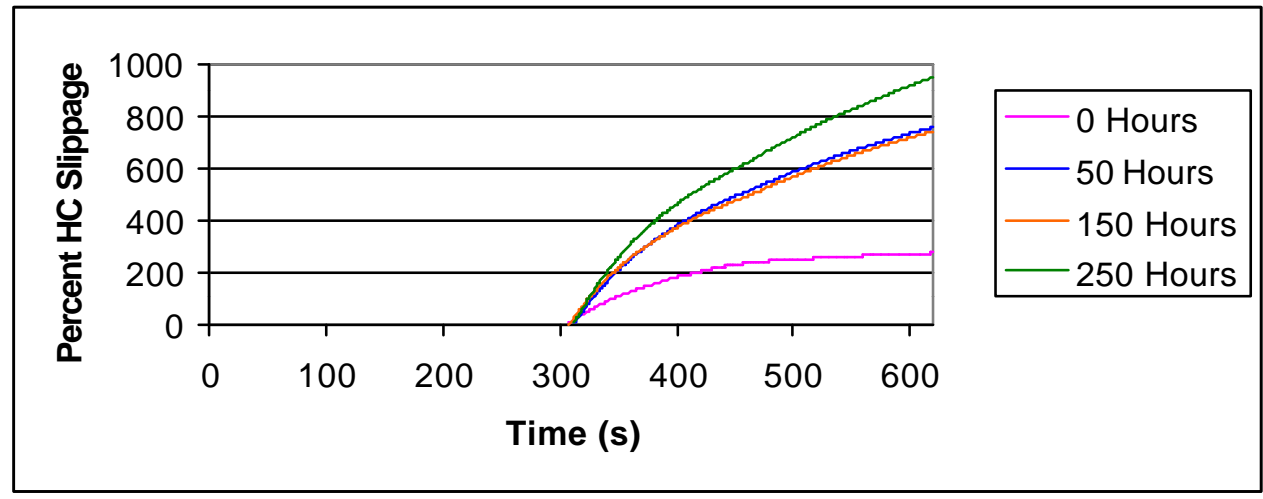

Figure 4.58: Percent increase of $\mathrm{HC}$ for 150ppm lean-NOx catalyst.

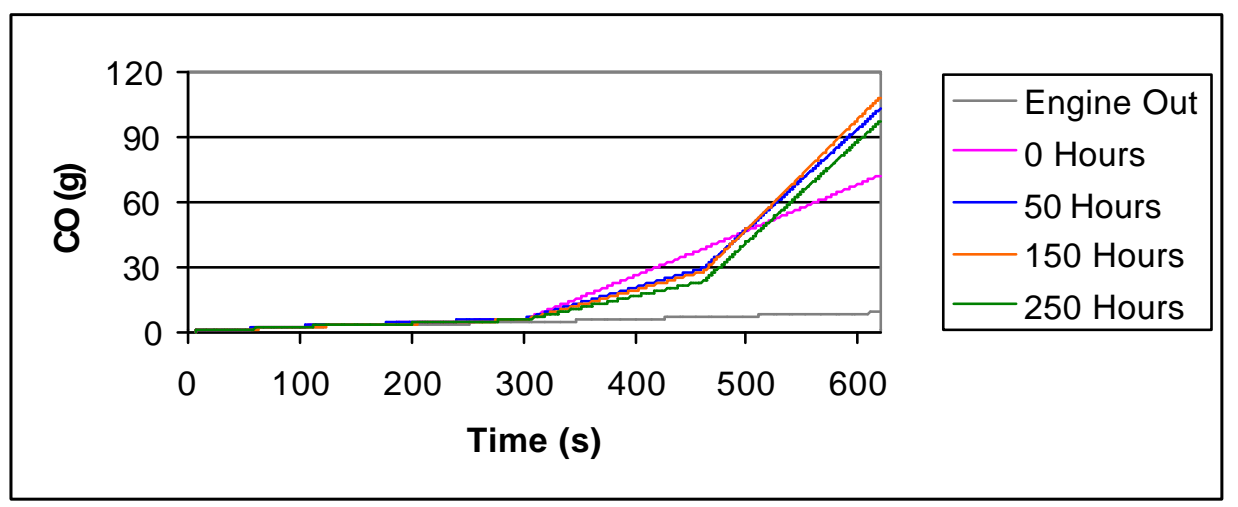

Figure 4.59: ESC4 accumulated CO for 150ppm lean-NO $O_{x}$ catalyst through the aging period. 


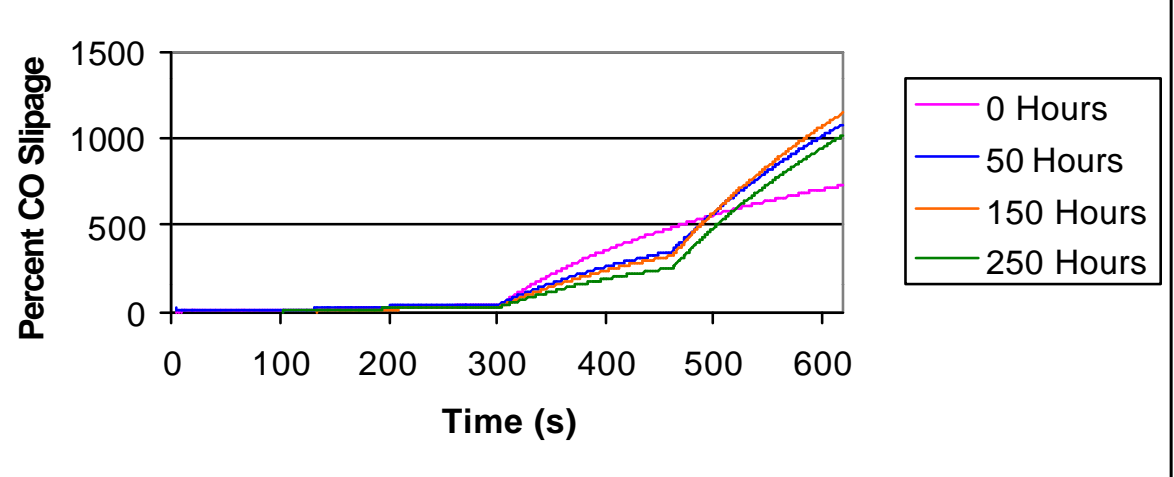

Figure 4.60: Percent increase of CO for 150ppm lean-NOx catalyst.

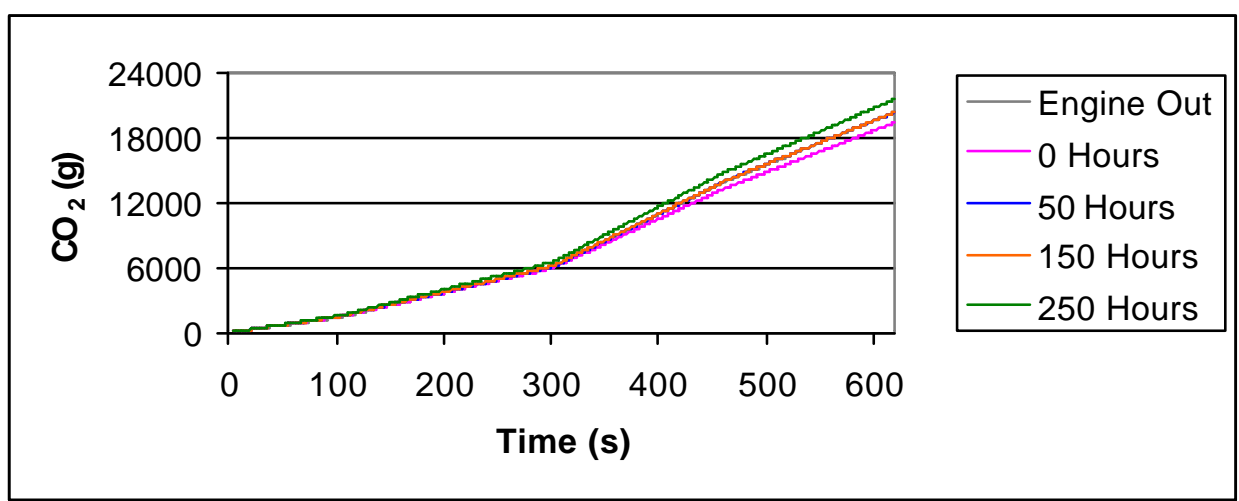

Figure 4.61: $\mathrm{ESC4}$ accumulated $\mathrm{CO}_{2}$ for 150ppm lean- $\mathrm{NO}_{x}$ catalyst through the aging period.

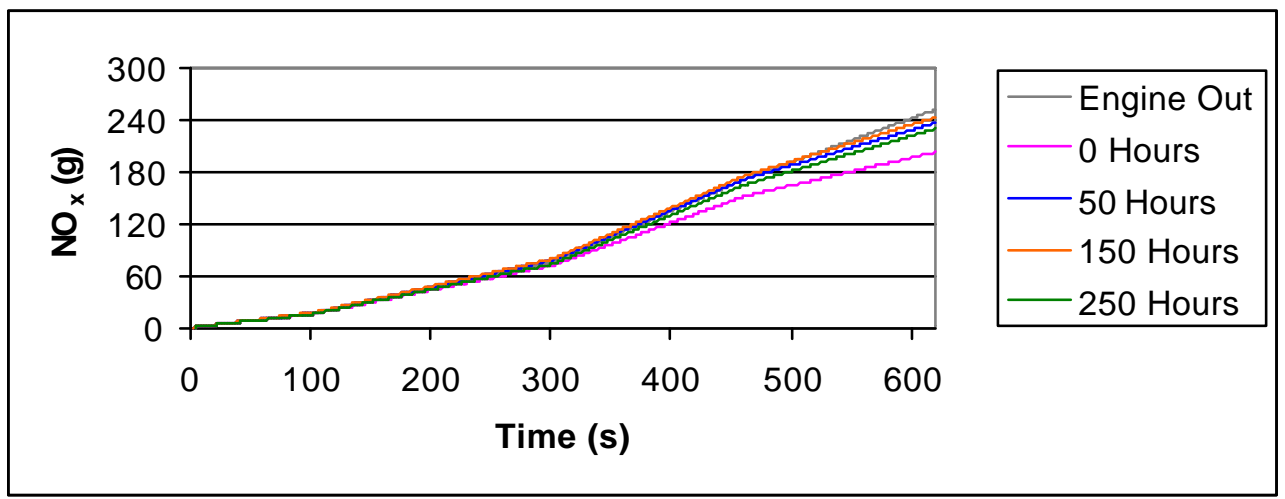

Figure 4.62: ESC4 accumulated $\mathrm{NO}_{x}$ for 150ppm lean-NO $\mathrm{O}_{x}$ catalyst through the aging period. 


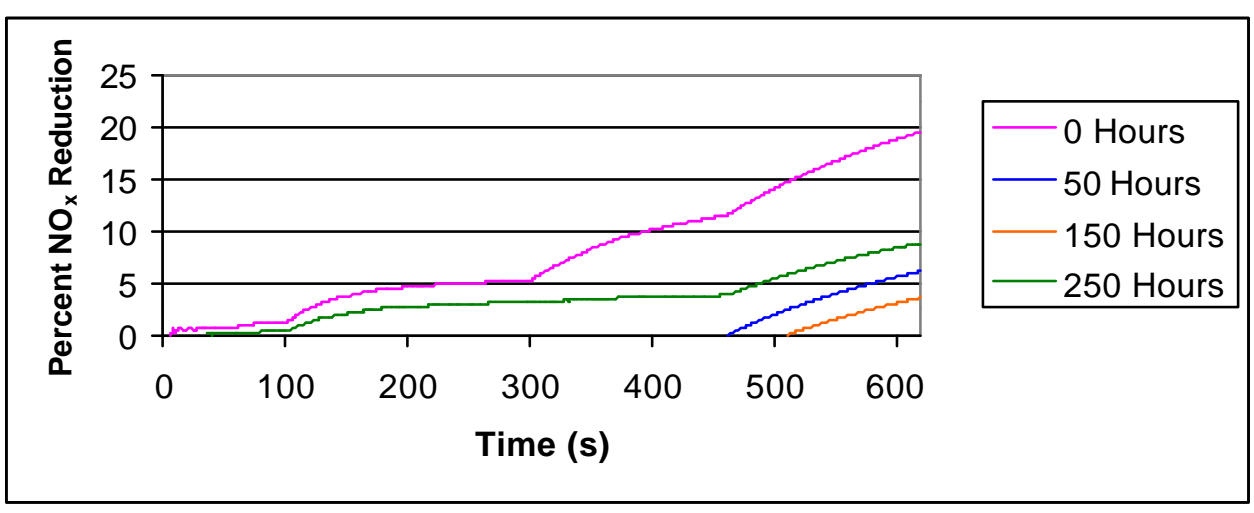

Figure 4.63: Percent reduction of $\mathrm{NO}_{x}$ for 150ppm lean-NO $\mathrm{O}_{x}$ catalyst.

\subsubsection{0ppm gaseous results}

Results were obtained from the Cummins ISM370 engine operating on 350ppm sulfur diesel fuel described in Section 3.2. Figure 4.64 presents the accumulated results of HC measured during the ESC4 cycle. As was the case with the 3ppm, 30ppm, and 150ppm results, HC increased during the last two modes from the reductant injection. Figure 4.65 shows approximately an $700 \%$ increase in $\mathrm{HC}$ from reductant injection at the final aging evaluation. The $\mathrm{HC}$ increase from the reductant injection increased as the catalyst aged which was consistent with the pervious three sets of results. Fuel sulfur concentration had no effect on the amount of increase that occurred.

$\mathrm{CO}$ accumulated throughout the ESC4 is shown in Figure 4.66. Figure 4.67 provides $\mathrm{CO}$ generated from the reductant injection as percent of the engine-out test with no reductant injection. The final 250 hour evaluation experienced an $1000 \%$ increase of CO compared to the engine-out test run with no reductant injection. The $\mathrm{CO}$ increase from the reductant injection increased as the catalyst was aged which supports the pervious results. Fuel sulfur concentration caused a increase in the amount of $\mathrm{CO}$ increase. The catalyst had negligible effect on $\mathrm{CO}_{2}$ which was consistent with the pervious results. 
Accumulated $\mathrm{NO}_{\mathrm{x}}$ from the steady-state cycle is illustrated in Figure 4.69. $\mathrm{NO}_{\mathrm{x}}$ demonstrated minimal affect by the catalyst until reductant injection but Figure 4.70 shows some reduction occurring before reduction injection for two aging periods. The catalyst initially reduced $\mathrm{NO}_{\mathrm{x}}$ by approximately $9 \%$ which increased to $10 \%$ after all aging was completed. The 150 hours evaluation provided a 5\% $\mathrm{NO}_{\mathrm{x}}$ reduction. A increase in $\mathrm{NO}_{\mathrm{x}}$ reduction from 150 hours evaluation to the 250 hours evaluation was observed with all four fuel sulfur concentrations without any explanation. Perhaps catalysts were not fully degreened in the first 250 hours.

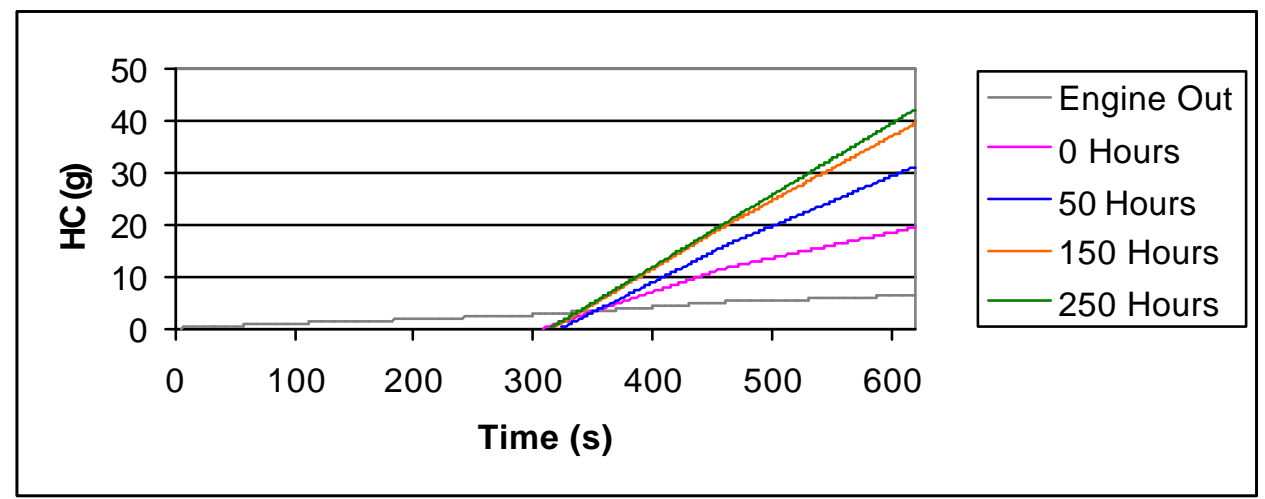

Figure 4.64: ESC4 accumulated HC for 350ppm lean-NO $\mathrm{O}_{x}$ catalyst through the aging period.

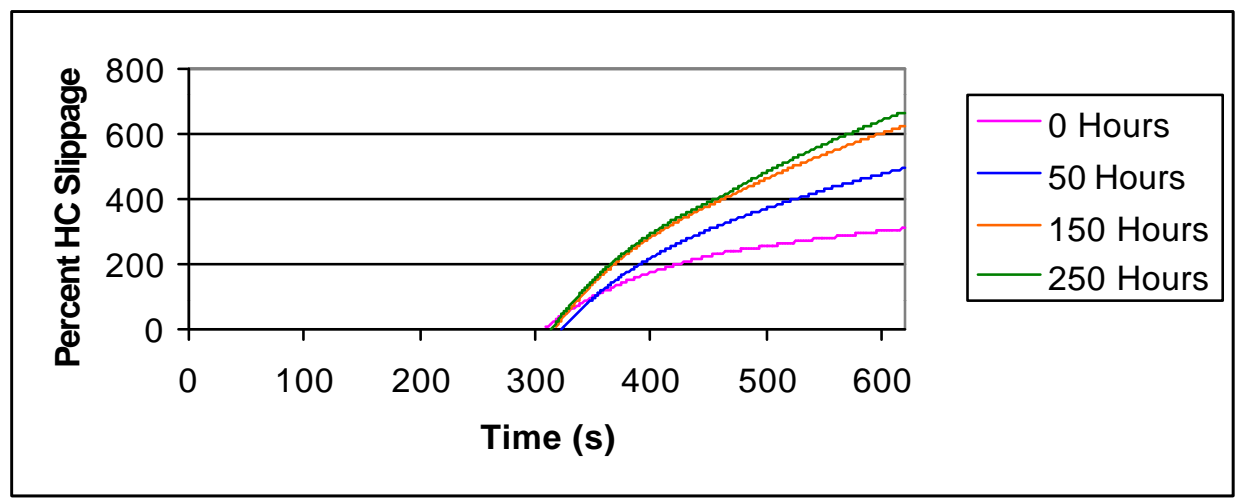

Figure 4.65: Percent increase of $\mathrm{HC}$ for 350ppm lean-NO $\mathrm{O}_{x}$ catalyst. 


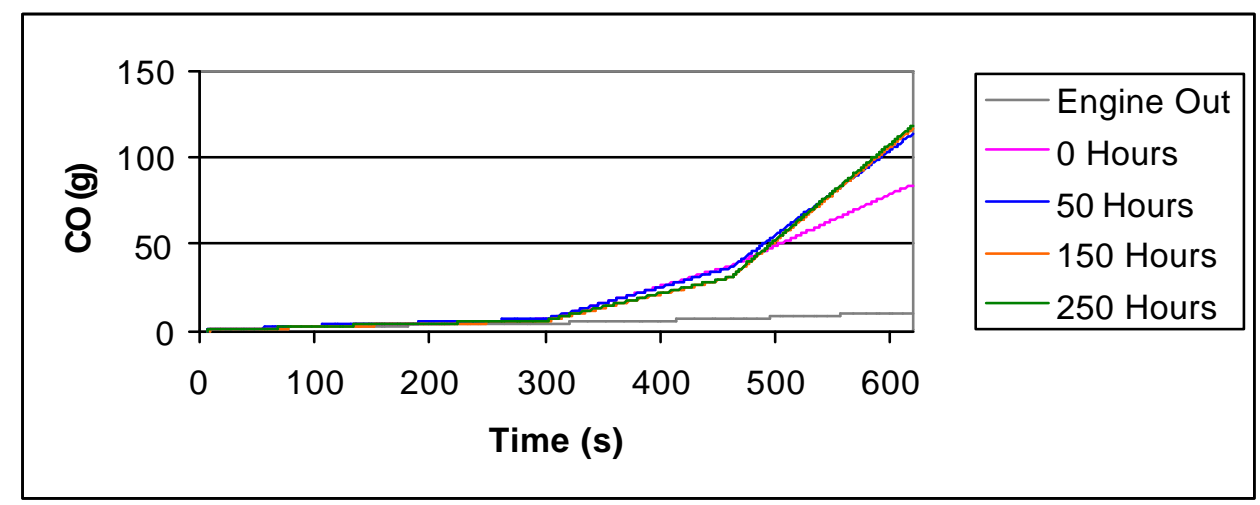

Figure 4.66: ESC4 accumulated CO for 350ppm lean-NO $\mathrm{O}_{x}$ catalyst through the aging period.

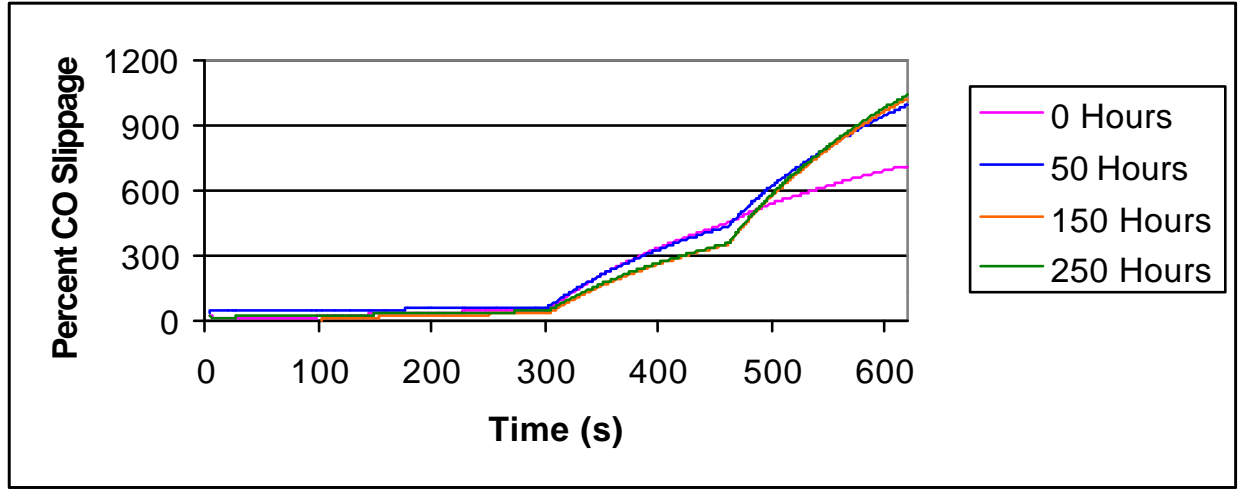

Figure 4.67: Percent increase of CO for 350ppm lean-NOx catalyst.

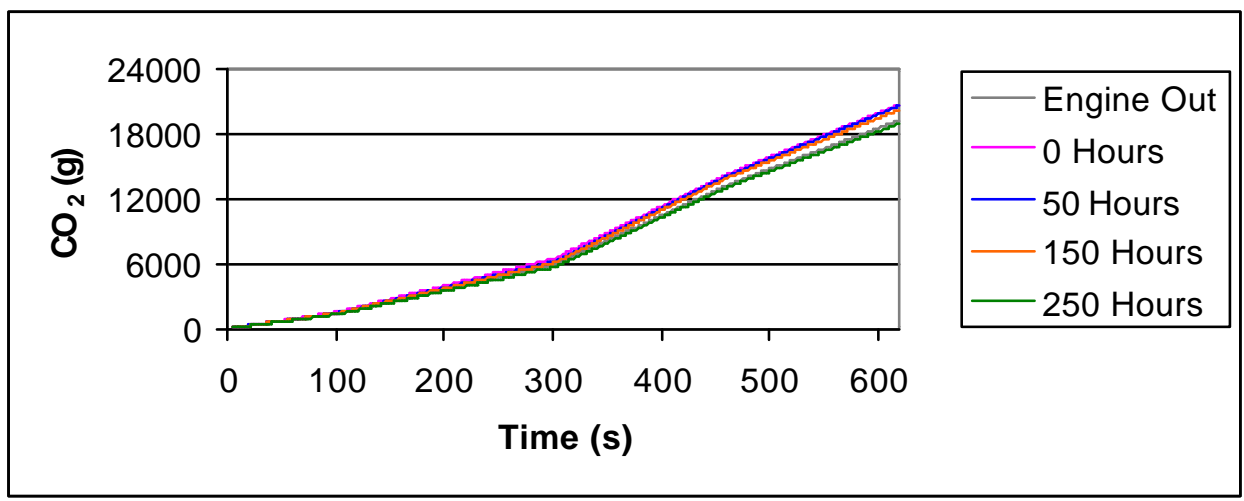

Figure 4.68: ESC4 accumulated $\mathrm{CO}_{2}$ for 350ppm lean-NO $\mathrm{O}_{x}$ catalyst through the aging period. 


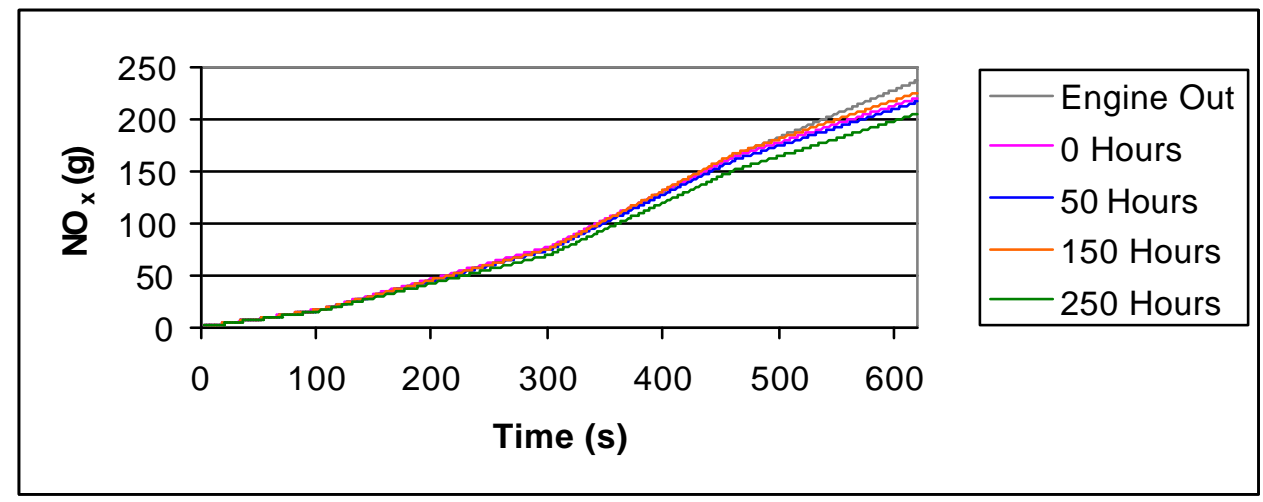

Figure 4.69: ESC4 accumulated $\mathrm{NO}_{x}$ for 350ppm lean-NO $\mathrm{O}_{x}$ catalyst through the aging period.

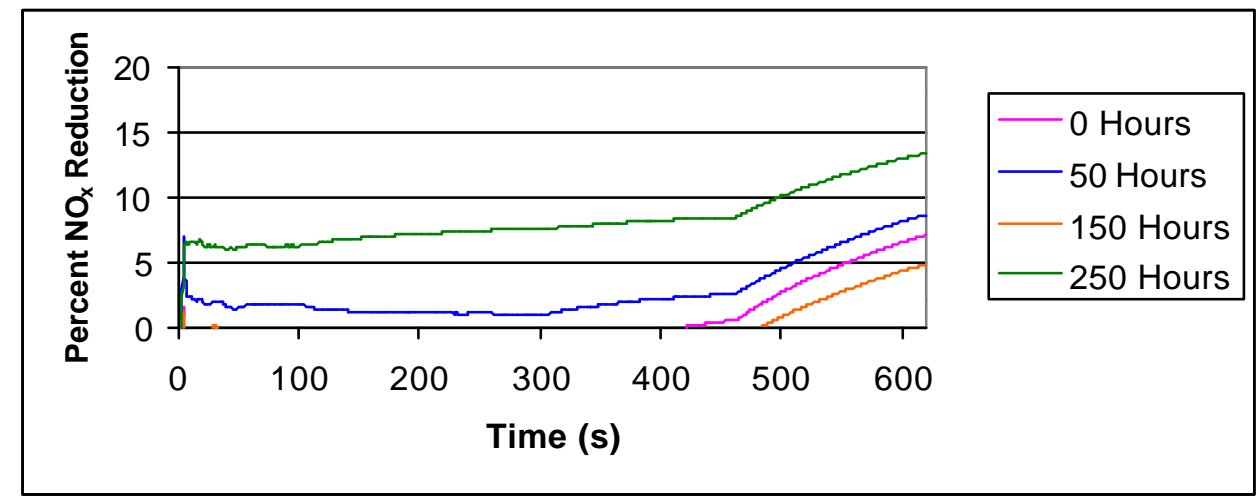

Figure 4.70: Percent reduction of $\mathrm{NO}_{x}$ for 350ppm lean-NO $\mathrm{O}_{x}$ catalyst.

\subsubsection{PM results}

Total particulate matter is presented on a brake-specific basis and on a continuous basis. PM was collected on filters as required by the CFR [1]. The process used to collect PM was described in Section 3.4.2. Measured PM was converted to units of $\mathrm{g} / \mathrm{bhp}-\mathrm{hr}$ for each catalyst evaluation. PM results of the lean- $\mathrm{NO}_{\mathrm{x}}$ catalysts as aging occurred for all fourfuel levels are presented in Figure 4.71. Equation 4.1 was used to determine the difference between initial and final measured PM during the aging process with initial data used as the reference. The $3 \mathrm{ppm}$ fuel provided a $70 \%$ increase in PM over the aging process. The 
remaining 30ppm, 150ppm, and 350ppm fuels demonstrated an increase in PM of 27\%, 81\%, and $18 \%$ respectively.

Figure 4.72 presented continuous PM measured with TEOM for the four different fuels. As described in Chapter 3, the lean- $\mathrm{NO}_{\mathrm{x}}$ catalyst was only evaluated under steadystate conditions and data was collected at the end of each mode. That explains the step changes in Figure 4.72. The TEOM reported that all four fuels generated the same amount of PM under steady-state operations.

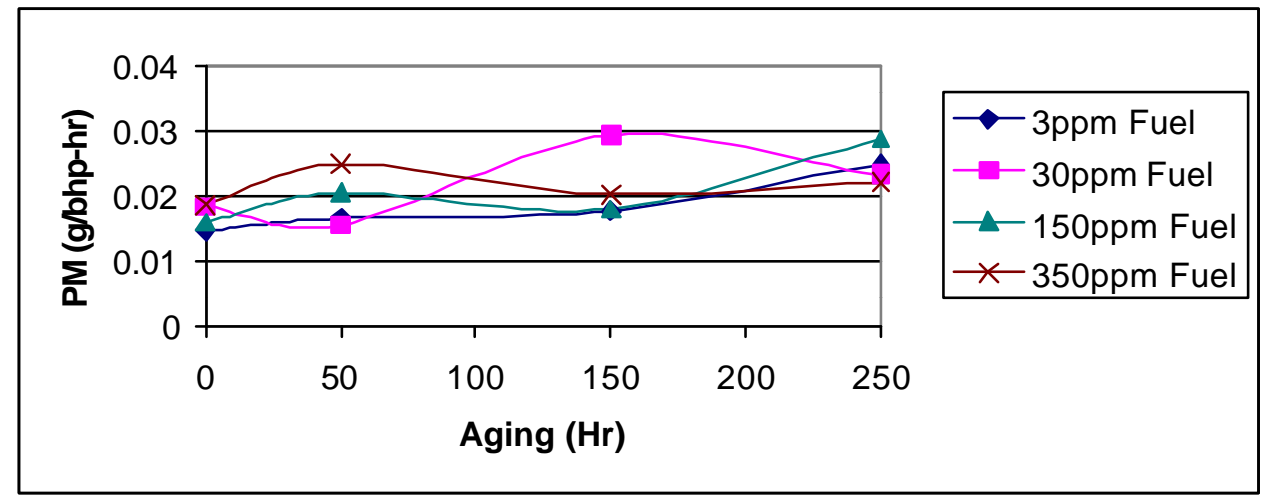

Figure 4.71: Total PM collected during lean-NOx catalyst evaluations.

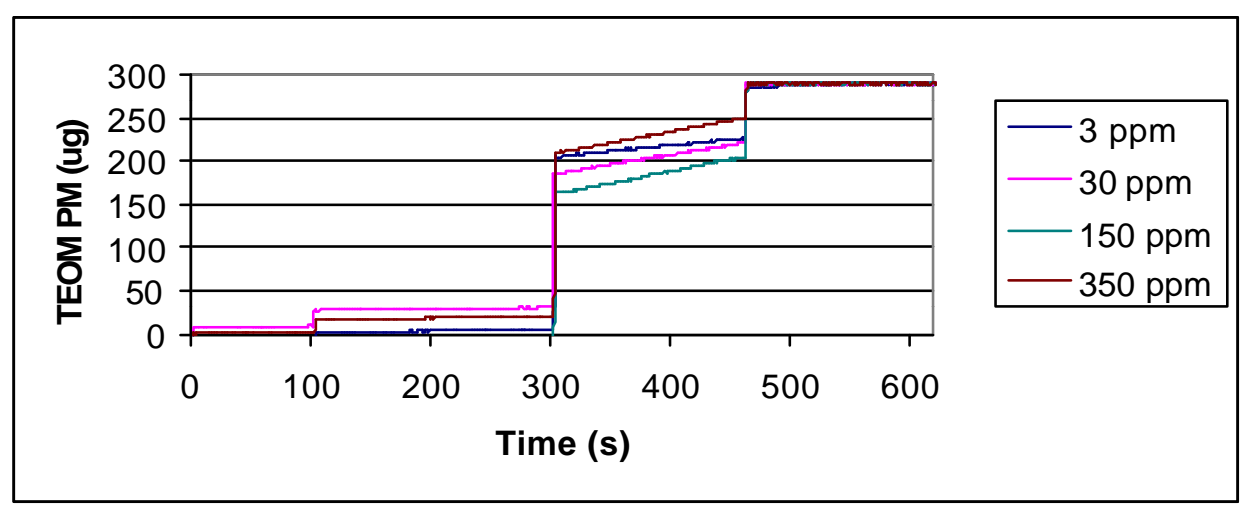

Figure 4.72: Continuous accumulated PM from TEOM for the lean-NO $O_{x}$ catalysts. 


\section{Conclusions}

The split exhaust system was balanced at three different exhaust flow rates entering the dilution tunnel during the system validation. Gaseous emissions were corrected based on a calculated $\mathrm{CO}_{2}$ ratio between the full exhaust stream and the partial stream. This ratio related split flow data back to full flow data within $1 \%$ for $\mathrm{HC}$, within $11 \%$ for $\mathrm{CO}$, within $3 \%$ for $\mathrm{NO}_{\mathrm{x}}$, and within $7 \%$ for $\mathrm{PM}$ on a brake-specific basis under transient engine operation. On an accumulated basis, gaseous emissions levels were within $8 \%$ of the full flow levels. With the engine operating under steady conditions, corrected data from the different flow rates was within $26 \%$ for $\mathrm{HC}$, within $14 \%$ for $\mathrm{CO}$, and within $13 \%$ for $\mathrm{NO}_{\mathrm{x}}$. Please note that these are maximum differences and the majority of corrected data was within $7 \%$ of the full flow values. No PM was collected during steady-state testing. It is concluded that the modest deviations in flow that may arise from split flow considerations are more than offset by the reduction in engine hours needed for aging by splitting the flow.

The four oxidation catalysts evaluated by the DECSE program initially demonstrated $80 \%$ or above reduction of $\mathrm{HC}$ with a slight decline in performance after the first aging period. HC reduction was then maintained for the remaining 200 hours of aging. The catalyst oxidized $\mathrm{HC}$ across the entire FTP cycle but $\mathrm{CO}$ was only oxidized during the second half of the cycle. Both 3ppm and 350ppm fuels experienced a decline from $40 \%$ to $30 \% \mathrm{CO}$ reduction during aging while $30 \mathrm{ppm}$ and $150 \mathrm{ppm}$ fuels began and maintained a $30 \% \mathrm{CO}$ reduction. No effect on $\mathrm{CO}_{2}$ and $\mathrm{NO}_{\mathrm{x}}$ was observed from the catalysts or from the increase in fuel sulfur concentrations during the testing of the oxidation catalysts.

The four lean- $\mathrm{NO}_{\mathrm{x}}$ catalysts evaluated by the DECSE program experienced $\mathrm{HC}$ increase from the reductant injection of initially $300 \%$ and increased to approximately $700 \%$ 
after the 250 aging hours. Fuel sulfur concentration had little effect on the break-through of $\mathrm{HC}$ but the different fuels effected $\mathrm{CO}$ increase. A $700 \%$ increase in $\mathrm{CO}$ for the low-sulfur $3 \mathrm{ppm}$ and 30ppm fuels was observed at the last catalyst evaluation but over 1000\% increase for the high-sulfur $150 \mathrm{ppm}$ and $350 \mathrm{ppm}$ fuels. Initially, $\mathrm{CO}$ increase was approximately $500 \%$ for the low-sulfur fuels and $700 \%$ for the high sulfur fuels. The lean- $\mathrm{NO}_{\mathrm{x}}$ catalysts demonstrated no effect on $\mathrm{CO}_{2}$ during the steady-state testing. Initial $\mathrm{NO}_{\mathrm{x}}$ reductions of approximately $10 \%$ were observed but decrease to $8 \%$ after 250 hours of aging. Some $\mathrm{NO}_{\mathrm{x}}$ reduction was observed on steady-state modes with no reductant injection. This was attributed to $\mathrm{HC}$ produced from the combustion serving as the catalyst reductant. 


\section{Recommendations}

Some research needs to be completed to examine the limits of the split exhaust system. For example, this thesis presented a maximum flow bias of $40 \%$, the $30 / 70$ case. Would testing be possible with a $50 \%$ bias such as a $25 / 75$ split? What is the maximum bias that can be achieved? Investigating using Annubars in each branch of the exhaust split using computer-controlled throttling valves to maintain the split ratio might yield interesting results.

The lean- $\mathrm{NO}_{\mathrm{x}}$ catalysts demonstrated an $8 \%$ reduction in $\mathrm{NO}_{\mathrm{x}}$ with a $700 \%$ increase of $\mathrm{HC}$ and $1000 \%$ increase of $\mathrm{CO}$. An $80 \%$ reduction of $\mathrm{HC}$ and a $30 \%$ reduction of $\mathrm{CO}$ were observed during the oxidation catalyst testing. Further testing needs to be performed with the lean- $\mathrm{NO}_{\mathrm{x}}$ and the oxidation catalyst in series to determine if the $8 \% \mathrm{NO}_{\mathrm{x}}$ reduction is achievable without any increase in $\mathrm{HC}$ or $\mathrm{CO}$.

Lean- $\mathrm{NO}_{\mathrm{x}}$ catalyst evaluations under transient engine operation might generate favorable results. The development of an interface between the engine and the injection system could be used to control reductant injection. This analysis would be beneficial if similar $\mathrm{NO}_{\mathrm{x}}$ reduction results observed by the steady-state DECSE results were achieved. Some time spend examining another means of $\mathrm{NO}_{\mathrm{x}}$ reduction such as urea injection with a selective catalytic reduction or a $\mathrm{NO}_{\mathrm{x}}$ adsorber might yield a larger $\mathrm{NO}_{\mathrm{x}}$ reduction the provided by the Lean $\mathrm{NO}_{\mathrm{x}}$ catalyst. 


\section{References}

1. Code of Federal Regulations, 40, Part 86, Subpart N, "Protection of Environment," U.S. Government Printing Office, 1998.

2. "Diamond II+ Annubars Primary Flow Element," Product Data Sheet 00813-0100-4760, Dieterich Standard, Boulder, Colorado 1998.

3. Diesel Emission Control - Sulfur Effects (DECSE) Program; Phase 1 Interim Data Report No. 1," Online. World Wide Web. http://www.ott.doe.gov/decse/, August 1999.

4. EPA Document, "Emission Standards Reference Guide for Heavy-Duty and Nonroad Engines," EPA420-F-97-014, 1997.

5. EPA Document, "U. S. Environmental Protection Agency Proposal for Cleaner HeavyDuty Trucks and Buses and Cleaner Diesel Fuel," Fact Sheet, 2000.

6. Evans, J.C., "Influence of Fuel Sulfur Content on Emissions from Diesel Engines Equipped with Oxidation Catalysts," Masters Thesis, West Virginia University, Morgantown, WV, 1999.

7. Feeley, J.S., Deeba, M. and Farrauto, R.J., "Abatement of $\mathrm{NO}_{\mathrm{x}}$ from Diesel Engines : Status and Technical Challenges," SAE 950747, 1995.

8. Fredholm, S., Andersson, S., Marsh, P., D’Aniello, Jr., M.J., Zammit, M.G. and Brear, F., "Development of Diesel Oxidation Catalysts for Heavy Duty Engines," SAE 932719, 1993.

9. Ghaffarpour, M. and Baranescu, R. "NO Intercooling in Diesel Engines," SAE 960845, 1996.

10. Graze, R.R., "Development of a Miniaturized, Dilution-Based Diesel Engine Particulate Sampling System for Gravimetric Measurement of Particulates," SAE 931190, 1993.

11. Havenith, C., and Verbeek, R.P., "Transient Performance of a Urea deNO ${ }_{\mathrm{x}}$ Catalyst for Low Emissions Heavy-Duty Diesel Engines," SAE 970185, 1997.

12. "Heavy-Duty FTP Transient Cycle," Online. World Wide Web. http://www.dieselnet.com/standards/cycles/ftp_trans.html. 16 May 2000.

13. Hirakouchi, N., Fukano, I., and Nagano, H., "Measurement of Unregulated Exhaust Emissions from Heavy-Duty Diesel Engine with Mini-Dilution Tunnel," SAE 900643, 1990. 
14. Konstandopoulos, A.G. and Kostoglou, M., "Periodically Reversed Flow Regeneration of Diesel Particulate Traps,” SAE 1999-01-0469, 1999.

15. "Measurement of Fluid Flow using Small Bore Precision Orifice Meters," The American Society of Mechanical Engineers, ASME MFC-14M-1995, New York, NY, 1995.

16. "Measurement of Gas Flow by Means of Critical Flow Venturi Nozzles," The American Society of Mechanical Engineers, ASME/ANSI MFC-7M-1987, New York, NY, 1987.

17. Mori, K., "Worldwide Trends in Heavy-Duty Diesel Engine Exhaust Emission Legislation and Compliance Technologies," SAE 970753, 1997.

18. Official Journal of the European Communities: "Directive 1999/96/EC of the European Parliament and of the Council of 13 December 1999 on the Approximation of the Laws of the Member States Relating to Measures to be Taken against the Emission of Gaseous and Particulate Pollutants from Compression Ignition Engines for Use in Vehicles, and the Emission of Gaseous Pollutants from Positive Ignition Engines Fuelled with Natural Gas or Liquefied Petroleum Gas for Use in Vehicles," European Parliament and Council, 1999.

19. Perry, R.G. and Green, D., Perry's Chemical Engineers' Handbook $6^{\text {th }}$ ed. United States McGraw-Hill, 1984.

20. Psaras, D., Summers, J.C., Das, P.K., Ceynow, K., Khair, M.K. and DiSilverio, W., "Achieving the 2004 Heavy-Duty Diesel Emissions using Electronic EGR and a Cerium Based Fuel Born Catalyst," SAE 970189, 1997.

21. Rankine, B.A., "Design and Development of a Microwave Enhanced Diesel Soot Oxidation System," Masters Thesis, West Virginia University, Morgantown WV, 1999.

22. "Revised Draft Assessment of Possible Diesel Health Hazards Published by the U. S. EPA,” Online. World Wide Web. http://www.dieselnet.com/news/9911epa2.html. 29 May, 2000.

23. Shade, B. C., "A Performance Evaluation of the MEMS- An On-Road Emission Measurement System Study," Masters Thesis, West Virginia University, Morgantown WV, 1999.

24. Stotler, R., and Human, D. "An ISO 8178 Correlation Study between Raw and Dilute Exhaust Sampling Systems," SAE 952060, 1995.

25. "US EPA proposes new heavy-duty diesel emission standards and low sulfur diesel fuel legislation," Online. World Wide Web.

http://www.dieselnet.com/news/0005epa.html. 29 May 2000. 
Appendix A: Certificates of Analysis of the Diesel Fuel Formulations with

Four Different Sulfur Levels 


\section{3ppm Fuel Analysis}

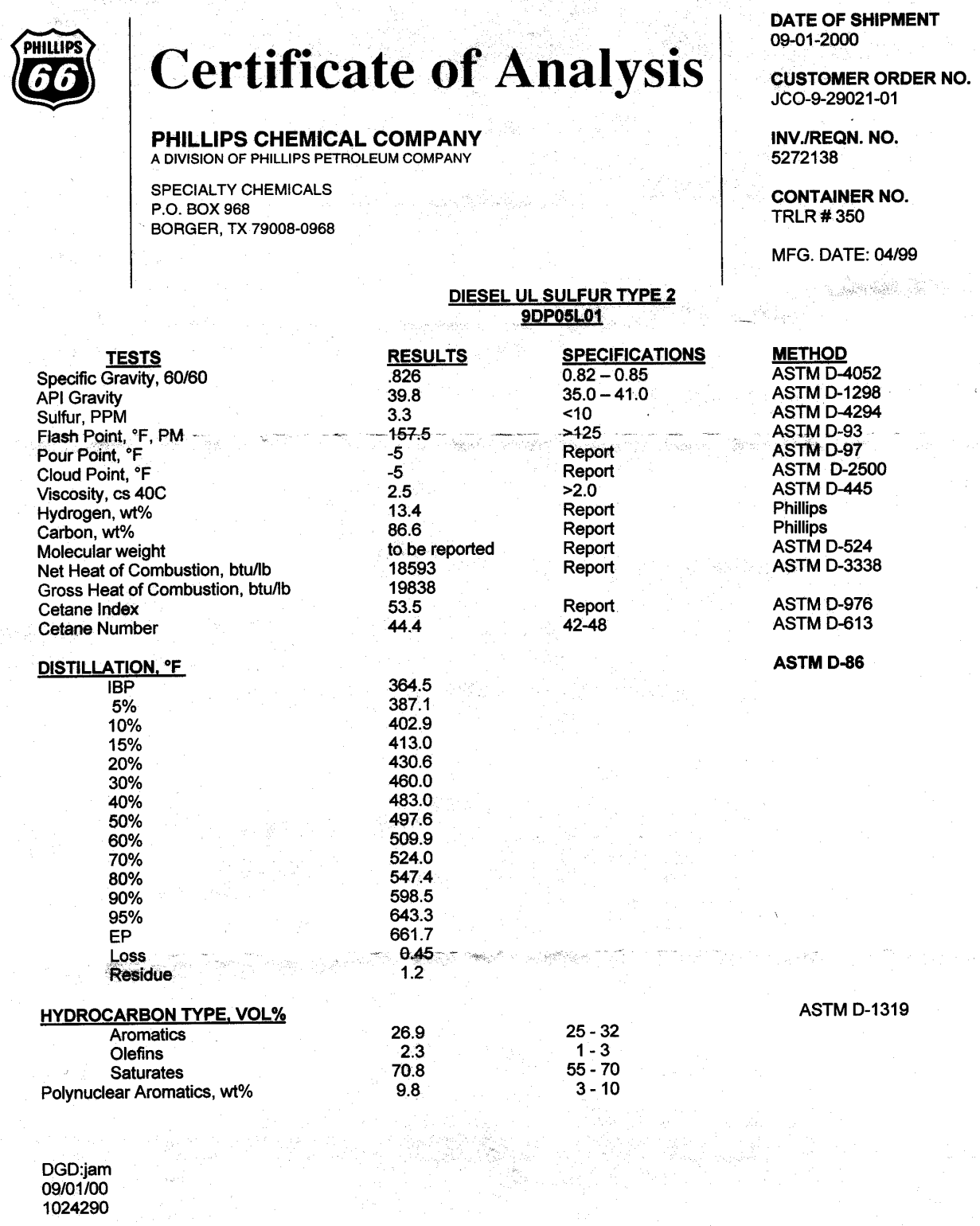




\section{0ppm Fuel Analysis}

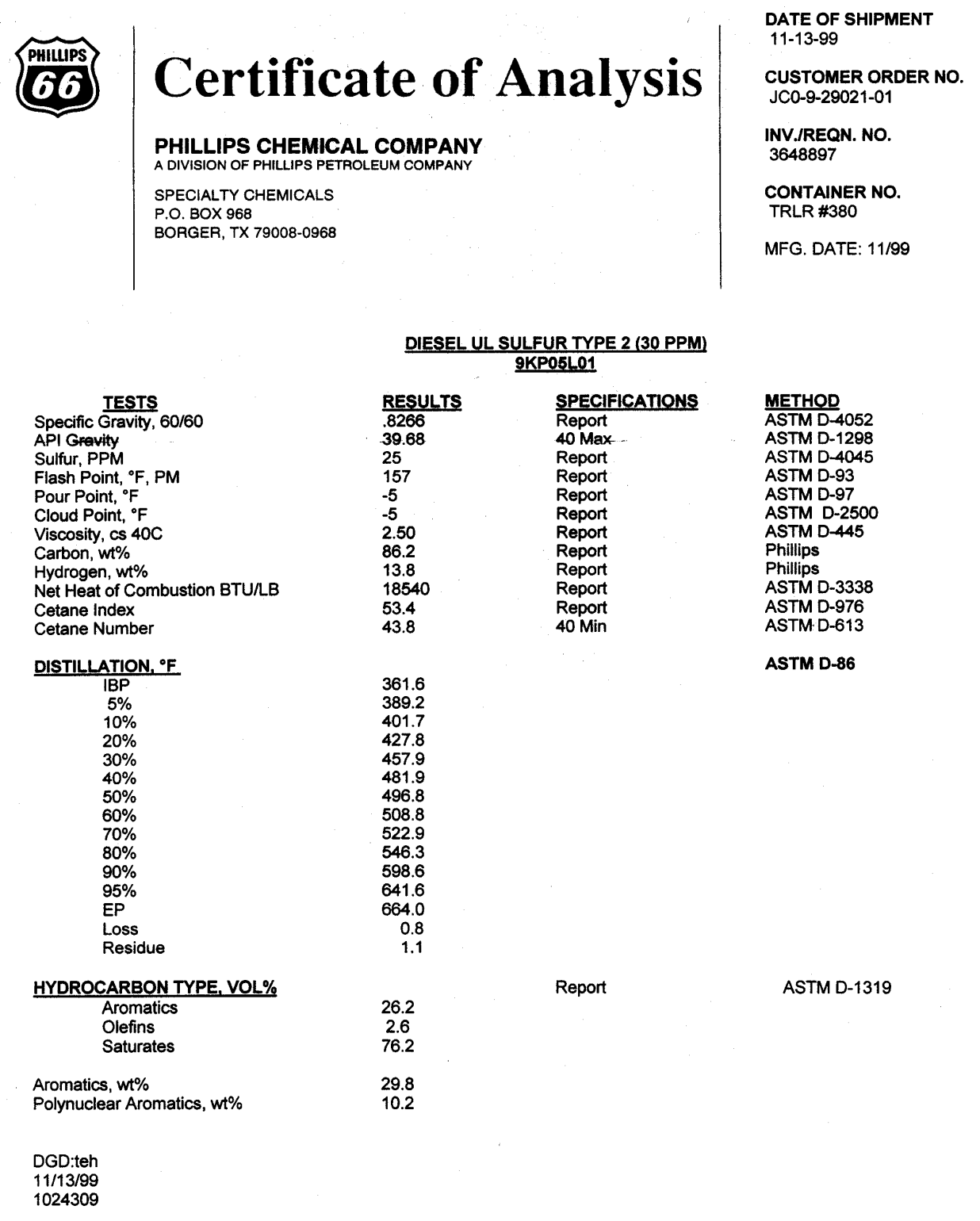




\section{0ppm Fuel Analysis}

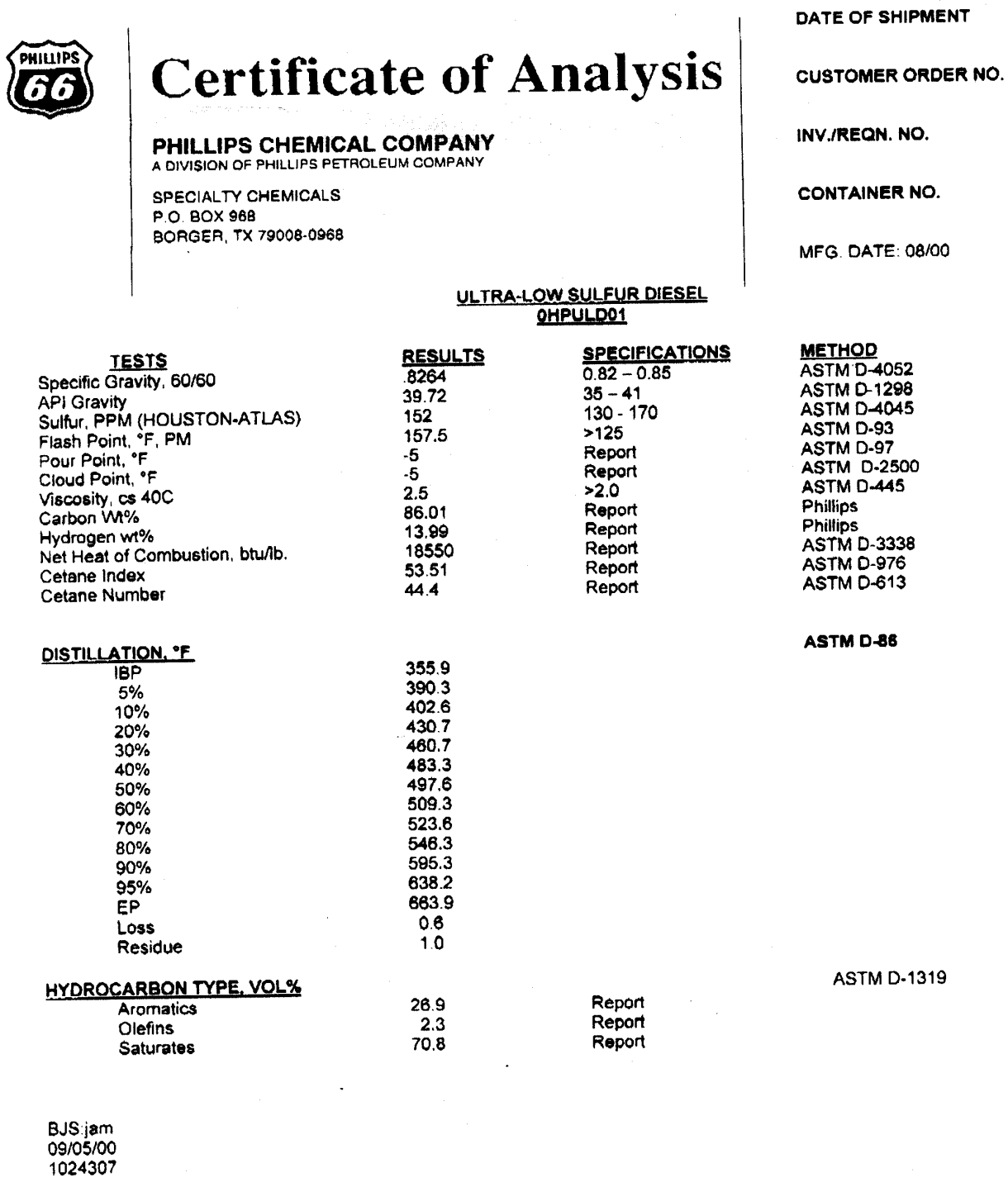




\section{0ppm Fuel Analysis}

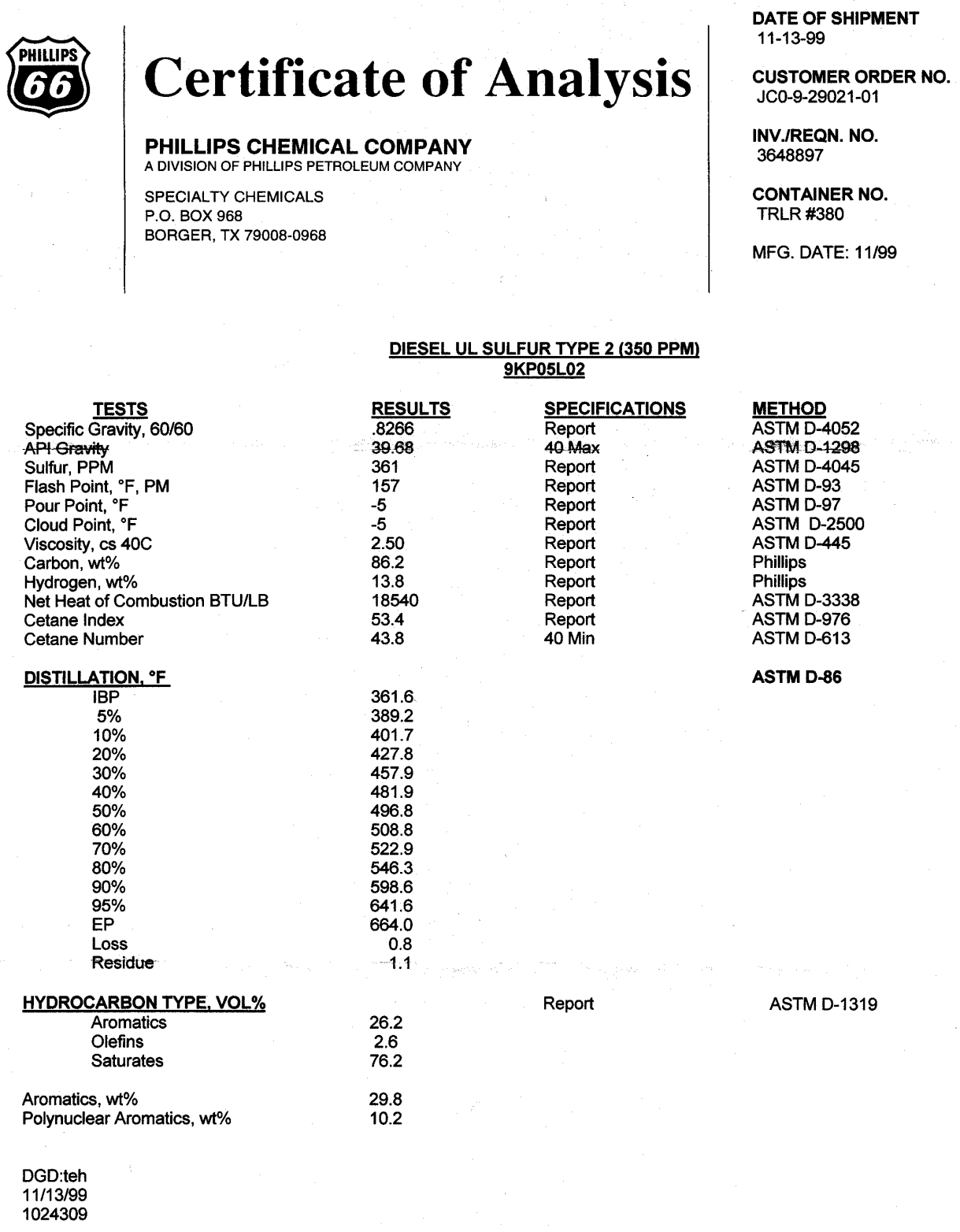

